\title{
ALTERNATE POWER AND ENERGY STORAGE/REUSE FOR DRILLING RIGS: REDUCED COST AND LOWER EMISSIONS PROVIDE LOWER FOOTPRINT FOR DRILLING OPERATIONS
}

\author{
A Thesis \\ by \\ ANKIT VERMA \\ Submitted to the Office of Graduate Studies of \\ Texas A\&M University \\ in partial fulfillment of the requirements for the degree of \\ MASTER OF SCIENCE
}

May 2009

Major Subject: Petroleum Engineering 


\title{
ALTERNATE POWER AND ENERGY STORAGE/REUSE FOR DRILLING RIGS: REDUCED COST AND LOWER EMISSIONS PROVIDE LOWER FOOTPRINT FOR DRILLING OPERATIONS
}

\author{
A Thesis \\ by \\ ANKIT VERMA \\ Submitted to the Office of Graduate Studies of \\ Texas A\&M University \\ in partial fulfillment of the requirements for the degree of \\ MASTER OF SCIENCE
}

\begin{abstract}
Approved by:
Chair of Committee, David Burnett

Committee Members, Jerome Schubert

Louise Darcy

Head of Department, Stephen A. Holditch
\end{abstract}

May 2009

Major Subject: Petroleum Engineering 


\begin{abstract}
Alternate Power and Energy Storage/Reuse for Drilling Rigs: Reduced Cost and Lower Emissions Provide Lower Footprint for Drilling Operations. (May 2009)

Ankit Verma, B.Tech., National Institute of Technology, Bhopal

Chair of Advisory Committee: Prof. David Burnett
\end{abstract}

Diesel engines operating the rig pose the problems of low efficiency and large amount of emissions. In addition the rig power requirements vary a lot with time and ongoing operation. Therefore it is in the best interest of operators to research on alternate drilling energy sources which can make entire drilling process economic and environmentally friendly. One of the major ways to reduce the footprint of drilling operations is to provide more efficient power sources for drilling operations. There are various sources of alternate energy storage/reuse. A quantitative comparison of physical size and economics shows that rigs powered by the electrical grid can provide lower cost operations, emit fewer emissions, are quieter, and have a smaller surface footprint than conventional diesel powered drilling.

This thesis describes a study to evaluate the feasibility of adopting technology to reduce the size of the power generating equipment on drilling rigs and to provide "peak shaving" energy through the new energy generating and energy storage devices such as flywheels. 
An energy audit was conducted on a new generation light weight Huisman LOC 250 rig drilling in South Texas to gather comprehensive time stamped drilling data. A study of emissions while drilling operation was also conducted during the audit. The data was analyzed using MATLAB and compared to a theoretical energy audit. The study showed that it is possible to remove peaks of rig power requirement by a flywheel kinetic energy recovery and storage (KERS) system and that linking to the electrical grid would supply sufficient power to operate the rig normally. Both the link to the grid and the KERS system would fit within a standard ISO container.

A cost benefit analysis of the containerized system to transfer grid power to a rig, coupled with the KERS indicated that such a design had the potential to save more than $\$ 10,000$ per week of drilling operations with significantly lower emissions, quieter operation, and smaller size well pad. 


\section{DEDICATION}

Firstly, I dedicate this thesis to Lord Shiva for giving me strength and will power.

To my parents, for their immense support and love

To my brother, for giving me moral strength 


\section{ACKNOWLEDGEMENTS}

I would like to express my sincere gratitude to the people who greatly contributed to the cause of this research: Mr. David Burnett, who is the chair of my graduate committee. He is always an inspiration, a person who always sees things ahead of time and is highly encouraging. I greatly appreciate him for trusting me always.

Thanks to other committee members; Dr. Jerome Schubert and Mrs. Louise Darcy for their time and support. I extend my thanks to Mr. Robert Van Kuilenberg of Huisman Itrec, USA, for his valuable technical guidance; Crisman participants for funding this project and making it feasible and Dr. Stephen Holditch, head of the Petroleum Engineering Department, who is a creator of opportunities for the students.

Thanks also to all my teachers for a world class masters degree experience; all

my friends, officemates and classmates for their cooperation and to Texas A\&M University for being such a wonderful home and alma mater. Finally, thanks to my entire family for their patience and love. 


\section{TABLE OF CONTENTS}

\section{Page}

ABSTRACT iii

DEDICATION

$\mathrm{V}$

ACKNOWLEDGEMENTS .............................................................. vi

TABLE OF CONTENTS ...................................................................... vii

LIST OF FIGURES ............................................................................ ix

LIST OF TABLES …..................................................................... xi

1. INTRODUCTION ............................................................................

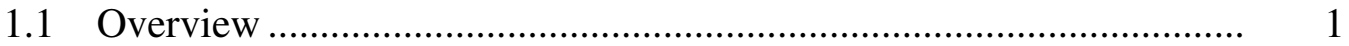

1.2 Current Problem .................................................................. 1

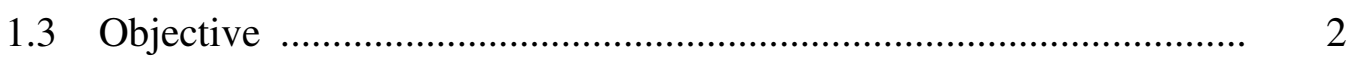

2. CHOICE OF ENERGY STORAGE DEVICE............................................. 4

$2.1 \quad$ Available Options ..................................................................... 4

2.1.1 Solar PV ....................................................................... 4

2.1.2 Wind Energy .................................................................... 5

2.1.3 Fuel Cells................................................................. 7

2.1.4 Storage Battery .............................................................. 8

2.1.5 Super Capacitors .............................................................. 8

2.1.6 Flywheels ................................................................ 10

3. METHODOLOGY ............................................................................... 12

3.1 Stepwise Procedure ....................................................................... 12

3.2 Drilling Rig Study ........................................................................... 12

3.2.1 Electrical System for LOC-400 ........................................... 16

3.2.2 Electrical System for LOC-250 ........................................ 18

3.3 Energy Audit ................................................................................. 20

3.3.1 Theoretical Energy Audit ..................................................... 20

3.3.2 Actual Energy Audit........................................................ 22

3.3.3 MATLAB Code...................................................................... 24

3.3.4 Simplified Description of MATLAB Code.............................. 27

3.3.5 Comparison of Theoretical and Actual Energy Audit............. 41 
4. SYSTEM DESIGN BASED ON DATA PROCESSING …............................. 42

4.1 Black Box Description .................................................................. 42

4.2 Component Description................................................................. 45

4.2.1 Power Line Cable .............................................................. 45

4.2.2 Storage Winch ................................................................. 46

4.2.3 Transformer and Switchgear .............................................. 47

4.2.4 SCADA System............................................................... 48

4.2.5 KERS System .................................................................. 48

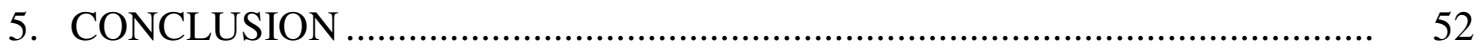

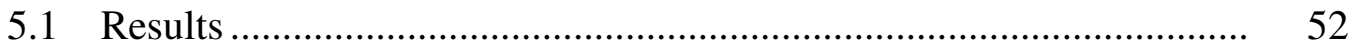

5.2 Inferences ............................................................................ 55

5.3 Future Work ........................................................................... 56

NOMENCLATURE ................................................................................. 57

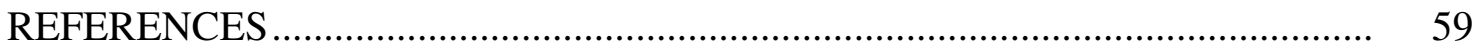

APPENDIX A VARIABLE DESCRIPTION FOR MATLAB CODE AND SCREENSHOTS ............................................... 61

APPENDIX B CONVERSION FACTORS ................................................. 67

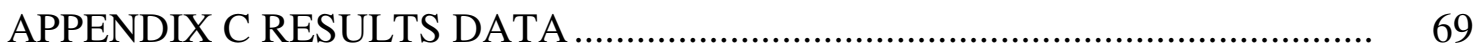

APPENDIX D OTHER IMPORTANT MATLAB PLOTS ................................ 73

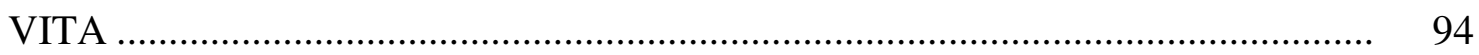




\section{LIST OF FIGURES}

Page

Figure 1 Various sizes of wind turbines with their capital cost.................... 6

Figure 2 Schematic of fuel cell ........................................................ 7

Figure 3 Test set up of super capacitor unit......................................... 8

Figure 4 Flywheel system coupled with crane's diesel engine..................... 10

Figure 5 Cost comparison of various technologies................................. 11

Figure 6 LOC 250 rig in actual field .................................................. 13

Figure 7 Single line diagram of LOC 400 with alternate power system.

Figure 8 Single line diagram of LOC 250 with alternate power system

Figure 9 Flow rate of one of the mud pumps and its variations with time.....

Figure 10 Pump pressure vs. time is and its variations

Figure 11 Instantaneous power of mud pumps vs. time and its variations

Figure 12 A moving average of window length 2 seconds and actual power curve of the mud pump are plotted vs. time in order to determine transient peaks for this window length

Figure 13 Difference between the actual curve and moving average curve for mud pump vs. time for the window length of 2 seconds

Figure 14 Difference between the actual power curve and moving average curve combined for mud pumps and top drive vs. time...

Figure 15 Variation of KERS power requirement with window lengths 
Figure 16 Energy curve for mud pumps and top drive for window length of 2 seconds

Figure 17 Comparison of actual energy consumption of top drive and mud pumps vs. time and consumption of energy by mud pumps and top drive during drilling operation.

Figure 18 Curve for drilling depth and simultaneous top drive power consumption vs. time

Figure 19 Power consumption of mud pumps and top drive vs time and its variation with drilling depth ......

Figure 20 Black box design for alternate power system.

Figure 21 Cross section of power cable with 3 inner cores and insulation

Figure 22 KERS system positioning and operation.

Figure 23 Detailed design of alternate power system inside ISO container.

Figure 24 Cost and savings curve for KERS system with diesel and electricity price variation. 


\section{LIST OF TABLES}

Page

Table 1 Possible risks of testing super capacitor unit .............................. 9

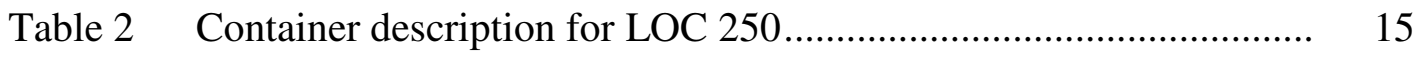

Table 3 Simultaneous power consumption of the rig with operating time

Table 4 Theoretical energy audit of LOC 250 with various actuator ratings

Table 5 List of SCADA signals measured on LOC 250

Table 6 Comparison of actual and theoretical energy audit.

Table 7 Data processing results and flywheel size determination.

Table $8 \quad$ Cost benefit analysis of KERS system ..................................... 52

Table 9 Emissions data from construction, transport and usage of drilling equipment 


\section{INTRODUCTION}

\subsection{Overview}

The rig power requirements vary a lot with time and ongoing operation. Therefore it is in the best interest of operators to research on alternate drilling energy sources which can make the entire drilling process economic and environmentally friendly. There are a lot of options available amongst renewable energy resources namely wind, solar, fuel cells and energy storage devices. Each of these has advantages and drawbacks in terms of economics or rig footprint. Research into alternate power systems both economically and practically feasible to modern oil and gas industry can be very useful. A system of electrical power grid in combination with an energy storage device such as a flywheel/super capacitor unit is one such source which can provide substantially cheaper energy as compared to diesel. This energy storage unit can supply/reuse the power above and below the base load and allow the rigs to draw the base load either from diesel engines or power grid and hence improve the drilling efficiency.

\subsection{Current Problem}

The drilling operation is like driving a car and putting its "pedal to the metal" for few seconds and releasing it totally again. Drillers seldom pay attention to the power consumption data making the entire drilling operation fuel inefficient. It is because either

This thesis follows the style of SPE Drilling and Completion. 
the rigs are not modern enough to capture each and every data point for all the installed actuators while in operation or the data is tight hole meaning it is kept confidential during the operation and is destroyed later. There is negligible effort by the industry to process the rig data in terms of power and energy consumption and improve drilling efficiency based on that actual data. Same is true for emissions data and rig footprint. The diesel engines give optimum performance only at a particular value of load. Intermittent power consumption of the rig poses problems for the diesel engines to reach that optimum load. The simultaneous power consumption of the rig has to be estimated and it is certainly not the sum of theoretical power rating of all the installed actuators (Huisman, 2005). A land rig's total power consumption is around $2 \mathrm{MW}$, all of which comes from diesel engines. These are low on fuel efficiency and produce harmful emissions because of cycle inefficiency or incomplete combustion (Kumar, Zheng 2008). Hence there is a growing need for developing an environmentally benign alternate power system which is economic and pragmatic. This study focus into various alternatives sources of energy storage and come up with a system design based on the best possible alternative source of energy storage/reuse available.

\subsection{Objective}

The goal of this project is to determine the feasibility of adopting technology to reduce the size of the power generating equipment and to provide "peak loading" energy through the use of new energy generating and energy storage devices. 
This project is part of a larger Proposed GPRI/Crisman Study to develop theoretically and empirically an energy inventory of the drilling process from a rig perspective. There are a number of current technologies that can be used to partially provide power to a rig and reduce fuel consumption and emissions. These need to be evaluated technically and economically to determine the feasibility of application to a drilling rig (e.g., diesel additives, types of fuels (gas, dual fuel system, synthetic fuels etc, wind energy, solar cells, fuel cells, power management, and gas turbine generators). Together with these technologies, new energy storage technology (specifically energy storage compatible with drilling operations) will be required.

Investigation into two peak shaving technologies to be utilized in the drilling rigs namely flywheels and super capacitors for lightweight rigs. Super capacitors are potential sources of peak energy which can be instantly discharged to remove transients. Flywheels offer advantages of reliable operation, instant response, high efficiency, cost effectiveness and are environmentally friendly with minimal maintenance requirements (Rojas, 2003). After determination of cost involved for electrically operated rigs, work will be extended to specification, modeling and layout of electrical systems in the drilling rigs. This work involves design of a black box which will serve as a link between power grid and the rig and also incorporate the energy storage/reuse technology. Attempts will be made to optimize this design in terms of mobility, working efficiency and cost. 


\section{CHOICE OF ENERGY STORAGE DEVICE}

\subsection{Available Options}

There are quite a number of devices which generate energy. This energy can later be stored. Solar panels, wind turbines, fuel cells, storage batteries, super capacitors and flywheels are some of the widely used devices. Apart from these there are also technologies which are under development phase. The above mentioned devices are considered viable for this project as they are used worldwide commercially. Energy is stored differently in all of these devices. In a wind turbine mechanical energy of wind is converted into electrical energy while in a fuel cell chemical energy is converted into electrical energy. Each of these energy storage devices is evaluated on the basis of following factors:

- Size.

- Economics.

- Power generating and storing capability in context of a drilling rig.

- Problems with installation and transport.

- $\quad$ Rig footprint.

\subsubsection{Solar $P V$}

A single solar cell unit produce approximately one watt of power. (www.eere.energy.gov). Solar cells have to be connected in series or parallel connection to obtain the desired value of power and the discussion of electrical connections of photo 
voltaic units is beyond the scope of this investigation. By using a solar calculator application designed by the U.S Department of Energy one can instantly come up with the cost of entire system in a particular area. The following system was designed which can provide power to only one of the mud pumps at full load.

Area

College Station

Solar Radiance

$5.16 \mathrm{kWh} / \mathrm{sq} \mathrm{m} / \mathrm{day}$

Average Monthly Usage $\quad 50,000 \mathrm{kWh}$

System Size

$201.22 \mathrm{~kW}$

Area Required

20122 sq ft.

Estimated Cost

$\$ 1,609,750$ (www.findsolar.com)

Hence, it is economically and practically unrealistic to install such a large unit at the rig site. It increases rig footprint. Also it is difficult to transport. One other problem is its dependency on the sun which itself is subjected to intermittent availability. Also solar cells need a large battery house which again has the constraints of cost and mobility.

\subsubsection{Wind Energy}

The wind turbine converts wind energy into rotating motion of the blades. The turbine is linked with generators through a gear mechanism. The details of the design of wind turbine are beyond the scope of this investigation. But to have a practical picture following parameters are obtained from a previous "Environmentally Friendly Drilling" report. 
Power Rating

$750 \mathrm{~kW}$ (approximately the size of one of the generator unit)

Total weight

116 tones

Tower height

$213 \mathrm{ft}$

Rotor Diameter

$80 \mathrm{ft}$

Cost

\$ 781, 940 (Rogers et.al, 2006)

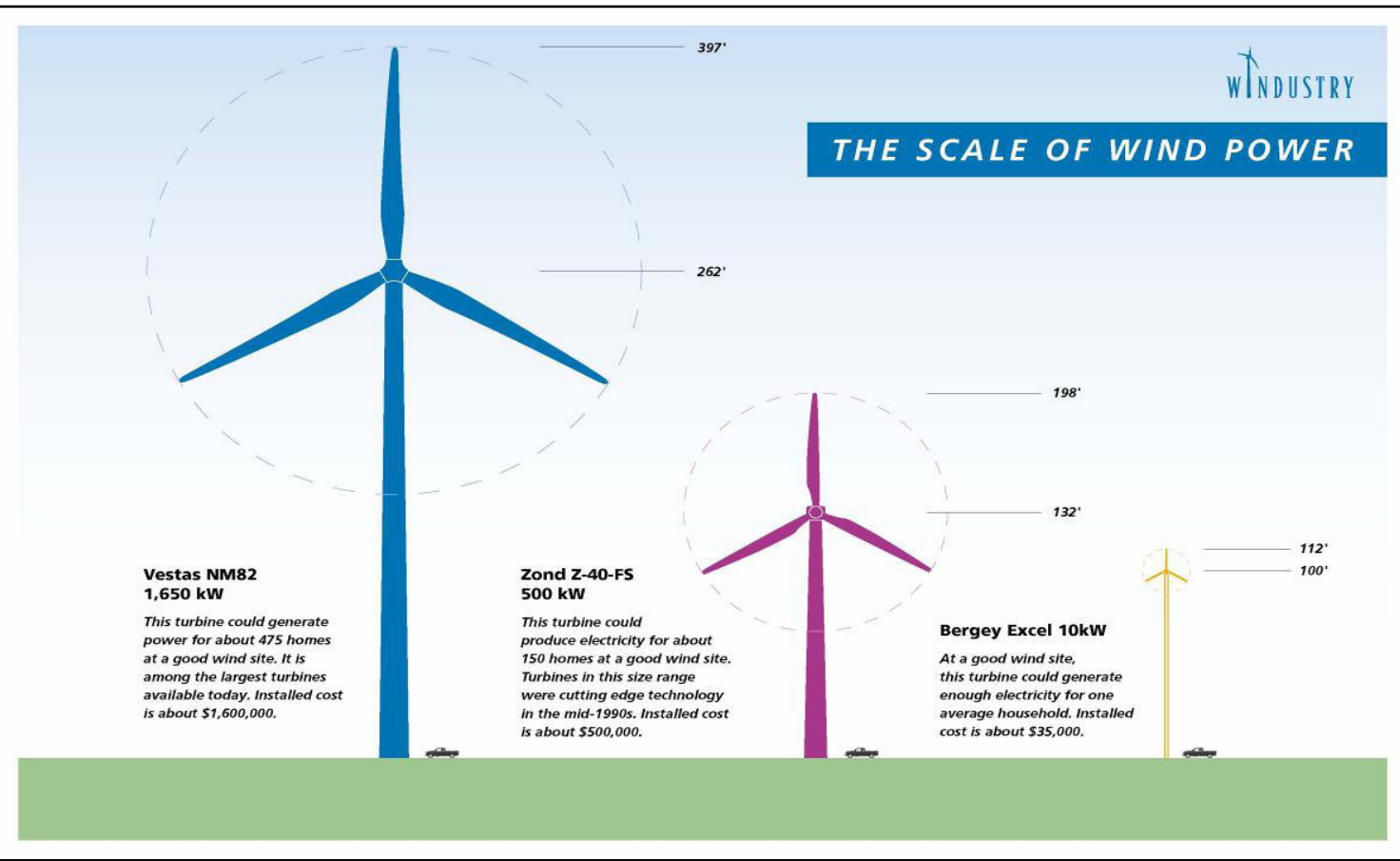

Figure 1 - Various sizes of wind turbines with their capital cost. (Rogers et.al, 2006) (Courtesy EFD Report).

Figure 1 shows the size variation of wind turbines with power. Hence due to larger rig footprint, transportation problems and high capital cost of investment with intermittent nature of power production this option is ruled out. 


\subsubsection{Fuel Cells}

Fuel cells convert chemical energy into electrical energy. Electrical current is produced by providing gaseous fuels to anode and oxidizing the cathode which are porous (Parsons, 2000). Figure 2 shows working of fuel cell.

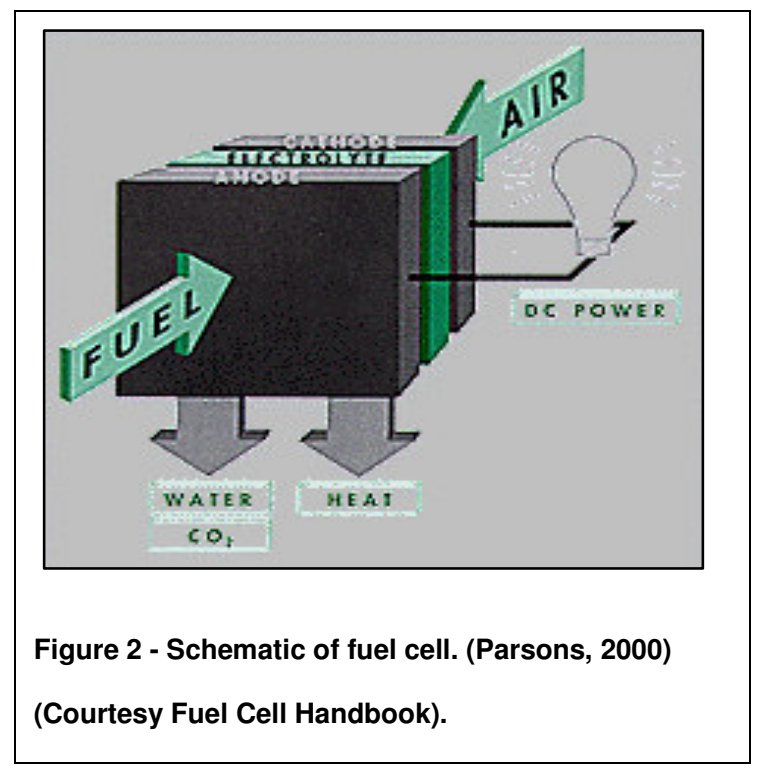

Fuel cells have the advantages of no emissions and instant loading. They also do not produce noise. But it is the economics which is preventing the application of fuel cells in this project (Walsh, Wichert, 2008) Current prices range from $\$ 3000$ to $\$ 4000 /$ $\mathrm{kW}$. In addition there is an associated power system and maintenance cost. Although entire unit can be accommodated in reasonable size and provides reliable power. 


\subsubsection{Storage Battery}

Storage battery unit is another viable option in terms of peak shaving. A stationary sulfur battery at an office park is set up in Ohio which can provide $100 \mathrm{~kW}$ of peak shaving for as much as 30 seconds which is considerably less than the rig requirements (Tamyurek and Nichols, 2003). Again the economics of the unit and battery life are restricting factors. In addition batteries fall more into low energy density systems which is not what is required in this project. This is because of the rig fluctuations which will cause the battery to partially charge and discharge hundreds of times in a day. It can adversely affect the battery life which is nearly 15 years or 2500 cycles of full charge and discharge with a cost of $\$ 164 / \mathrm{kW}$ (Nichols and Eckroad). Even after a successful design the battery unit will be a separate entity which will add an extra container to the rig and hence additional transportation costs.

\subsubsection{Super Capacitors}

Super capacitors are used for supplying equipment with low power consumption

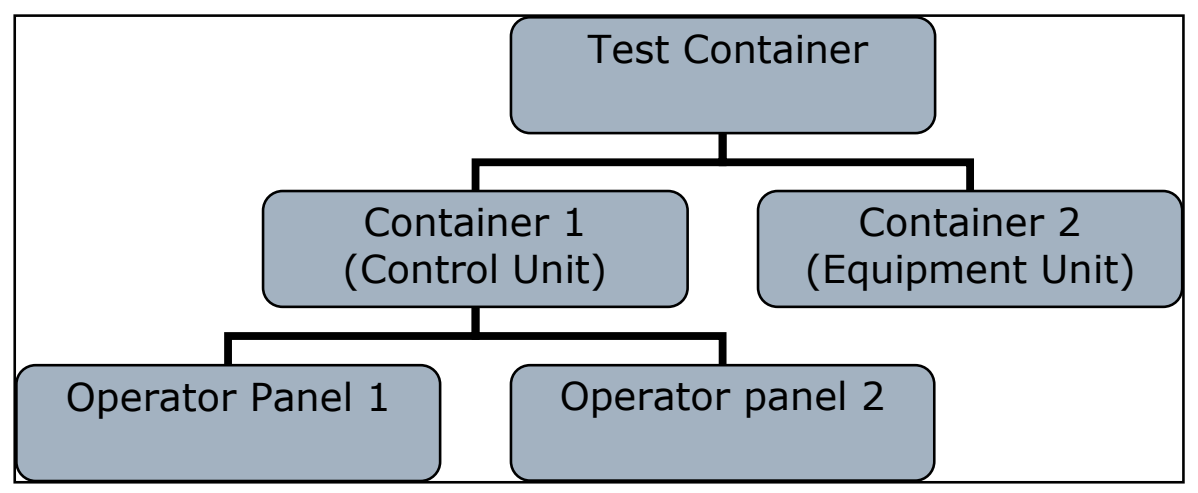

Figure 3 - Test set up of super capacitor unit. 
and high current requirement with fast charging and discharging time. The test study of Huisman dealt with 10 modules of 43 capacitors 1500 Farad each (Palthe, 2008).

Figure 3 shows the test set up for super capacitors conducted by Huisman. The test would be conducted on a $30 \mathrm{~kW}$ motor with 5 seconds of hoisting for discharging and lowering for charging of the ultra capacitor unit. The electrical circuits with converters and their regulators, communication systems and detailed design of controllers are beyond the scope of this research. Table 1 shows the risks which are associated with this experimentation.

Table 1- Possible risks of testing super capacitor unit. (Courtesy Huisman Itrec).

\begin{tabular}{|l|l|l|}
\hline Possible problem & Result & Solution \\
\hline \hline $\begin{array}{l}\text { Voltage swing on } \\
\text { the DC-bus to high } \\
\text { at direct } \\
\text { connection of the } \\
\text { DC-DC converter }\end{array}$ & The inverter trips & $\begin{array}{l}\text { Change to indirect } \\
\text { connection of the } \\
\text { DC-DC converter }\end{array}$ \\
\hline $\begin{array}{l}\text { Voltage too high } \\
\text { on the DC-bus }\end{array}$ & The inverter trips & $\begin{array}{l}\text { Adjust the chopper } \\
\text { for this voltage level } \\
\text { and dissipate } \\
\text { energy in resistors }\end{array}$ \\
\hline $\begin{array}{l}\text { At indirect } \\
\text { connected DC/DC } \\
\text { converter, the } \\
\text { switch over from } \\
\text { step-up mode to } \\
\text { step-down mode } \\
\text { and visa versa at } \\
\text { the wrong } \\
\text { moment }\end{array}$ & $\begin{array}{l}\text { The DC/DC } \\
\text { the Boostcap } B \\
\text { is not } \\
\text { charged }\end{array}$ & $\begin{array}{l}\text { Voltage range not } \\
\text { sufficient, needs to } \\
\text { be adjusted } \\
\text { Monitoring by an } \\
\text { external signal } \\
\text { Change rectifier } \\
\text { settings } \\
\text { (parameters) }\end{array}$ \\
\hline
\end{tabular}


This pilot project is still under testing phase on a small scale of $30 \mathrm{~kW}$ and the results with cost benefit analysis are awaited. This technology has advantages of no noise, less maintenance and high performance. Therefore efforts are being made to extend it to drilling rigs.

\subsubsection{Flywheels}

Flywheels are proven technology for power regulation of telecommunication equipment and high power industrial equipment support. They offer advantages of reliable operation, instant response, high efficiency, cost effectiveness and are environmentally friendly with minimal maintenance requirements (Rojas 2003). Modern flywheel system rotates with high speed in vacuum with magnetic bearings. Flywheels are successfully tested for peak shaving in cranes.

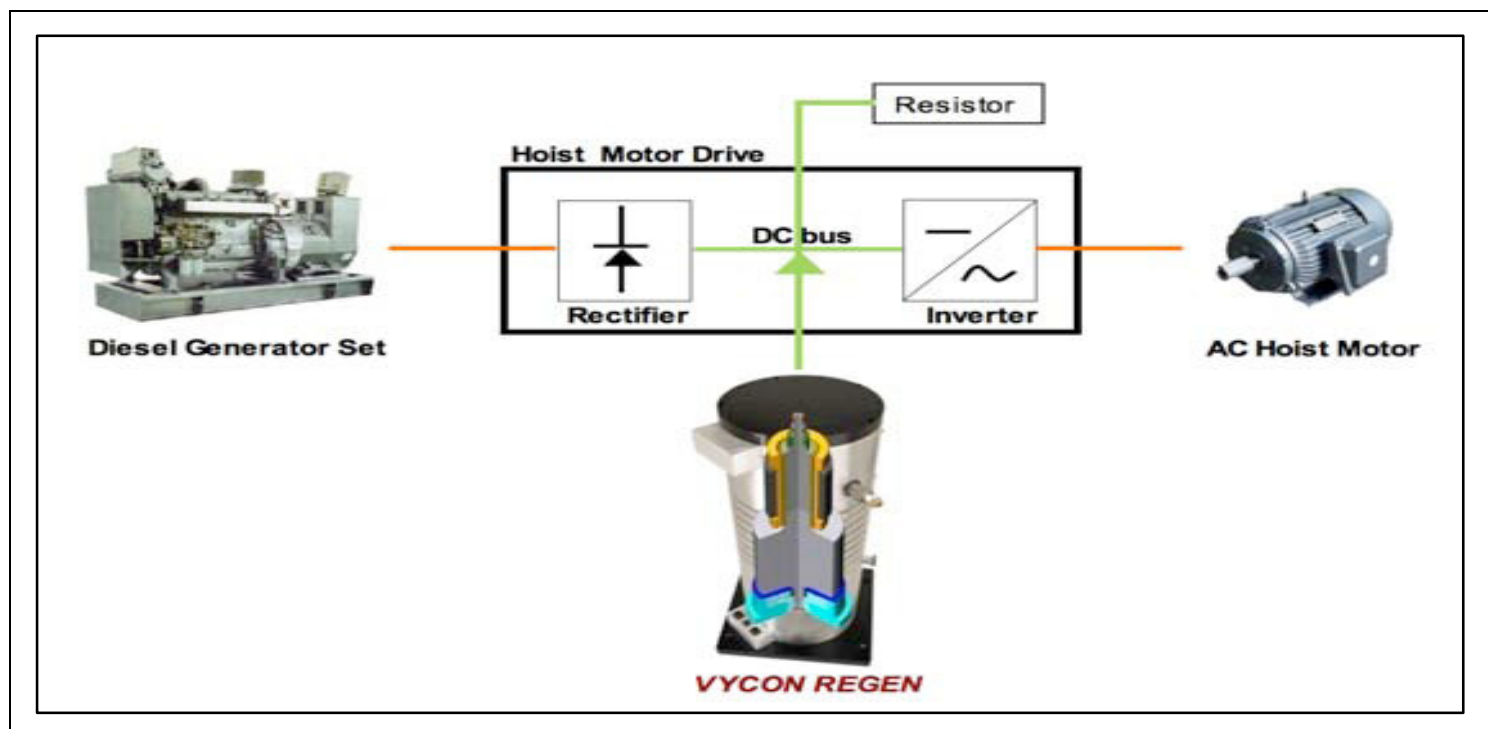

Figure 4 - Flywheel system coupled with crane's diesel engine. (Courtesy VYOCON). 
One very promising example shown in Figure 4 was when a diesel generator was coupled with a flywheel it reduced the fuel consumption by as much as $38 \%$ (Romo et al., VYOCON).Flywheels are also a tested technology which can handle load in the range of rig's peak shaving values with virtually no maintenance cost. Also there is no limit to the number of charging and discharging cycles. Noise and emissions do not occur, not even lead poisoning like in case of storage battery. A look into commercially available flywheel units showed that they match the dimensions of ISO container along with the rest of the power system and can be easily transported. Hence flywheel unit was chosen to be the energy storage device for this project. Figure 5 compares cost of power quality for all the storage devices discussed above. Clearly flywheels also prove to be most economic.

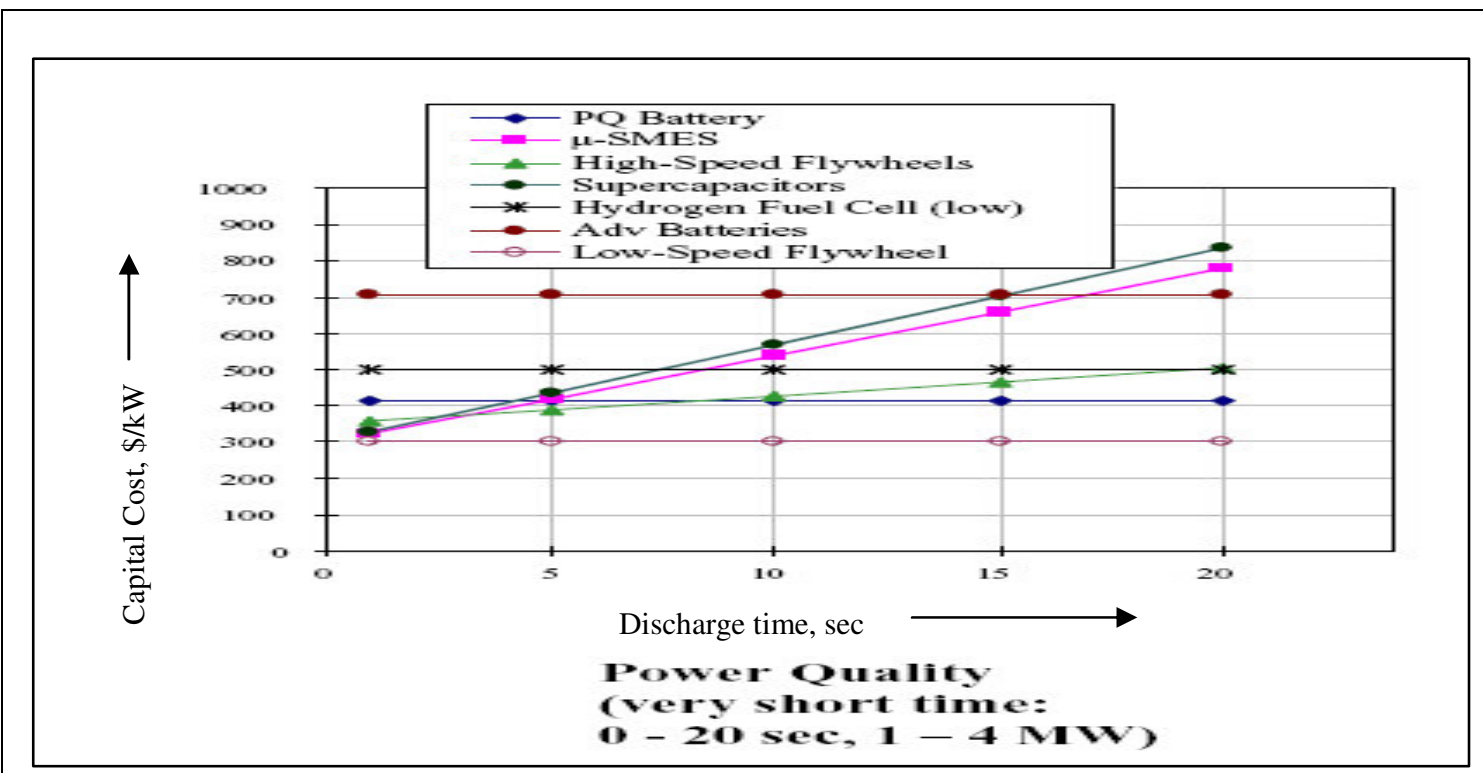

Figure 5 - Cost comparison of various technologies. (Courtesy: Sandia National Labs). 


\section{METHODOLOGY}

\subsection{Stepwise Procedure}

1. Read various drilling rig manuals and understood the functioning of rig components and made a theoretical energy audit by identifying actuators based on nameplate specifications.

2. Visited a rig site in Texas for interviewing the service engineer and driller to understand the working and drawbacks of the rig for this new design and gathered comprehensive time stamped drilling data. Studied emissions produced while drilling operation.

3. Analyzed and comprehended this data using MATLAB for making an actual energy audit of the rig. Interview with flywheel expert at Texas A\&M University was done to determine the specifications of flywheel unit.

4. Compared theoretical energy audit with actual audit and designed the optimized system followed by a cost benefit analysis to determine the return of investment.

5. Designed and encapsulated the power system into the size constraint of ISO container.

6. Studied diesel engines performance curves to determine exact load which the energy storage unit has to provide for effective peak shaving.

\subsection{Drilling Rig Study}

Land Offshore Containerised (LOC) rigs are casing while drilling rigs which offer a number of advantages like faster drilling time, safe and efficient operation, very 
little or no trip time, offline BOP testing, less energy requirement for drilling operation, highly automated control system and fewer crew members (Huisman, 2005) . The study was conducted on this rig because it has a sophisticated supervisory control and data acquisition (SCADA) system monitoring various drilling parameters.

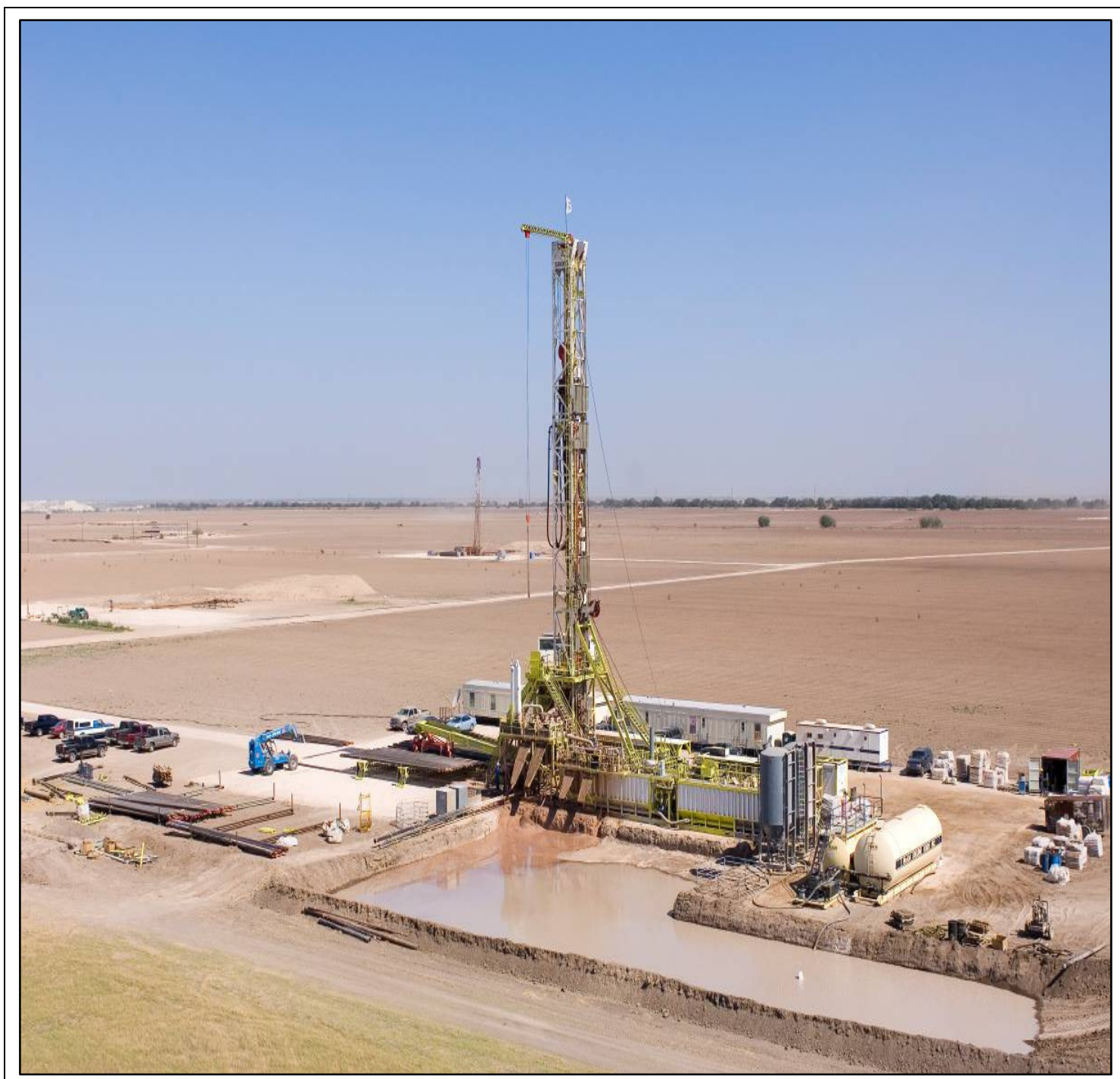

Figure 6 - LOC 250 rig in actual field. 
A set up of LOC 250 rig in the field is shown in Figure 6. Additionally these are ISO containerised rigs which means they are easy to relocate and transport. LOC 250 (Land and Offshore Containerized Unit, hook load 250 tonnes) contains 17 containers while LOC-400 (Land and Offshore Containerized Unit, hook load 400 tonnes) consist of 16 containers (Huisman, 2005). These are the two Casing While Drilling (CWD) rigs under consideration in this study. Table 2 provides description of various containers of LOC 250. A comprehensive energy audit of both of these rigs is done in order to determine the overall power and energy these rigs consume and also the values of transient power peaks which should be provided by our alternate power system. For this purpose time stamped data from one of the LOC-250 rig was obtained and processed. LOC-400 is a successor of LOC-250 and it is assumed that the processed values from LOC-250 will match closely to that of LOC-400. This is because LOC-400 is an improved version of LOC-250 and is still under construction. Hence operational data from LOC-400 is unavailable. Nonetheless theoretical energy audit of LOC-400 is done in this study. 
Table 2- Container description for LOC 250. (Courtesy Huisman US Inc.).

\begin{tabular}{|c|c|c|c|c|c|}
\hline Short & Name & size & Description & [mton] & [sht] \\
\hline$\overline{\mathrm{BASE}}$ & Base container & $40^{\prime}$ & Stabilizers, rig up winch, erection frame & 36 & 40 \\
\hline DWK & Drawworks container & $20^{\prime}$ & $\begin{array}{l}\text { Drawworks, reeving winch, wire line } \\
\text { winch }\end{array}$ & 36 & 40 \\
\hline MP1 & Mud pump 1 container & $20^{\prime}$ & Mud pump, electrical distribution panel & 30 & 33 \\
\hline MP2 & Mud pump 2 container & $20^{\prime}$ & $\begin{array}{l}\text { Mud pump, rig up hydraulic power unit, } \\
\text { emergency electrical power unit }\end{array}$ & 30 & 33 \\
\hline $\mathrm{BOP}$ & $\begin{array}{l}\text { Blow Out Preventor } \\
\text { container }\end{array}$ & $20^{\prime}$ & BOP, trip tank, BOP hoist system & 30 & 33 \\
\hline MLS & Mast Lower Section & $40^{\prime}$ & $\begin{array}{l}\text { Rotary table with power slips, standpipe } \\
\text { manifold }\end{array}$ & 30 & 33 \\
\hline MMS & Mast Middle Section & $40^{\prime}$ & $\begin{array}{l}\text { Top drive, service loop, kelly hose, large } \\
\text { floodlights }\end{array}$ & 30 & 33 \\
\hline MCS & Mast Crown Section & $40^{\prime}$ & Service crane, tuggers & 30 & 33 \\
\hline $\mathrm{PH}$ & Pipe Handler & $40^{\prime}$ & Pipe handler & 28 & 31 \\
\hline PR & Pipe Rack & $40^{\prime}$ & Two tilting piperacks & 20 & 22 \\
\hline $\mathrm{DC}$ & Drillers Cabin & $40^{\prime}$ & $\begin{array}{l}\text { Water tank, water pumps, high pressure } \\
\text { cleaner, driller's cabin }\end{array}$ & 30 & 33 \\
\hline PU & Power Unit & $40^{\prime}$ & $\begin{array}{l}\text { Electrical generator set, main electrical } \\
\text { distribution, two diesel engines with } \\
\text { hydraulic pumps, hydraulic tank, hydrau- } \\
\text { lic coolers, electrically driven constant } \\
\text { pressure pump }\end{array}$ & 36 & 40 \\
\hline ATM & Atmospheric degasser & $20^{\prime}$ & $\begin{array}{l}\text { Atmospheric degasser, choke manifold, } \\
\text { coarse scalping shakers }\end{array}$ & 25 & 27.5 \\
\hline AMC & Active Mud Container & $40^{\prime}$ & $\begin{array}{l}\text { Active tank, sand trap, fine screen shak- } \\
\text { ers, charge pumps, vacuum degasser, } \\
\text { agitators, level sensors, manifolds }\end{array}$ & 25 & 27.5 \\
\hline MMC & Mud Mix Container & $40^{\prime}$ & $\begin{array}{l}\text { Reserve tank and pill pits, shear mixer } \\
\text { hopper, mix pumps, agitators, caustic } \\
\text { barrel }\end{array}$ & 25 & 27.5 \\
\hline$\overline{\mathrm{ACCU}}$ & Accumulator & $40^{\prime}$ & $\begin{array}{l}\text { BOP control unit, BOP test pump, air } \\
\text { compressor and dryer, tool room/ } \\
\text { workshop, oil storage }\end{array}$ & 28 & 31 \\
\hline FUEL & Fuel container & $20^{\prime}$ & Fuel tank with transfer pump & 15 & 16.5 \\
\hline
\end{tabular}




\subsubsection{Electrical System for LOC-400}

The main power consumers namely mud pump, drawworks and top drive of LOC-400 rig are mounted on the main dc bus. There are two or three diesel generators with total rated power of $2400 \mathrm{KW}, 480 \mathrm{~V}, 60 \mathrm{~Hz}, 3000 \mathrm{KVA}$. Two transformers convert this into $690 \mathrm{~V}, 60 \mathrm{~Hz}$ and feed it to the invertors which then convert it into DC and supply to the main bus where all major consumers are mounted. Regenerated power is dissipated in the brake resistors. The single line diagrams for LOC 400 with bus bars and different actuators and is shown in Figure 7. A close look at the boxes connected to the main bus shows the two transformer containers which basically forms the alternate power system. The details of these containers will be described later.

According to Huisman specification manual for LOC-400, it should not be

difficult for the rig to take power from the utility grid. If there are strong reasons in terms of cost savings and efficiency, such a possibility should be thoroughly explored. 


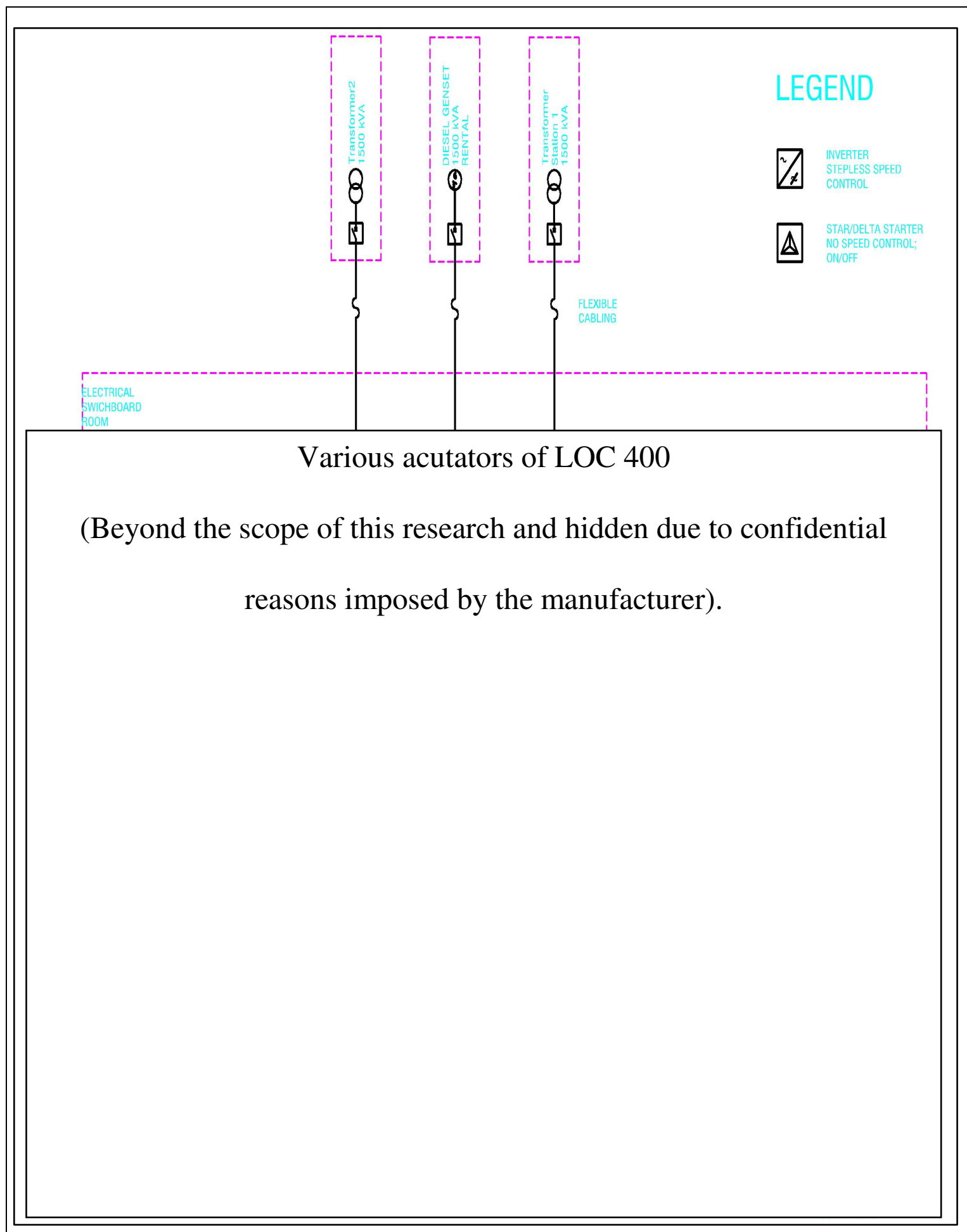

Figure 7 - Single line diagram of LOC 400 with alternate power system. 


\subsubsection{Electrical System for LOC-250}

There are two generators feeding the $480 \mathrm{~V}$ main bus which itself feeds the hydraulic power unit (HPU) and one generator feeding electrical power unit (EPU). Variable frequency drives are mounted in order to attain different speeds. There are no invertors feeding the main power consumers rather they are AC motors as opposed to LOC-400. The hydraulic power system in LOC-250 is replaced by electrical system in LOC-400 which is the reason why it is considered to be a better version of LOC-250. Also this is one of the reasons why there is no efficiency loss in LOC-400 when converting the regenerative power from hydraulic to mechanical and then electrical which is the case with LOC-250. The single line diagram for LOC 250 with bus bars and different actuators in place is shown in Figure 8. Some of the actuators installed are not shown in the single line diagram because of confidential reasons. However they do not pertain to the scope of this project and hence not required by the reader to know. 


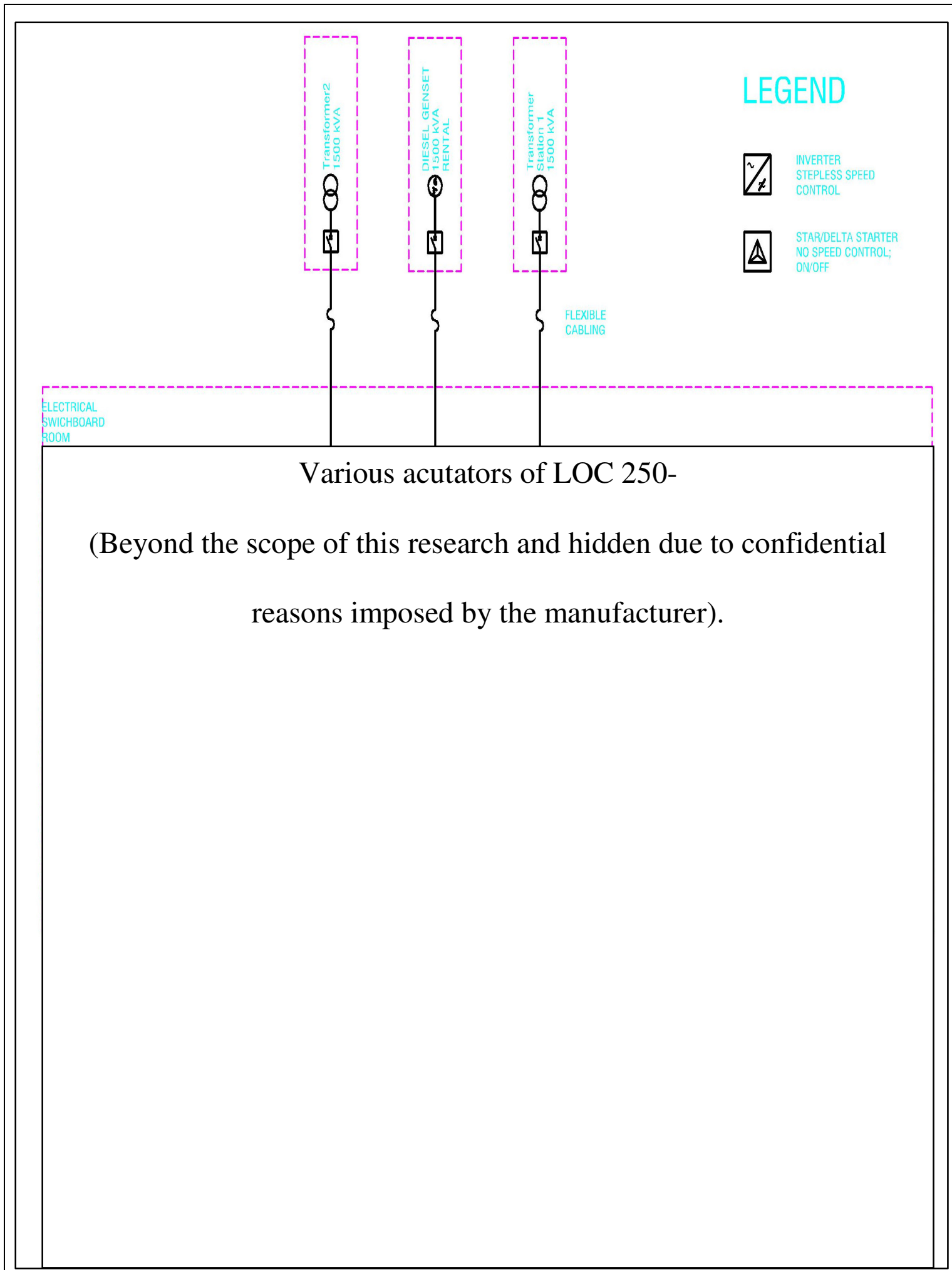

Figure 8 - Single line diagram of LOC 250 with alternate power system 


\subsection{Energy Audit}

\subsubsection{Theoretical Energy Audit}

The rig does not operate on its full rating all the time. Rather the power consumption is distributed as given by Table 3. Initially a theoretical energy audit for the rig was conducted based on the specifications of the rig. This was done by reading various nameplate ratings of the drives installed on the rig. For hydraulic system power was calculated based on the flow multiplication by pressure ratings in the hydraulic diagrams. Hydraulic drives are mainly mounted on LOC 250 rig.

Table 3- Simultaneous power consumption of the rig with operating time. (Courtesy Huisman US Inc.).

\begin{tabular}{|c|c|}
\hline Share Load of Engines & Operating Time \\
\hline $75 \%$ & $60 \%$ \\
\hline $50 \%$ & $30 \%$ \\
\hline $10 \%$ & $10 \%$ \\
\hline
\end{tabular}

Table 4 exhibits the theoretical values of rig specifications for various actuators. Hence design of this KERS system based on theoretical energy audit will simply result in an overly designed system which will be uneconomic and underutilized. Therefore an actual energy audit of LOC-250 is required. 
Table 4 - Theoretical Energy audit of LOC 250 with various actuator ratings.

\begin{tabular}{|c|c|c|}
\hline Main Power Consumers & Power in kW & No. \\
\hline Drawworks & $2 \times 400$ & 2 \\
\hline Mudpump & $3 \mathrm{X} 400$ & 3 \\
\hline Topdrive & $1 \mathrm{X} 440$ & 1 \\
\hline Wire line traction & $2 \times 55$ & 2 \\
\hline Wire line storage & $2 \times 25$ & 2 \\
\hline Total installed Power & 2578 & \\
\hline Maximum simultaneous Power Consumption & 1600 & \\
\hline \multicolumn{3}{|l|}{ Secondary Power Consumers } \\
\hline Shaker & $2 \times 3$ & 2 \\
\hline Degasser & 18.5 & 1 \\
\hline Agitator & $12 \times 5.5$ & 12 \\
\hline Centrifugal Pumps & $3 X 55$ & 3 \\
\hline Mud Pump liner wash pump & tbd & \\
\hline BOP control Unit & 15 & 1 \\
\hline Hydraulic Power Unit & $2 \mathrm{X} 110$ & 2 \\
\hline Compressors & 15 & \\
\hline Miscellaneous & tbd & \\
\hline Total Installed Power & 500 & \\
\hline Max Simultaneous Power Consumption & 400 & \\
\hline Hydraulic Drives & $2 \mathrm{X} 110$ & 2 \\
\hline Rig Up and Emergency Diesel Pump & 40 & 1 \\
\hline
\end{tabular}




\subsubsection{Actual Energy Audit}

To obtain a realistic measure of power consumption an actual audit of the rig is required. This can be done by processing real time operational rig data. The process starts with gathering the rig data from its SCADA system. This data can be converted to comma separated format by the use of Trend Reader software. These comma separated files after a little conditioning can be imported to MATLAB. There were as much as 23 rig parameters obtained from SCADA system. Each of these parameters was as much as 1.3 million lines long. Excel can process data only a little more than 65000 lines. Hence a comprehensive tool with multiple functionalities was required. This is the reason why MATLAB was chosen for this research. Table 5 shows various rig parameters. The highlighted parameters were those signals which were later combined in MATLAB for obtaining relevant results. 
Table 5 - List of SCADA signal measured on LOC 250

\begin{tabular}{|c|c|c|c|c|c|}
\hline Title & Total Headers & Start & End & Continuous & $\begin{array}{c}\text { Sample } \\
\text { Time(sec) }\end{array}$ \\
\hline Gas Units & 51 & 06-25-07,00:00:00 & 06-22-2008,23:59:59 & Yes & 0.5 \\
\hline Auxiliary Pressure & 51 & 06-25-07,00:00:00 & 06-22-2008,23:59:59 & Yes & 1 \\
\hline Bit Location & 51 & 06-25-2007 00:00:00 & 06-22-2008,23:59:50 & Yes & 10 \\
\hline Block Position & 51 & 06-25-2007 00:00:00 & 06-22-2008,23:59:59 & Yes & 1 \\
\hline Depth & 51 & 06-25-2007 00:00:00 & 06-22-2008,23:59:50 & Yes & 10 \\
\hline Dexponent & 51 & 05-28-2007 00:00:00 & 05-25-2008 23:59:50 & Yes & 10 \\
\hline Flow Bell Nipple & 51 & 05-28-2007 00:00:00 & 06-22-2008 23:59:58 & Yes & 2 \\
\hline GainLoss & 51 & 06-25-2007 00:00:00 & 06-22-2008 23:59:58 & Yes & 2 \\
\hline HookLoad & 51 & 06-25-2007 00:00:00 & 06-22-2008 23:59:58 & Yes & 2 \\
\hline MudPump1GPM & 51 & 06-25-2007 00:00:00 & 06-22-2008 23:59:58 & Yes & 2 \\
\hline MudPump1SPM & 51 & 06-25-2007 00:00:00 & 06-22-2008 23:59:58 & Yes & 2 \\
\hline MudPump1Total strokes & 51 & 04-06-2007 00:00:00 & 01-06-2008 23:59:58 & Yes & 2 \\
\hline MudPump2GPM & 51 & 06-25-2007 00:00:00 & 06-22-2008 23:59:58 & Yes & 2 \\
\hline MudPump2SPM & 51 & 06-25-2007 00:00:00 & 06-22-2008 23:59:58 & Yes & 2 \\
\hline MudPump2Total strokes & 51 & 04-6-2007 00:00:00 & 01-06-2008 23:59:58 & Yes & 2 \\
\hline PillTank1Volume & 51 & 06-18-2007 00:00:00 & 06-15-2008 23:59:50 & Yes & 10 \\
\hline PillTank2Volume & 51 & 06-18-2007 00:00:00 & 06-15-2008 23:59:50 & Yes & 10 \\
\hline Pipe Velocity & 51 & 06-25-2007 00:00:00 & 06-22-2008 23:59:50 & Yes & 10 \\
\hline Pit Volume Total & 51 & 06-18-2007 00:00:00 & 06-15-2008 23:59:58 & Yes & 2 \\
\hline Pump Pressure & 51 & 06-25-2007 00:00:00 & 06-22-2008 23:59:58 & Yes & 2 \\
\hline Rate of Penetration & 51 & 06-25-2007 00:00:00 & 06-22-2008 23:59:58 & Yes & 2 \\
\hline ReserveTankVolume & 51 & 06-18-2007 00:00:00 & 06-15-2008 23:59:50 & Yes & 10 \\
\hline RotaryTableRPM & 51 & 06-25-2007 00:00:00 & 06-22-2008 23:59:50 & Yes & 10 \\
\hline RotaryTableTorque & 51 & 06-25-2007 00:00:00 & 06-22-2008 23:59:50 & Yes & 10 \\
\hline ShakerTankVolume & 51 & 06-18-2007 00:00:00 & 06-15-2008 23:59:50 & Yes & 10 \\
\hline SICP & 51 & 06-25-2007 00:00:00 & 06-22-2008 23:59:58 & Yes & 2 \\
\hline SuctionTankVolume & 51 & 06-18-2007 00:00:00 & 06-15-2008 23:59:50 & Yes & 10 \\
\hline TopDriveRPM & 51 & 06-25-2007 00:00:00 & 06-22-2008 23:59:58 & Yes & 2 \\
\hline TopDriveTorque & 51 & 06-25-2007 00:00:00 & 06-22-2008 23:59:58 & Yes & 2 \\
\hline TotalGPM & 51 & 06-25-2007 00:00:00 & 06-22-2008 23:59:58 & Yes & 2 \\
\hline TotalStrokes & 51 & 01-6-2008 23:59:00 & 05-21-2007 00:00:00 & Yes & 10 \\
\hline TripTankVolume & 51 & 06-18-2007 00:00:00 & 06-15-2008 23:59:58 & Yes & 2 \\
\hline WeightOnBit & 51 & 06-25-2007 00:00:00 & 06-22-2008 23:59:59 & Yes & 0.5 \\
\hline WireLineDepth & 51 & 11-6-2007 00:00:00 & 06-15-2008 23:59:58 & Yes & 2 \\
\hline WireLineLoad & 51 & 06-25-2007 00:00:00 & 06-15-2008 23:59:58 & Yes & 2 \\
\hline WireLineSpeed & 51 & 06-25-2007 00:00:00 & 06-22-2008 23:59:58 & Yes & 2 \\
\hline
\end{tabular}




\subsubsection{MATLAB Code}

The following procedure was followed in MATLAB:

- [date,time,mp1gpmdatadata]=textread['C:IUserslankit\Desktop $\backslash$ Signal combinationlMudPump1GPM.txt','\%s\%s\%n'];

- $\quad$ date,time,ppdata]=textread['C:IUserslankit\Desktop $\backslash$ Signal combination\PumpPressure.txt','\%s\%s\%n'];

- \%Delete date and time for both of the above

- $\operatorname{plot}(m p 1 g p m d a t a)$;

- $\operatorname{plot}(p p d a t a)$

- $\quad$ mppower=mp1gpmdata. ${ }^{*}$ ppdata;\%point wise vector multiplication

- $\operatorname{plot}(m p p o w e r)$;

- $\quad \operatorname{mpmv}=$ filter(ones(1,2)/2,1,mppower); \% Moving Average for 2 seconds

- $\operatorname{plot}(\mathrm{mpmv}) ; \%$ Plotting moving average curve

- $\mathrm{z}=[1: 1330000] \%$ defining a column vector $\mathrm{z}$

- $\mathrm{z}=\mathrm{Z}^{\prime}$

- $\operatorname{plot}(\mathrm{z}, \mathrm{mppower}, \mathrm{z}, \mathrm{mpmv}) ; \%$ plotting original curve VS moving average curve

- $\quad$ mpdifference $=\operatorname{mppower}(2: 1330000,1)-\operatorname{mpmv}(1: 1329999,1) ; \%$ Calculating the difference between the two curves with 2 seconds lag

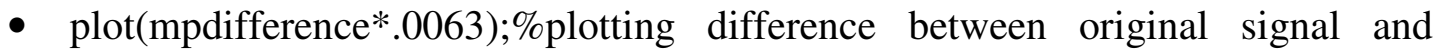
moving average on $\mathrm{KW}$ scale

- $\quad$ mpdifference1=mpdifference(4e5:6e5)\%segmenting a part of 'difference'

- $\quad$ mpdifference $1=$ mpdifference $1 * .0063 \%$ converting into KW scale 
- mpenergy $1=$ filter(ones(1,200001)/1,1,mpdifference1);\%adding Nth value to all $(\mathrm{N}-1)$ values for obtaining energy curve

- \%Entire procedure is repeated for top drive with a conversion factor of .00010046

- $\operatorname{plot}(m p d i f f e r e n c e(1: 1309725)+m p 2$ difference(1:1309725)+tddifference);\%plotti ng total difference of power for mud pump1,mud pump2 and top drive which the flywheel has to supply(2 sec)

- $\operatorname{plot}(\mathrm{z}(200001: 400001)$, mpenergy1,z(400001:600001),mpenergy2,z(600001:800 001),mpenergy3);\%Plotting overall energy for mud pump1

- $\%$ Remove the offset from above curve

- $\operatorname{plot}(\mathrm{z}(200001: 400001), \mathrm{mp} 2 \mathrm{energy1,z(400001:600001),mp2energy2,z(600001:8}$ 00001),mp2energy3);\%Plotting energy for mud pump2

- $\%$ Remove the offset from above curve

- $\operatorname{plot}(\mathrm{z}(200001: 400001), \operatorname{tdenergy1,z(400001:600001),tdenergy2,z(600001:80000~}$ 1),tdenergy3);\%Plotting cumulative energy for top drive

- $\%$ Remove the offset from above curve

- $\operatorname{plot}(m p d i f f e r e n c e(1: 1309733)+m p 2$ difference(1:1309733)+tddifference);\%Plotti ng total difference of power for mud pump1, mud pump2,top drive for $2 \mathrm{sec}$

- $\quad \operatorname{plot}(z(200001: 400001)$, mpenergy1,'b',z(400001:600001),mpenergy2,'b',z(600001 :800001),mpenergy3,'b',z(200001:400001),mp2energy1,'g',z(400001:600001),mp 2energy2,'g',z(600001:800001),mp2energy3,'g',z(200001:400001),tdenergy1,'y',z 
(400001:600001),tdenergy2,'y',z(600001:800001),tdenergy3,'y');\%Comparing energy curves for mud pump1,2 and top drive

- $\operatorname{plot}(\mathrm{z}(4 \mathrm{e} 5: 6 \mathrm{e} 5), \mathrm{mp} 2 \mathrm{energy} 1+\mathrm{mpenergy} 1+\mathrm{tdenergy} 1, \mathrm{z}(6 \mathrm{e} 5: 8 \mathrm{e} 5), \mathrm{mp2energy2+mp}$ energy2+tdenergy2,z(8e5:10e5),mp2energy3+mpenergy3+tdenergy3);

- grid \%Adding energy curves for mud pump1,2 and top drive

- \%maximum value of cumulative energy curve for $2 \mathrm{sec}=550 \mathrm{KJ}$; Including an efficiency factor of 0.7 for the entire system $E_{\max }($ flywheel $)=785 \mathrm{KJ}$

- \%maximum value of difference of power curve for $2 \mathrm{sec}=100 \mathrm{KW}$; Including an efficiency factor of 0.7 for the entire system $P_{\max }($ flywheel $)=143 \mathrm{KW}$

- \%entire procedure is repeated for window period of 10 seconds

- \%maximum value of cumulative energy curve for $10 \mathrm{sec}=20000 \mathrm{KJ} ;$ Including an efficiency factor of 0.7 for the entire system $E_{\max }($ flywheel $)=28570 \mathrm{KJ}$

- \%maximum value of difference of power curve for $10 \mathrm{sec}=140 \mathrm{KW}$; Including an efficiency factor of 0.7 for the entire system $P_{\max }($ flywheel $)=200 \mathrm{KW}$

- \%entire procedure is repeated for window period of 20 seconds

- \%maximum value of cumulative energy curve for $20 \mathrm{sec},=86000 \mathrm{KJ}$;Including an efficiency factor of 0.7 for the entire system $E_{\max }($ flywheel $)=122857 \mathrm{KJ}$

- \%maximum value of difference of power curve for $20 \mathrm{sec}=152 \mathrm{KW}$; Including an efficiency factor of 0.7 for the entire system $P_{\max }($ flywheel $)=217 \mathrm{KW}$

- $\operatorname{plot}(\mathrm{z}(200001: 400001)$, mpenergy1,z(400001:600001),mpenergy2,z(600001:800 001),mpenergy3,z(200001:400001),tdenergy1,z(400001:600001),tdenergy2,z(60 
0001:800001),tdenergy3)\%Comparing Cumulative Energy Curves for Mud Pump and Top Drive for all window lengths

\subsubsection{Simplified Description of MATLAB Code}

An easier description for MATLAB code follows. For various variable names refer to Appendix A:

- Import the text file data in MATLAB by using either import wizard or textread command. Say data for Mud Pump is imported.

- Three vectors namely date, time and data are formed. As MATLAB plots the data VS index by default and index can be scaled to sample time we can delete the date and time vectors for simplicity. Plot the Mud Pump Flow VS Time (Figure 9).

- Vector mpdata is ready to use. A similar procedure is followed for pump pressure data to obtain and plot ppdata vector (Figure 10). 


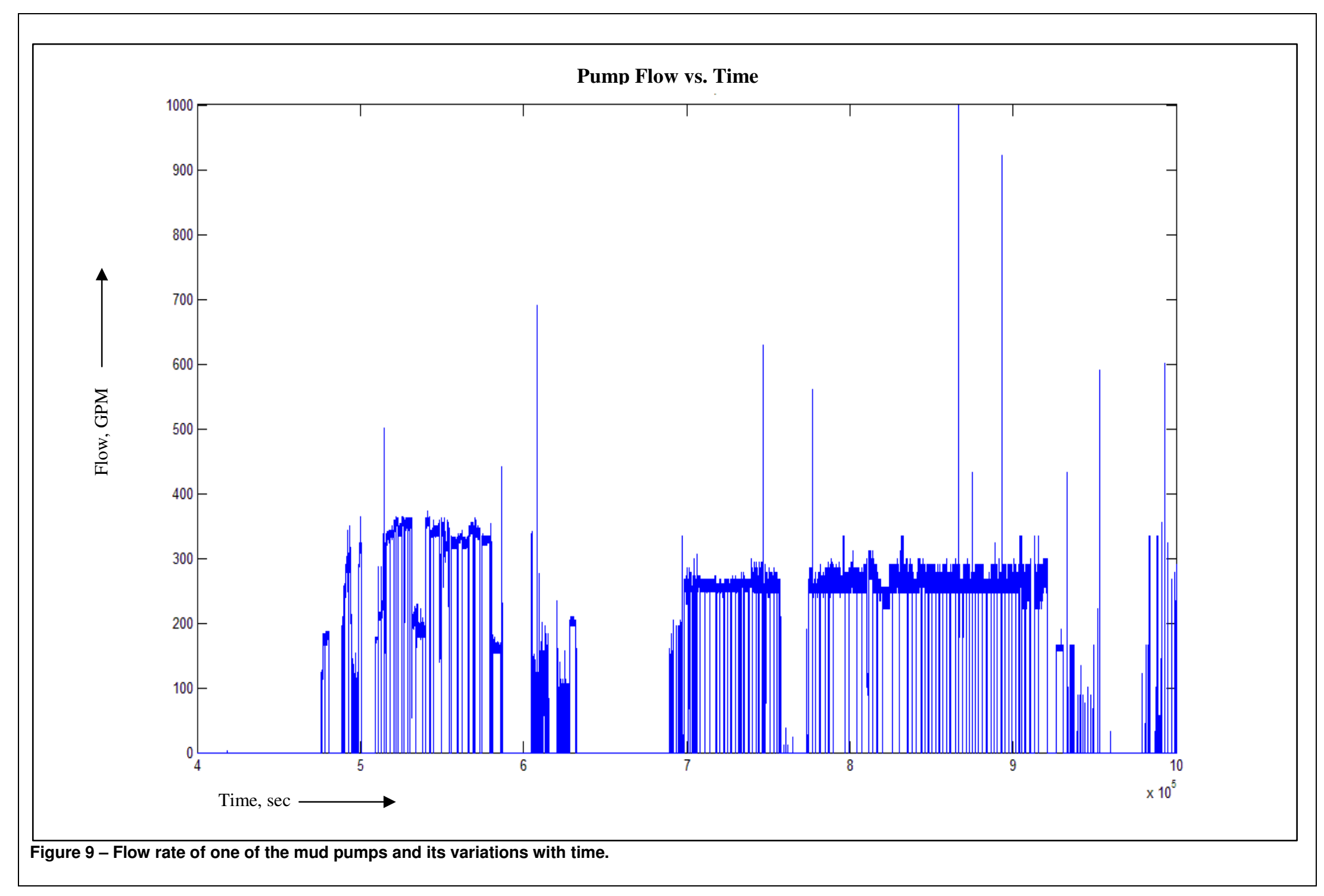


- Point wise multiplication of pump pressure and mud pump flow will give the instantaneous power for the mud pump on time scale (Figure11).

- A moving average for a window length of 2 seconds is taken and plotted against this Mud Pump power curve. This is done because moving average is assumed to converge to the average value of a certain dataset and by increasing the window length the curve will move closer to base load value (Figure 12).

- Larger is the time period of moving average, greater will be the difference between original and moving average curve, lower will be the base load and larger will be the size of the flywheel.

- Rest of the peaks (difference between moving average and power) are plotted. The flywheel design is based on this difference between actual and moving average curve (Figure 13).

- A cumulative difference curve for Mud Pumps and Top Drive is plotted. This is the summary of all the peaks that flywheel unit will supply (Figure 14).

- An energy curve is obtained by adding all the previously consumed power peaks for both the mud pumps and top drive. This is done by adding all the $n-1$ values to the $\mathrm{n}^{\text {th }}$ value of peak and multiplying it by the time to give energy in KJ. This is done by using an inbuilt filter in MATLAB and can be found in the code given in the previous heading. All energy curves for the given window length are added. 


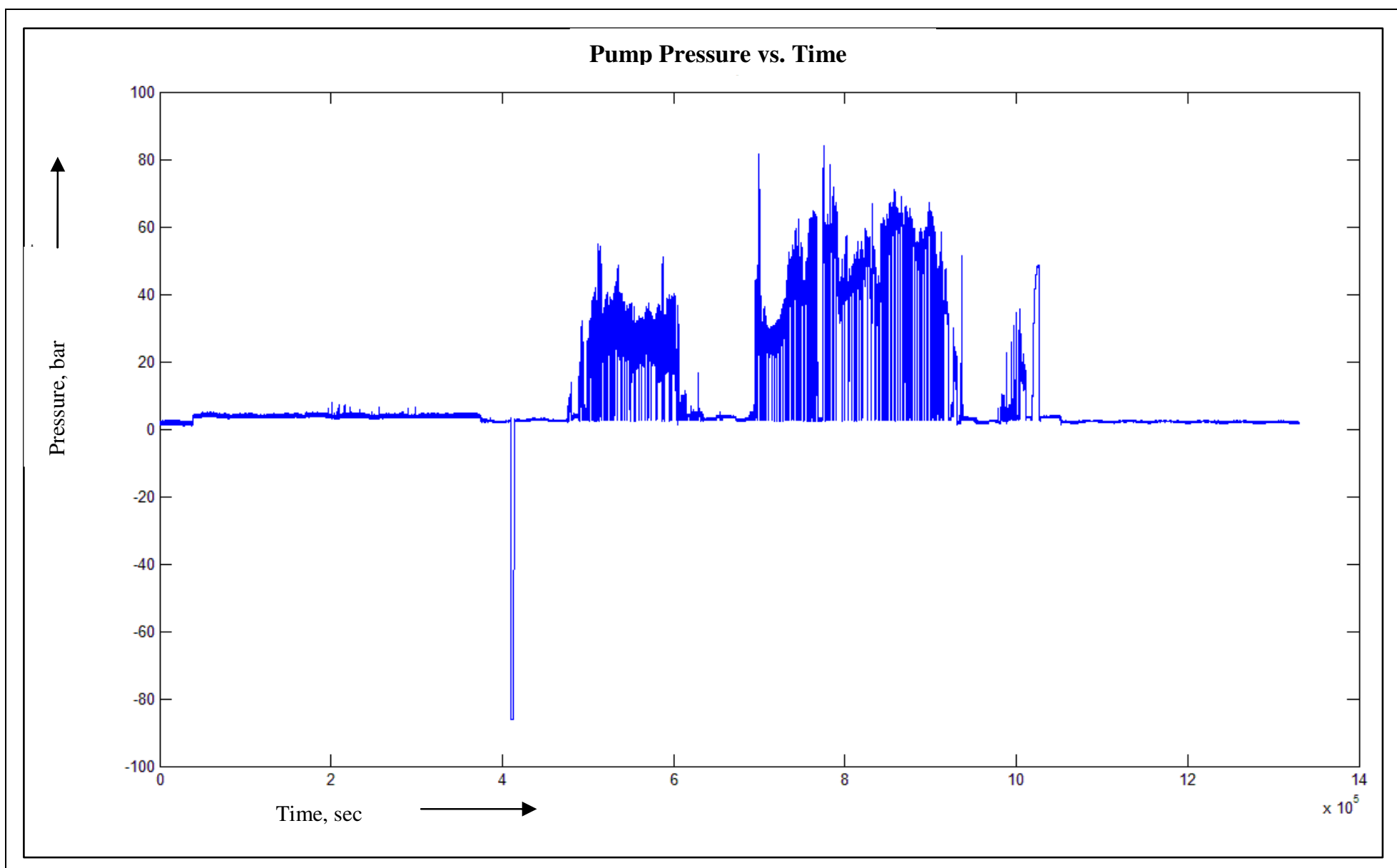

Figure 10 - Pump pressure vs. time is and its variations. Negative peak is considered to be a false triggered signal. 


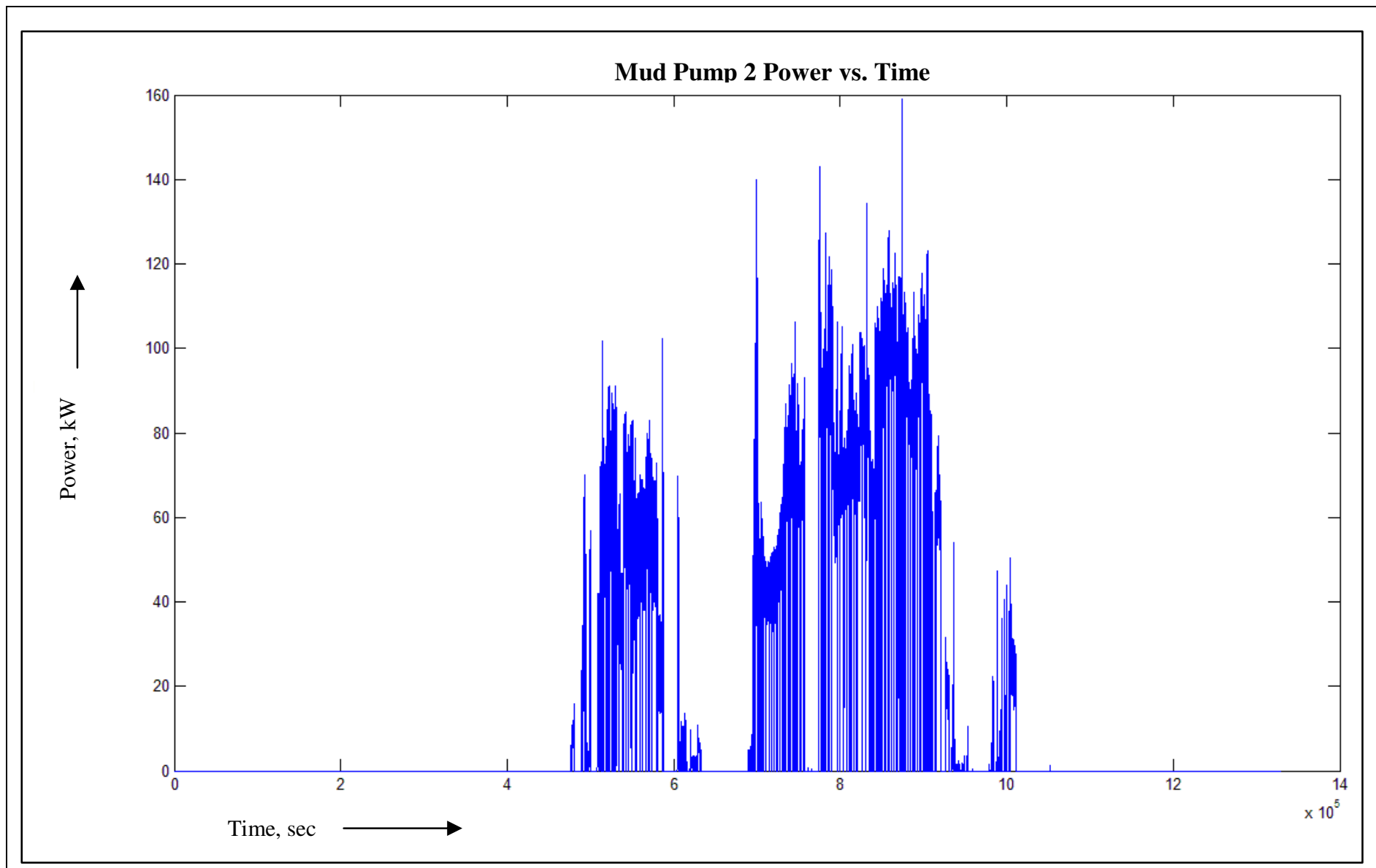

Figure 11 - Instantaneous power of mud pumps vs. time and its variations. Some of the exceptionally high values are considered to be false triggered. 


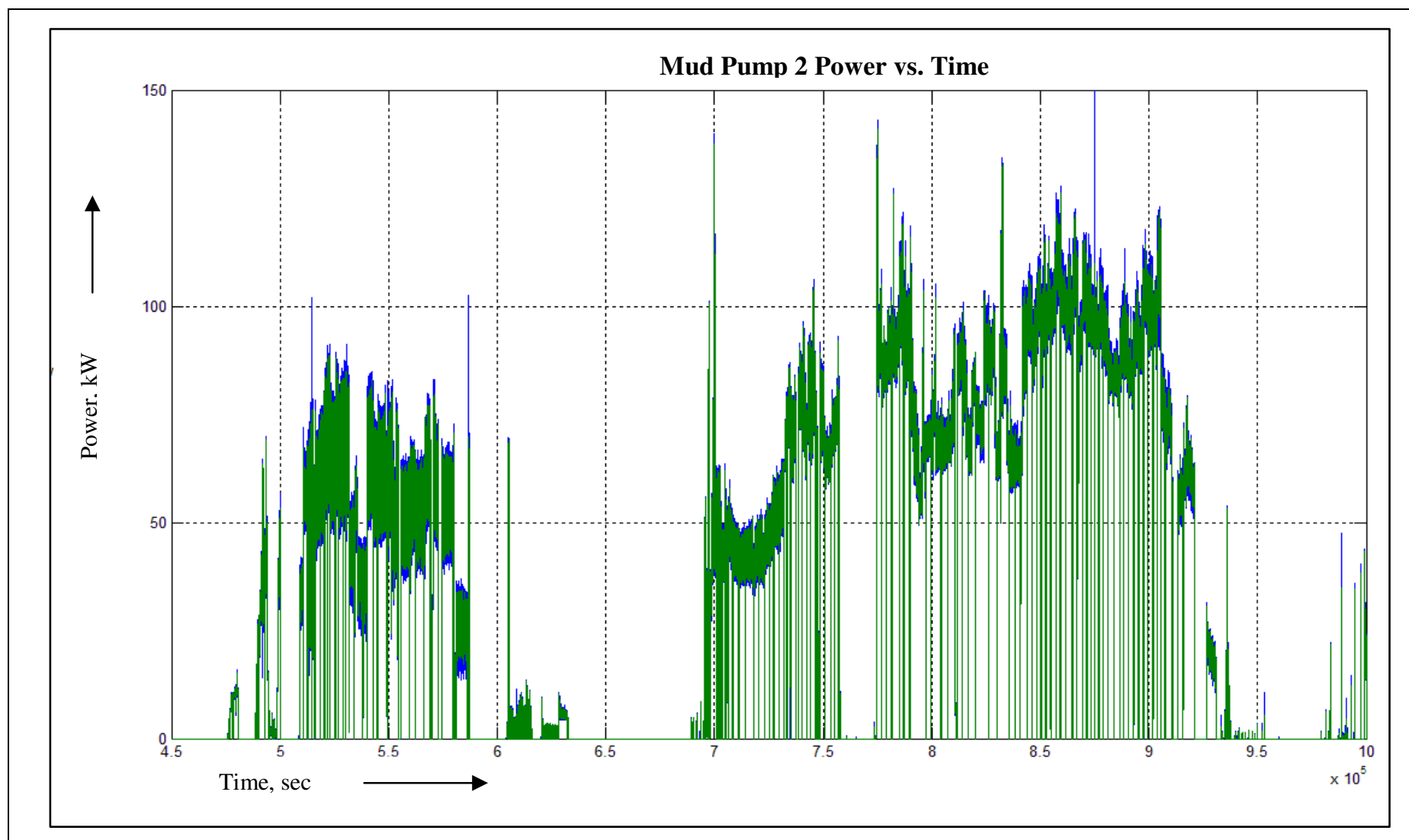

Figure 12 - A moving average of window length 2 seconds and actual power curve of the mud pump are plotted vs. time in order to determine transient peaks for this window length. 


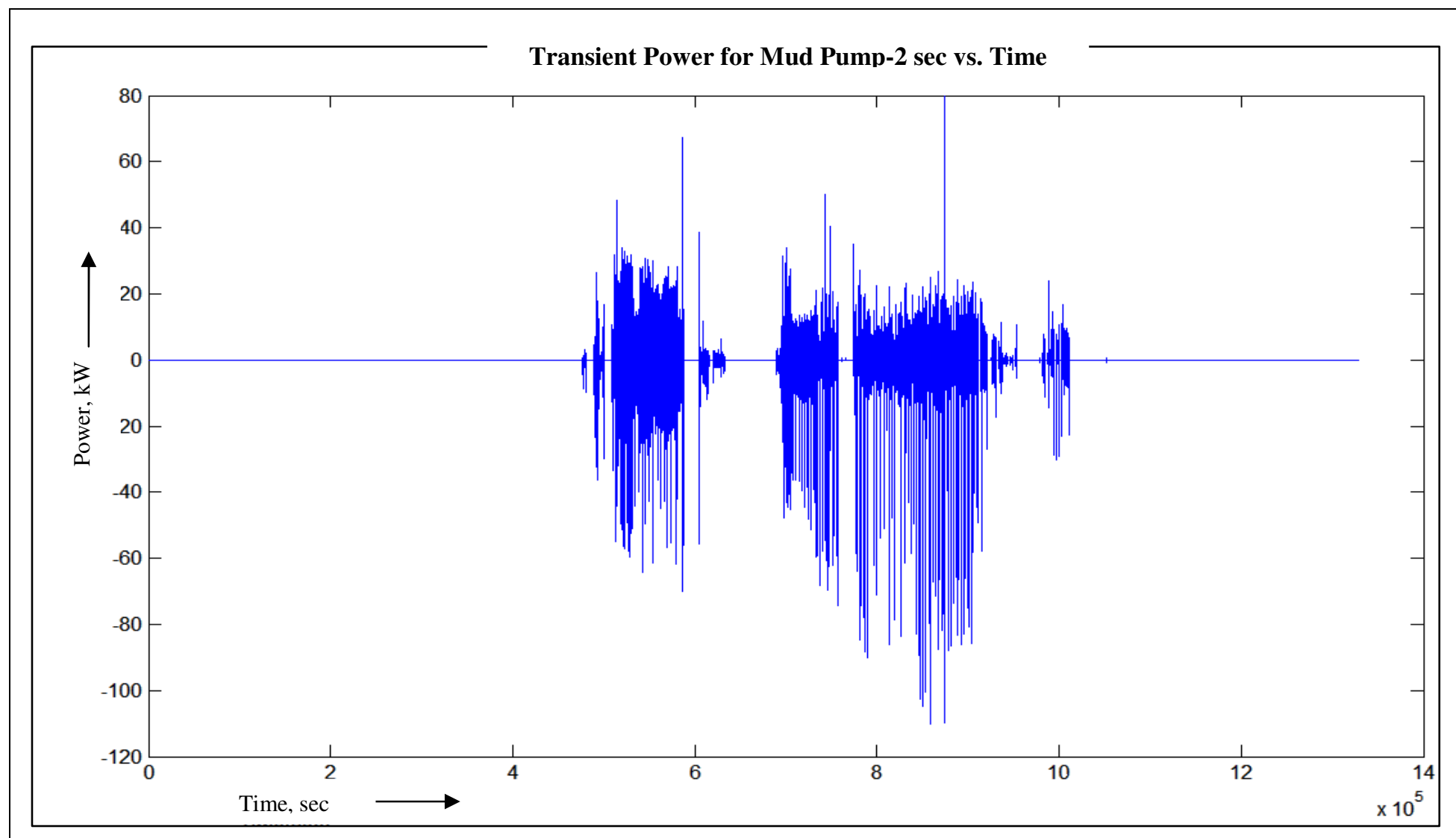

Figure 13 - Difference between the actual curve and moving average curve for the mud pump vs. time for the window length of 2 seconds. 


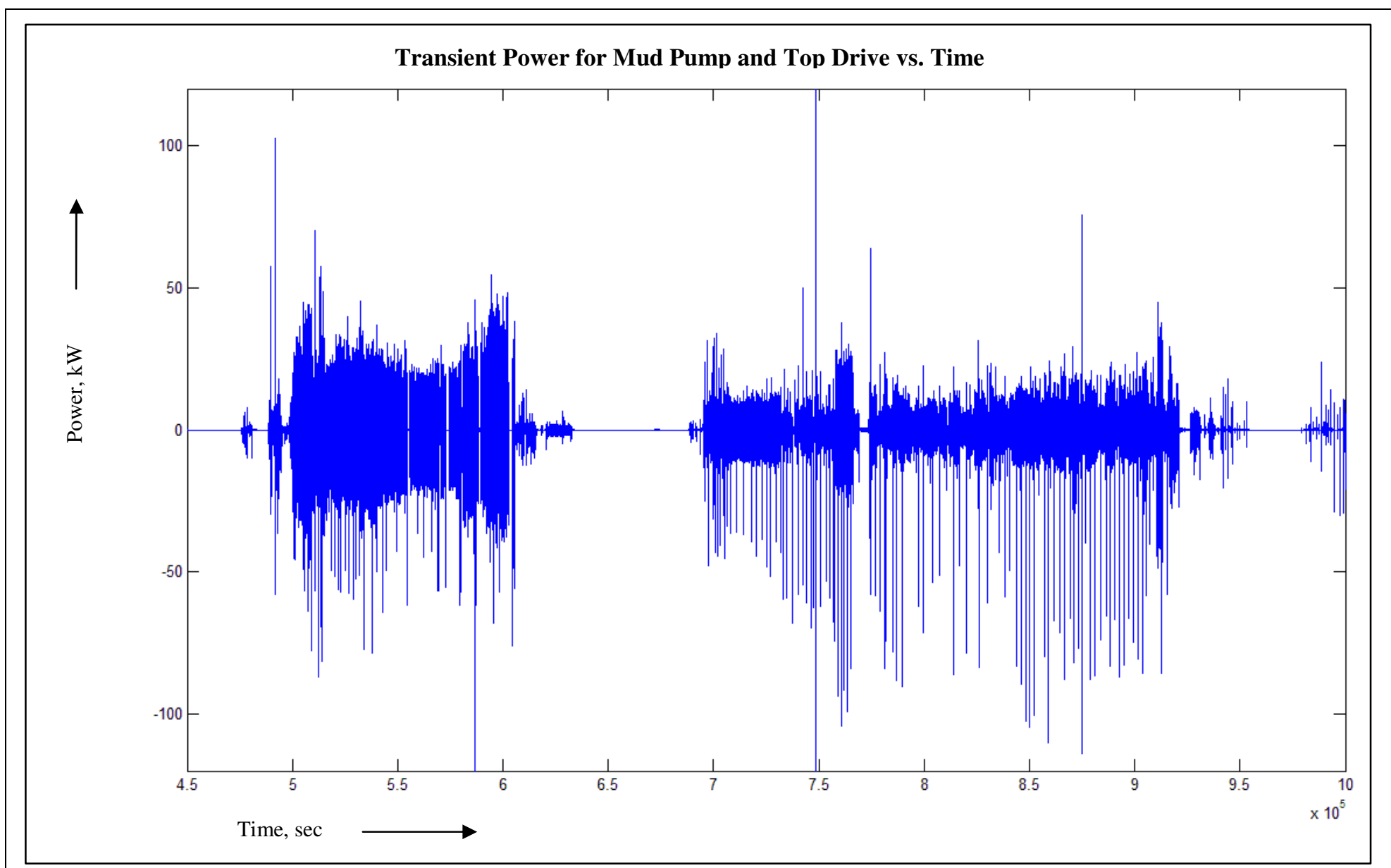

Figure 14 - Difference between the actual power curves and moving average curve combined for mud pumps and top drive vs. time. 
- The peaks in this curve represents the minimum amount of energy flywheel unit should have for effective peak shaving. These energy curves are drawn for all window periods and are attached in the appendix. Hence after these eight steps we have the values for $E_{\max }$ and $P_{\max }$ for the flywheel unit.

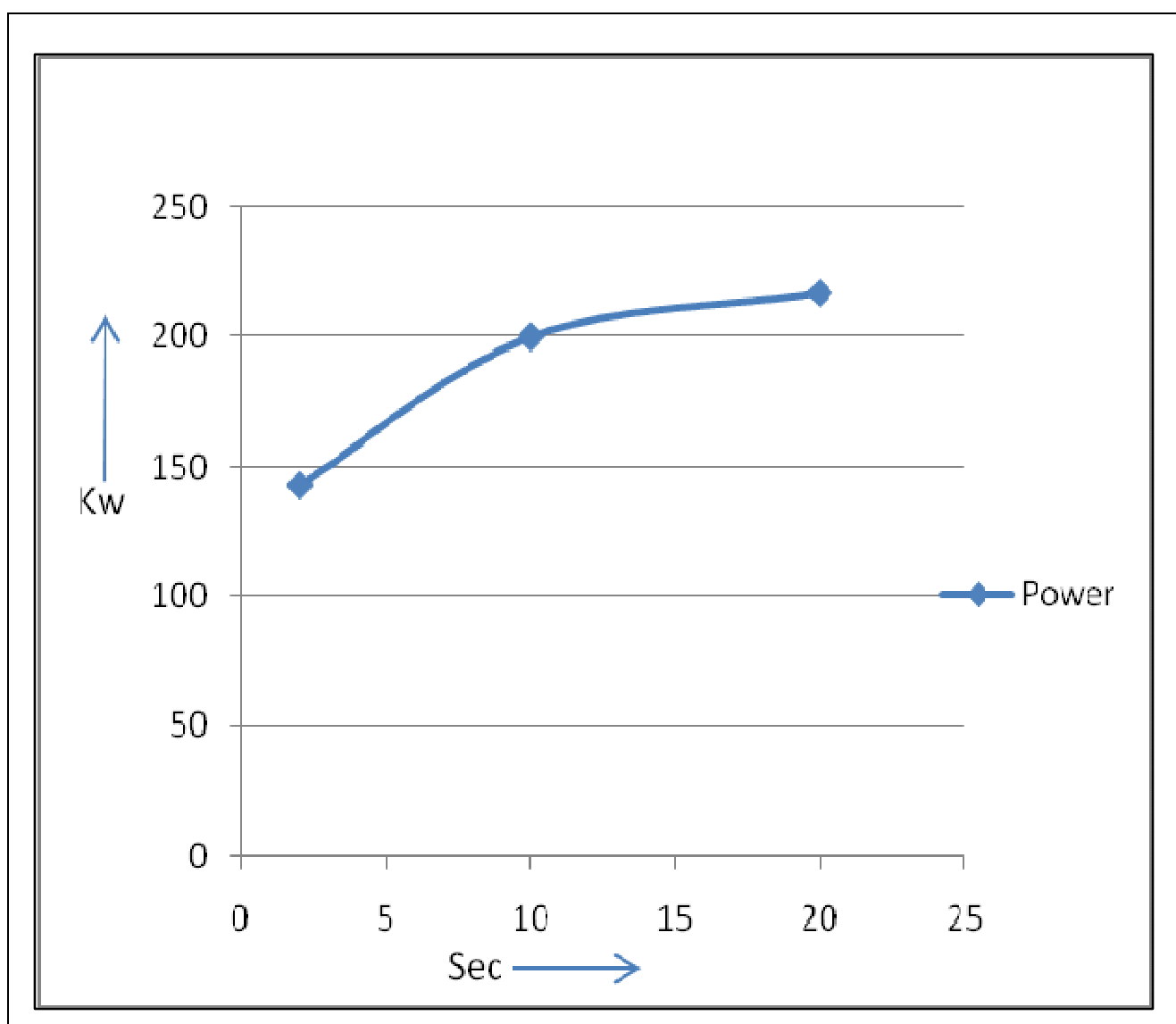

Figure 15 - Variation of KERS power requirement with window lengths. 
Hence after a rigorous data processing we come up with the moving maximum power and maximum energy values which the flywheel unit has to provide in order to be effective for peak shaving. Figure 15 show variations of the value of power which increases with the increasing window length.

- The energy curve for mud pumps and top drive for window period of 2 seconds is shown (Figure 16).

- The energy consumption for both mud pumps and top drive is compared and shown in cumulative energy comparison graph. This graph proves that mud pumps are the largest energy consumers (Figure 17). This energy comparison is also done for all window lengths.

- Another curve of interest would be top drive power and depth on the same time scale which shows stages of drilling where top drive consumed power (Figure $18)$.

- Lastly power comparison with depth for mud pumps and top drive is made. These curves summarize the drilling operation. Drilling process started near to 9600000 second and halted at 12400000 second where there is no power consumption by any component. Again power consumption begins at 1400000 second and goes up to 1800000 second. The amount of power consumed individually by these pumps and top drive is also shown (Figure 19). 


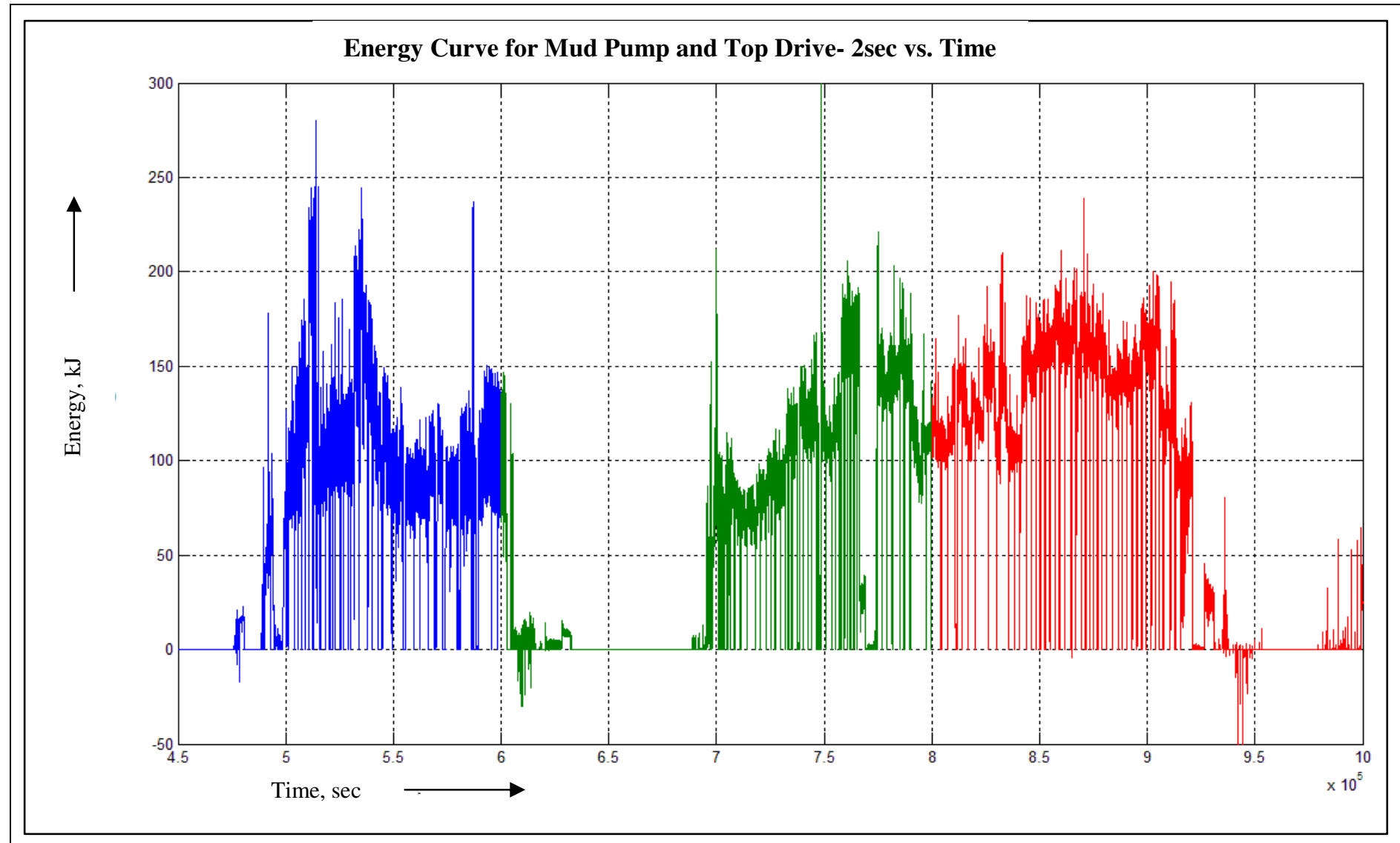

Figure 16- Energy curve for mud pumps and top drive for window length of 2 seconds. 


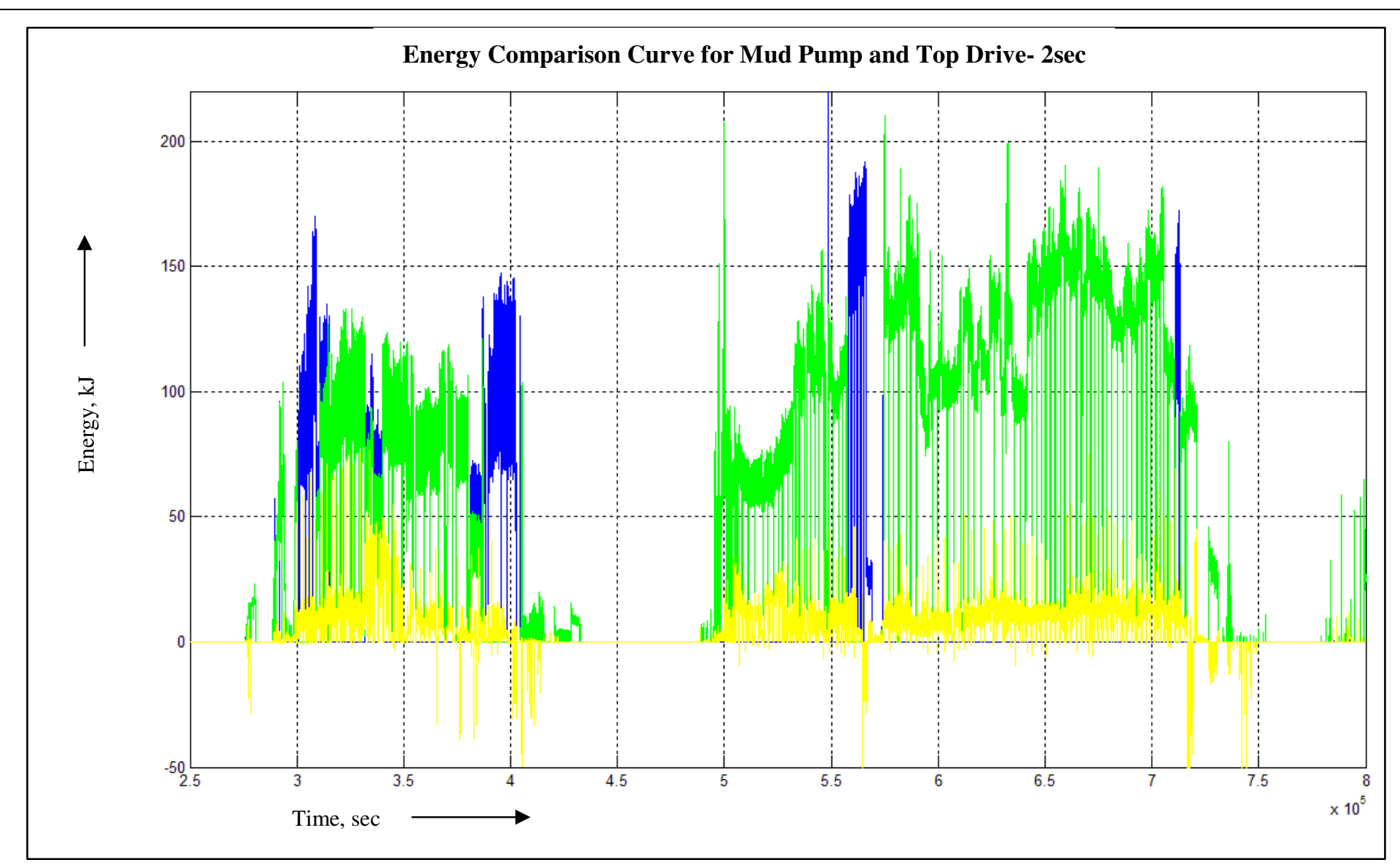

Figure 17 - Comparison of actual energy requirement of top drive and mud pumps vs. time and consumption of energy by mud pumps and top drive during drilling operation. 


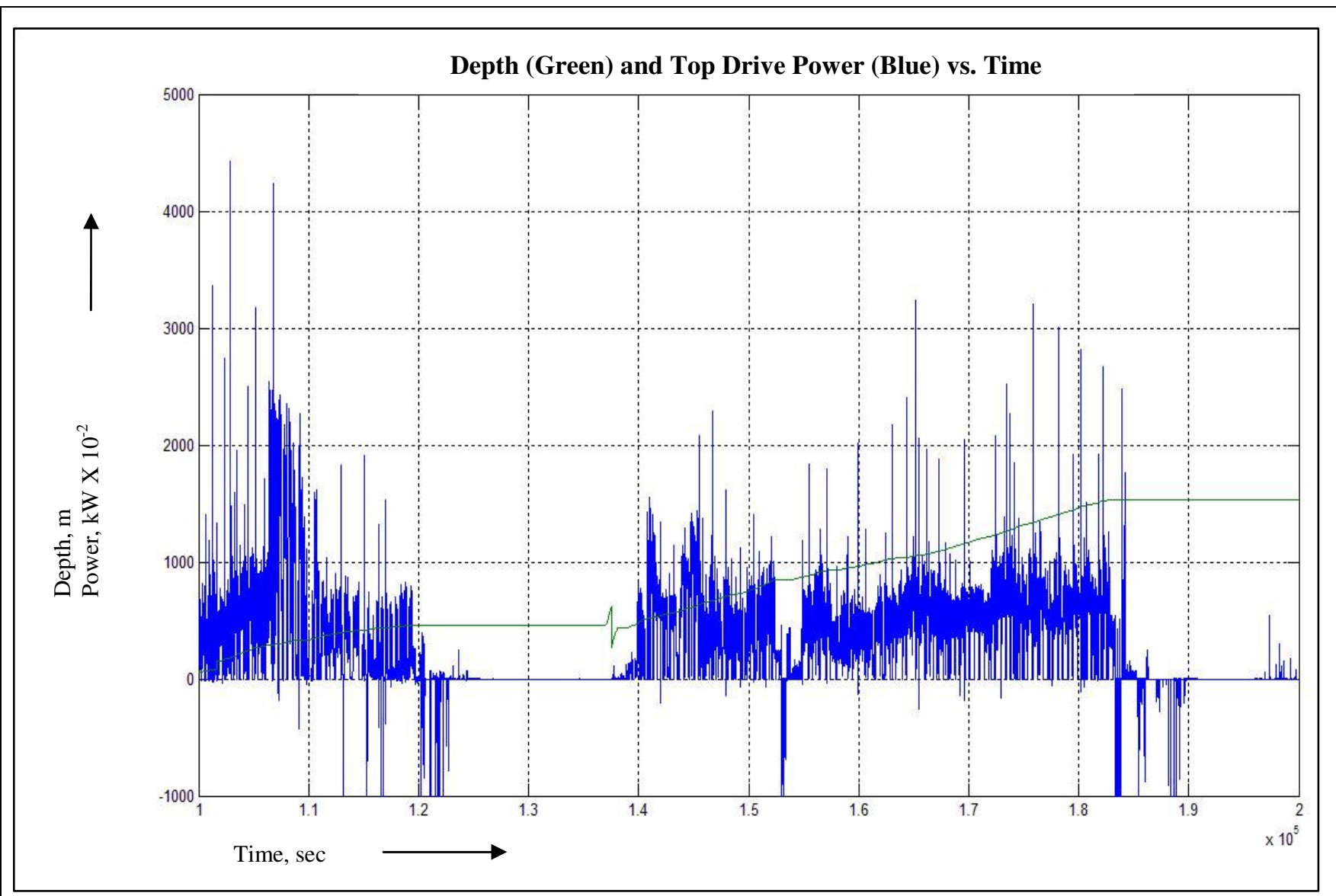

Figure 18 - Curve for drilling depth and simultaneous top drive power consumption vs. time. 


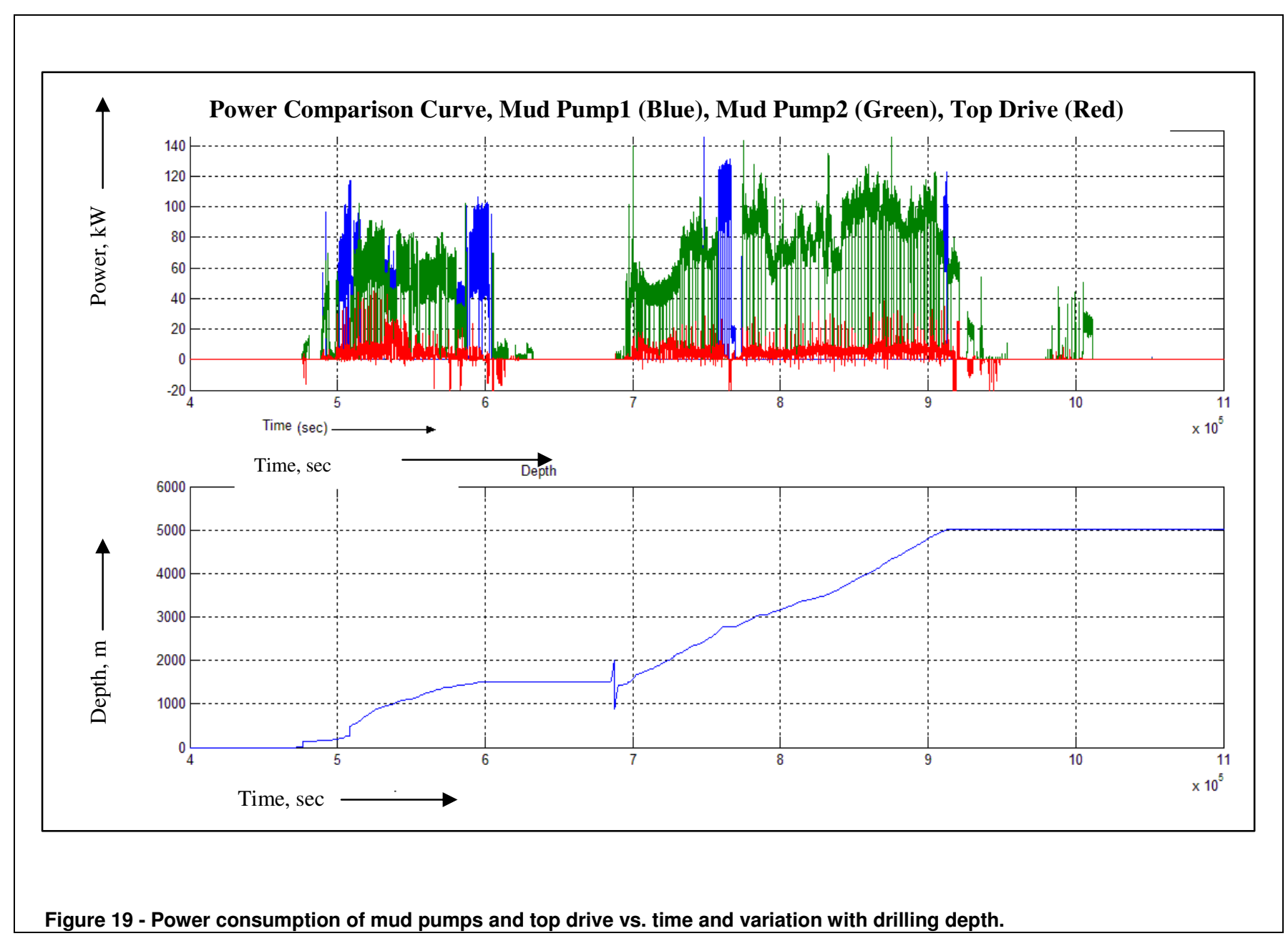




\subsubsection{Comparison of Theoretical and Actual Energy Audit}

The following Table 6 shows a comparison between actual and theoretical energy audits conducted. Hence it is clear from these values that designing a system merely on the nameplate rating would have resulted in an overly designed system. Such a system would have been bulky and costly.

Table 6 - Comparison of actual and theoretical energy audit

\begin{tabular}{|l|l|c|}
\hline Actuator & $(\mathbf{H p})$ & $(\mathbf{H p})$ \\
\hline & Theoretical Values & Actual Values \\
\hline Top Drive & 103 & 57 \\
\hline Mud Pump1 & & 215 \\
\hline Mud Pump2 & & 213 \\
\hline Total Power for Mud Pumps & 490 & 428 \\
\hline
\end{tabular}




\section{SYSTEM DESIGN BASED ON DATA PROCESSING}

This section will illustrate the important components of alternate power system and their corresponding description. All of design mentioned here is based on the rig specification and data processing results.

\subsection{Black Box Description}

Initially the power system under design is assumed to be a black box. Following important points are considered before designing any component:

- Efficient Operation

Design should be such that all kind of losses should be minimized. This includes T\&D losses and all transformer losses.

- Reliable

The possibility of total equipment breakdown should be negligible. Two transformers with a back up diesel generator add to the redundancy. Even if all the three fails the emergency rig up power can be used which itself can be operated from an energy storage device like flywheel or a super capacitor unit.

- Cost Effective

In order for the system to be lucrative to operators, initial cost incurred should be minimal. With fluctuating gas prices, drilling with electricity can be economical. The goal will be to make this design much cheaper as compared to diesel fed rig.

- Safe Operation 
Risk of shocks or accidents should be minimized. Huisman standards will be incorporated. Some of these measures include:

1. Equipment provided for protection of persons at work near electrical installations.

2. Equipment ability to bear electrical stresses and shocks.

3. Bus bar protection.

4. Protection from excess/short circuit current.

5. Cut off and isolation.

6. Working conditions, lighting, competent personal.

7. Protection against indirect contact.

8. Adequate earthing requirements.

- Mobile

A mobile unit can reduce great deal of operator reluctance for transportation and set up. The switchbox dimensions will be decided so as to fit it in a $20 \mathrm{ft}$ or $40 \mathrm{ft}$ ISO standard container.

- Remote Operation

The existing SCADA system on LOC 400 will be used to operate the transformer unit remotely and to monitor various predefined parameters.

A black box design is illustrated in Figure 19 considering all of the above factors. This diagram shows constituent components of the black box. A brief description of the black box design is also given following the diagram. 


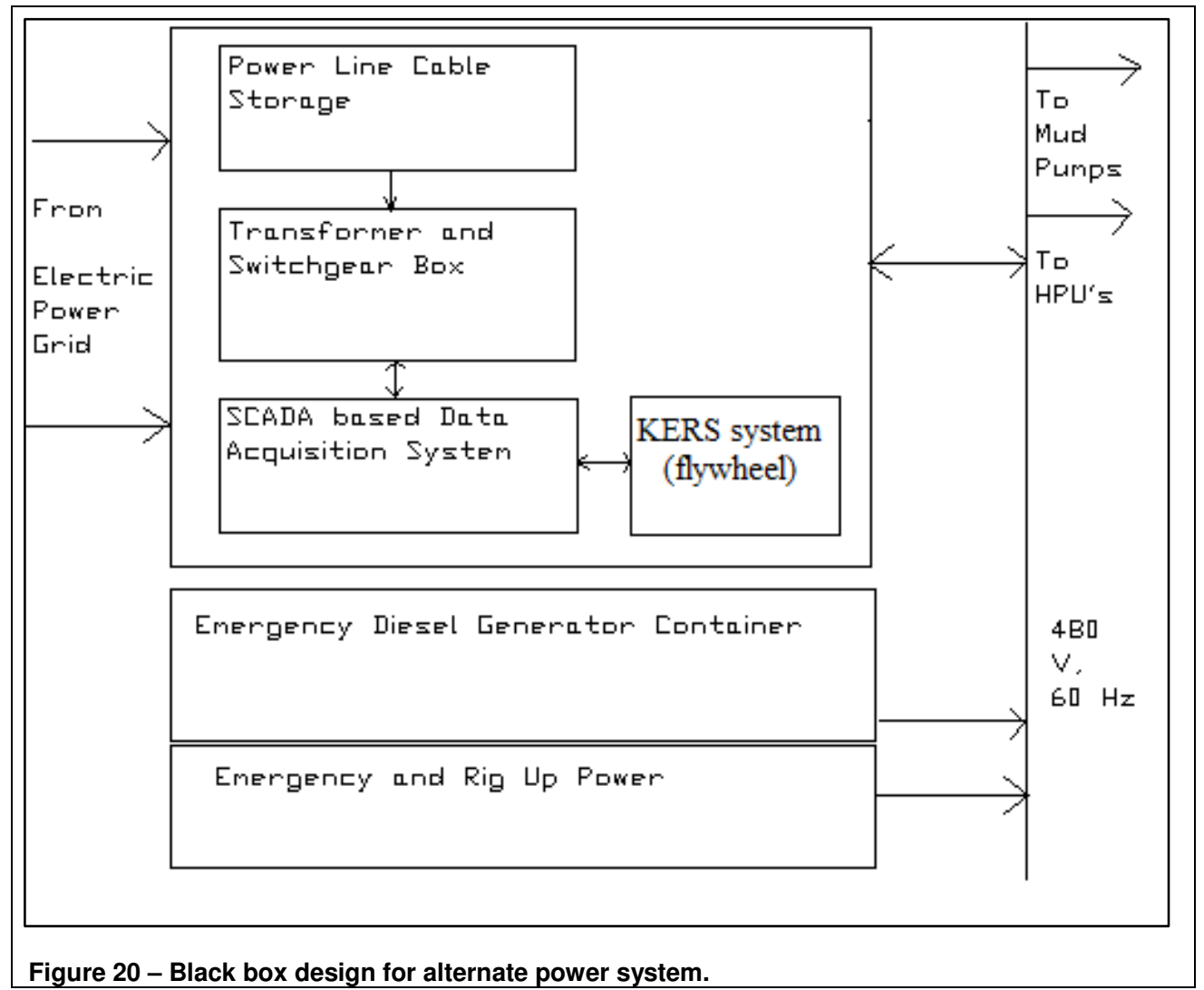

The switchbox above contains many inbuilt blocks. One such block is dedicated transformer switchgear with feeder cables. Such a transformer station can be connected to a service voltage of $11 \mathrm{KV}$ by a feeder cable which is another specially designed component. This 2 mile long feeder cable will be on a storage winch. The winch will have a close circuit coolant circulation in order to avoid overheating of the mounted cable while in operation. Another block would be the flywheel unit. Size, rating and specification of the flywheel unit are determined on the basis of rig data processing. There is one more data acquisition block which will monitor all the parameters while the unit is functional. Such a SCADA system is already in place in these rigs. After 
appropriate size determination all of these blocks will be placed in a $20 \mathrm{ft}$ or $40 \mathrm{ft}$ closed ISO container which has the inherent advantage of easy transportation with no special freight regulations. The overall system also contains emergency back up diesel generator unit in case the electrical design fails or power trips. A detailed design with dimensions will be shown later.

\subsection{Component Description}

\subsubsection{Power Line Cable}

Assuming an overall derating factor of 0.6 for ground (including air and ground temperatures, grouping of cables, depth of burial, overall derating factors for ground and air) (McAllister 1987) and calculating the transformer primary winding current for 3.3 MVA loading. The equation governing the primary current is given by:

$I_{p}=3300000 /(\sqrt{ } 3 \times 11000)=173.4$ Amps.....................Equation 1 where $\mathrm{I}_{\mathrm{p}}$ is the primary winding current.

Cable equivalent current for $25^{\circ} \mathrm{C}=173.4 / 0.6=289.01$ Amps.........Equation 2

This value corresponds to a 3 core cable with cross sectional area of $95 \mathrm{~mm}^{2}$ and outer core diameter of $12 \mathrm{~mm}$ in standard tables in the cable handbook (Fink and Beaty 1987).Thus the overall diameter of the cable would be $36 \mathrm{~mm}$ (Figure 13). This cable might be oil cooled from within. Environmental regulations governing laying this high 
voltage cable will be discussed later. Other details are-cable coding BS6622 95/100 $\mathrm{mm}^{2}, 37$ wires for $600 \mathrm{~V}, \mathrm{PVC}$ insulation, current rating of 3 core cable $11 \mathrm{KV}$ XLPE insulation (McAllister 1987). Figure 20 shows a cross section of the power cable with the dimensions.

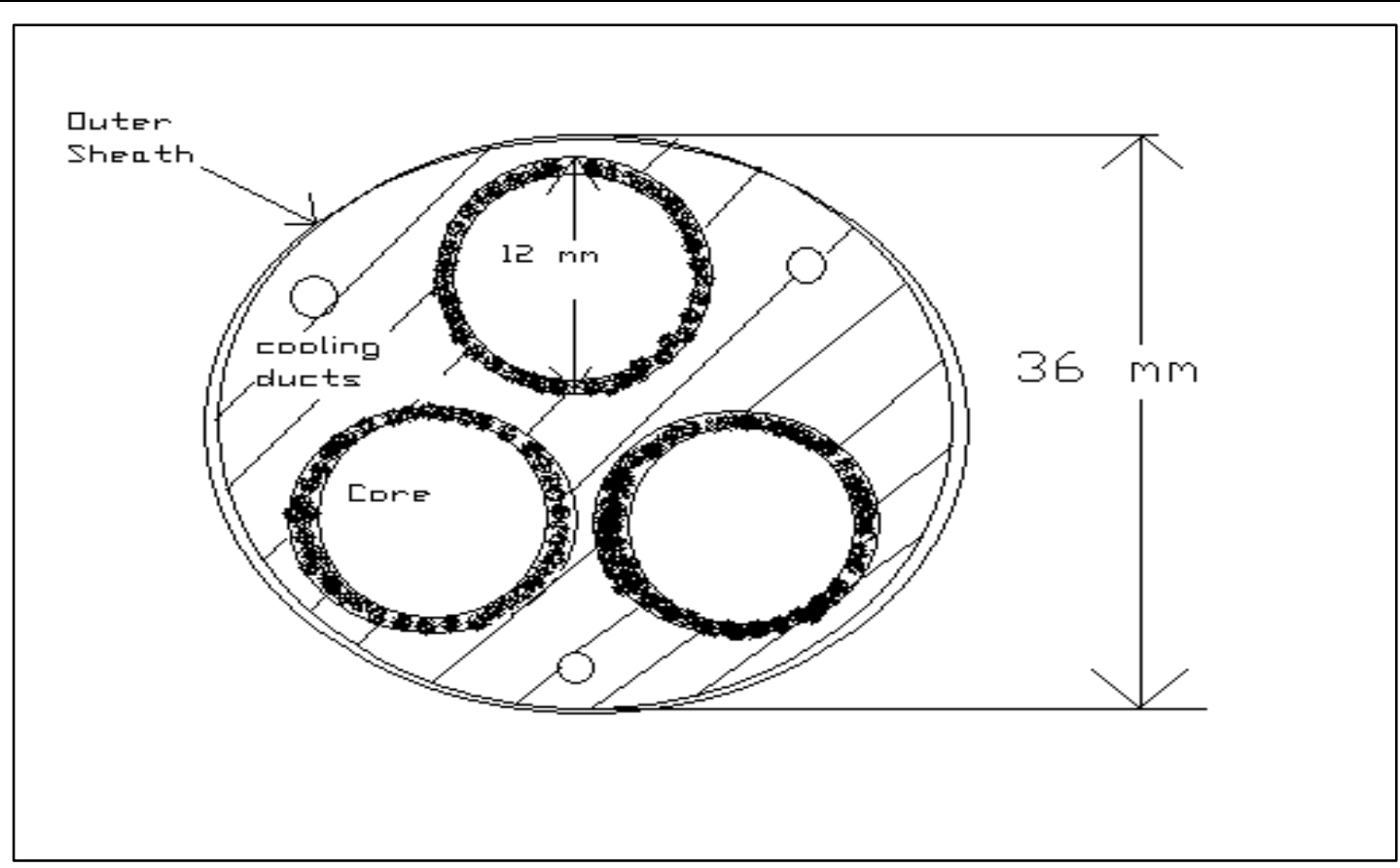

Figure 21 - Cross section of power cable with 3 inner cores and insulation.

\subsubsection{Storage Winch}

Storage winch in this system is used for holding as much as 3000 meters long power cable which can be used as an alternative to connect the rig to the power grid 
instead of constructing power lines to drill site. This winch has to be accommodated into 2.2 meter height and width dimension of ISO container. The winch's main design parameters are wire diameter $36 \mathrm{~mm}$, drum wire storage $3042 \mathrm{~m}$, number of safety windings 3, number of layers 16, drum diameter in groove $640 \mathrm{~mm}$, length of the drum $2200 \mathrm{~mm}$, ratio of wire/ drum diameter 17.78 , pitch of the drum $37.44 \mathrm{~mm}$.

\subsubsection{Transformer and Switchgear}

3 Phase, distribution type, 11 KV/480 V,60 Hz, Class F,DZ. 2 transformers will be needed to replace either of the diesel engines. Incoming and bus bar section circuit breakers should be $3 / 4$ pole for low voltage based on air break. For high voltage they should be either $\mathrm{SF}_{6}$ or vacuum based. Earthing bars should be high grade copper located at front or rear enclosure, screen clamping type. Standard lightning arrestor and cabinet cooling system is also recommended (Alstom T\&D Protection and Control 1995). Main bus bar is 400 amps, high grade copper (Westinghouse Electric Cooperation 1964). Control and indicators include power factor meter, voltmeter, ammeter, frequency meter, synchronising devices and varmeter. Fuses are in series with contactor with rating of 1.5 2 times normal load current. Standards for safety vary from designer to designer and the manufacturer. Detailed design is left up to the electrical design and installation company and superior quality equipment or equipment with industry wide standard usage is recommended. 


\subsubsection{SCADA System}

Same as currently installed to measure all the drilling parameters. In addition a feature of measuring power and current usage and transient could be included for obtaining additional data sets.

\subsubsection{KERS System}

A high speed generator is coupled to the flywheel so as to attain maximum energy storage density. Magnetic bearing provides frictionless motion of the shaft. The entire unit is mounted in a vacuum enclosure to provide enhanced service life. Further a fully controlled inverter and a variable speed motor is connected which controls the charging and discharging of the unit. This arrangement is shown in Figure 21. A monitoring system is mounted on this for controlled operation (Kirby 2004). Flywheel in the current system is designed for recycling energy. It discharges energy when the load exceeds the prescribed limit. A commercially available flywheel system is considered to fit in the described system. Its ratings are- rated power $140 \mathrm{~kW}$, duration 15 seconds, useable energy storage $2244 \mathrm{~kW}$-sec max., flywheel rotational speed 36 to 24 KRPM,

input voltage 420 - 600 VDC, recharge rate factory adjustable (per application) 12 minutes, typical stand by losses 2000 Watts, voltage discharge 400-500 VDC (adjustable per application), voltage regulation $+/-1 \%$, DC ripple less than $2 \%$, operating temperature $-20{ }^{\circ} \mathrm{C}$ to $40{ }^{\circ} \mathrm{C}$, humidity $95 \%$ non-condensing, altitude $1500 \mathrm{~m}$ max (without derating), audible noise $66 \mathrm{dBA}$ at 1m, height $1981 \mathrm{~mm}$, width $1219 \mathrm{~mm}$, depth $610 \mathrm{~mm}$, weight $872 \mathrm{~kg}$ (www.chloridepower.com). Table 6 summarize the results 
from data processing and explore the possibility of this flywheel unit for being successfully implemented in the overall system. Other modern high speed flywheel units can also be incorporated considering size constraint of $20 \mathrm{ft}$ ISO container and safety regulations. This investigation is primarily concerned with proving that flywheel unit can be successfully implemented for peak shaving in drilling rigs.

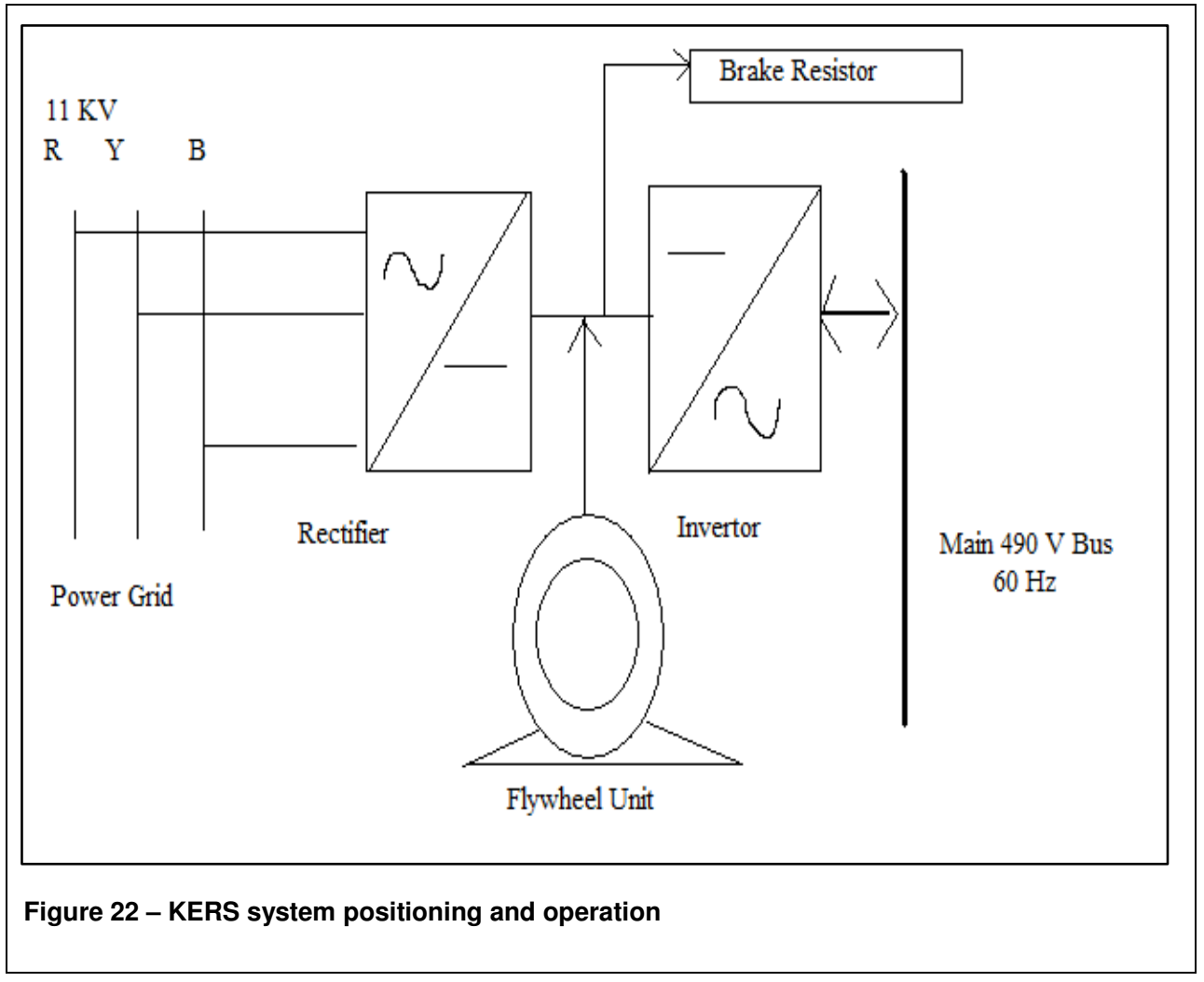


Table 7 - Data processing results and flywheel size determination

\begin{tabular}{|c|c|c|c|c|c|c|c|c|}
\hline $\begin{array}{c}\text { Window } \\
\text { Length } \\
(\mathbf{s e c})\end{array}$ & $\begin{array}{c}\text { Maximum } \\
\text { Energy } \\
(\text { KJ) }\end{array}$ & KWh & $\begin{array}{c}\text { Maximum } \\
\text { Power } \\
(\text { KW })\end{array}$ & $\begin{array}{c}\text { Flywheel } \\
\text { height } \\
(\mathbf{c m})\end{array}$ & $\begin{array}{c}\text { Flywheel } \\
\text { weight } \\
(\text { Kg })\end{array}$ & $\begin{array}{c}\text { Cost } \\
(\$ / \mathbf{K W})\end{array}$ & $\begin{array}{c}\text { No. of } \\
\text { Flywheels }\end{array}$ & $\begin{array}{c}\text { Speed } \\
(\text { Krpm })\end{array}$ \\
\hline 2 & 785 & .2 & 143 & 198 & 872 & 300 & 1 & $24-36$ \\
\hline 10 & 28570 & 8 & 200 & 198 & 8720 & 300 & 10 & $24-36$ \\
\hline 20 & 122857 & 34 & 217 & 198 & $\begin{array}{c}\text { Not } \\
\text { Feasible }\end{array}$ & 300 & $\begin{array}{c}\text { Not } \\
\text { feasible }\end{array}$ & $24-36$ \\
\hline
\end{tabular}

Thus from Table 6 it is clear that a flywheel unit with the specifications mentioned can be successfully implemented for peak shaving up to 10 seconds. A comprehensive ISO container with all the components installed is shown in Figure 22. This is the concept phase design with basic details which shows feeder cables, transformer units and their cooling fans, switchgear, storage winch, winch cooling mechanism, AC unit, lighting unit. Intricate design of bus bars, circuit breaker and isolators, motor control centre cubicles and fuses are beyond the scope of investigation and are left up to the electrical design company. 


\section{Conceptual Design of Alternate Power System}

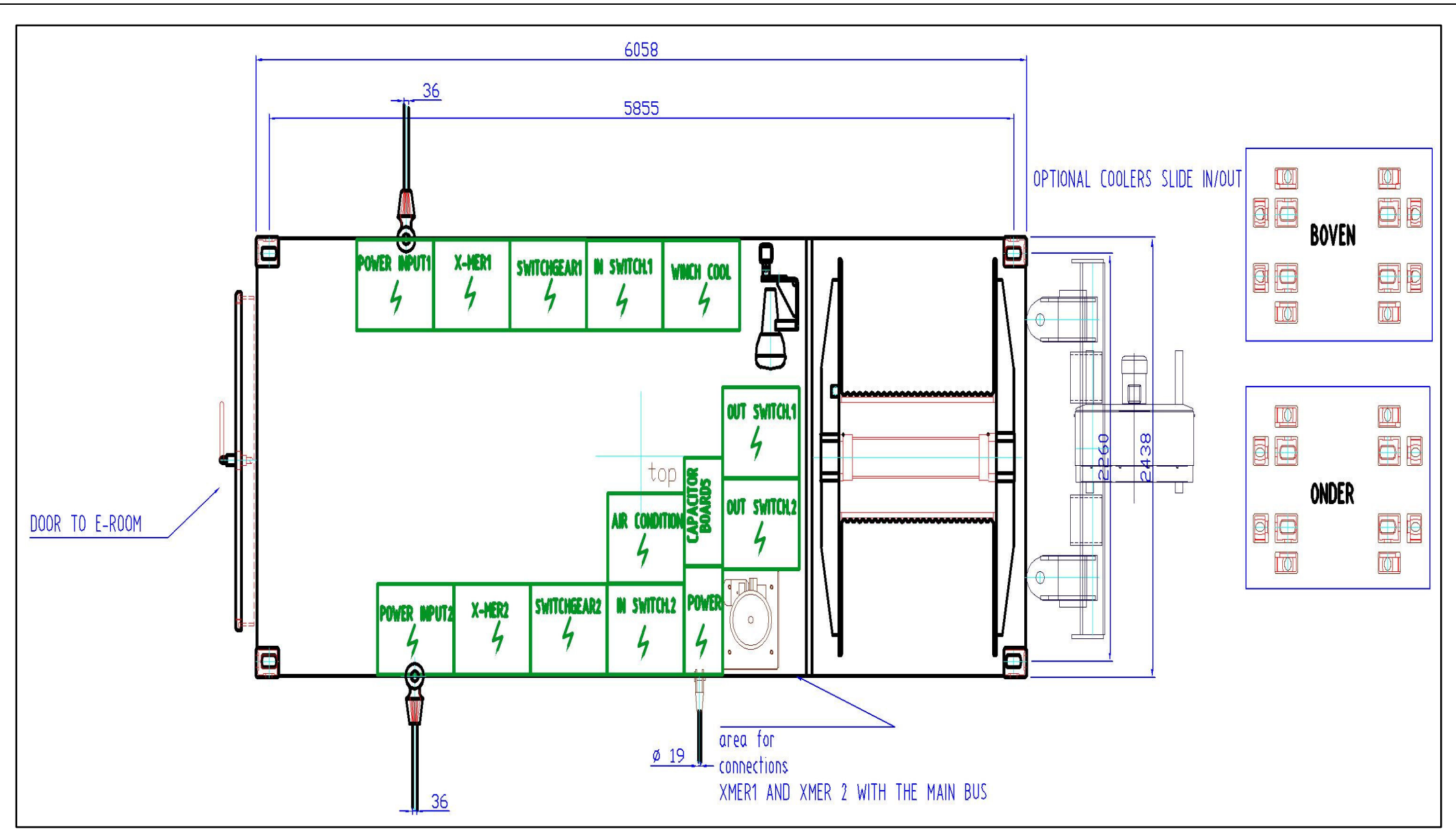

Figure 23 - Detailed design of alternate power system inside ISO container 


\section{CONCLUSION}

\section{$5.1 \quad$ Results}

It is the operator who pays for diesel and its transportation. Hence electricity as an alternate energy source with peak shaving technology is lucrative in terms of return of investment and operational cost. In addition it is emission free and environmentally friendly technology. Table 8 exhibits a cost benefit analysis of grid drilling with peak shaving with conventional diesel drilling. Table 9 estimates various emissions during construction, transportation and usage of drilling equipment (Hendriks and Janzic, 2005). It also indicates that such emissions are much higher in case of conventional rigs as compared to the rig under consideration here. This system can eliminate the emissions during drilling and hence can play a crucial role in environmental protection.

Table 8- Cost benefit analysis of KERS system

\begin{tabular}{|c|c|c|c|}
\hline $\begin{array}{l}\text { Sr. } \\
\text { No. }\end{array}$ & Parameter & Diesel Operation & Electric Operation \\
\hline 1 & Consumption & $\begin{array}{llll}3400 \mathrm{~L} / \text { day } & \text { or } & 870 & \mathrm{Gal} / \text { day } \\
\text { and } 11920 & \mathrm{Gal} & \text { overall } \\
\text { (Huisman 2006) } & \end{array}$ & $\begin{array}{l}\text { 366769KWh@7cents/KWh } \\
\text { and @ } 0 \% \text { of diesel fuel } \\
\text { equivalent }\end{array}$ \\
\hline 2 & Cost & $\begin{array}{llll}\mathbf{\$ 2 8 6 0 0} @ & \$ 2.4 / \mathrm{Gal} & \text { for } & 20 \\
\text { Days }\end{array}$ & \$26674 for 20 Days \\
\hline 3 & Emissions & Noisy operation & $\begin{array}{l}\text { Noise free operation (no moving } \\
\text { parts like a generator) }\end{array}$ \\
\hline 4 & $\begin{array}{l}\text { Pollution and } \\
\text { Environment }\end{array}$ & $\begin{array}{l}\text { Emissions and pollutants } \\
(\mathrm{CO} 2, \mathrm{CO}, \mathrm{NOx}, \mathrm{SOx}) \text { due to } \\
\text { transport and drilling }\end{array}$ & Environmentally friendly \\
\hline
\end{tabular}


Table 9 - Emissions data from construction, transport and usage of drilling equipment

\begin{tabular}{|c|c|c|c|c|c|c|c|}
\hline & & $\begin{array}{l}\text { LOC- } \\
250\end{array}$ & Share (\%) & Standard(low) & Share $(\%)$ & Standard(High) & Share (\%) \\
\hline Weight & \begin{tabular}{|l|}
$(\mathrm{t} / \mathrm{well})$ \\
\end{tabular} & 475 & & 600 & & 1000 & \\
\hline \multicolumn{8}{|c|}{ Transport } \\
\hline $\mathrm{CO}_{2}$ & t/well & 4 & 8 & 5 & 7 & 8 & 7 \\
\hline $\mathrm{No}_{\mathrm{x}}$ & $\mathrm{Kg} /$ well & 41 & 7 & 52 & 6 & 87 & 6 \\
\hline $\mathrm{CO}$ & $\mathrm{Kg} /$ well & 8 & 5 & 10 & 4 & 17 & 4 \\
\hline $\mathrm{PM}$ & $\mathrm{Kg} /$ well & 1 & 11 & 2 & 9 & 3 & 9 \\
\hline $\mathrm{SO}_{2}$ & $\mathrm{Kg} /$ well & 5 & 65 & 7 & 65 & 11 & 65 \\
\hline \multicolumn{8}{|c|}{ Drilling } \\
\hline $\mathrm{CO}_{2}$ & \begin{tabular}{|l|}
$\mathrm{t} /$ well \\
\end{tabular} & 42 & 88 & 67 & 90 & 106 & 90 \\
\hline $\mathrm{No}_{\mathrm{x}}$ & $\mathrm{Kg} /$ well & 551 & 93 & 868 & 94 & 1374 & 94 \\
\hline $\mathrm{CO}$ & $\mathrm{Kg} /$ well & 140 & 79 & 220 & 83 & 349 & 82 \\
\hline $\mathrm{PM}$ & $\mathrm{Kg} /$ well & 12 & 89 & 19 & 91 & 29 & 91 \\
\hline $\mathrm{SO}_{2}$ & Kg/well & 0 & 0 & 0 & 0 & 0 & 0 \\
\hline \multicolumn{8}{|c|}{\begin{tabular}{l|l|l|} 
Construction & & \\
\end{tabular}} \\
\hline $\mathrm{CO}_{2}$ & t/well & 2 & 4 & 2 & 3 & 4 & 3 \\
\hline $\mathrm{No}_{\mathrm{x}}$ & $\mathrm{Kg} /$ well & 2 & 0 & 2 & 0 & 4 & 0 \\
\hline $\mathrm{CO}$ & $\mathrm{Kg} /$ well & 29 & 16 & 36 & 14 & 60 & 14 \\
\hline PM & $\mathrm{Kg} /$ well & 0 & 0 & 0 & 0 & 0 & 0 \\
\hline $\mathrm{SO}_{2}$ & $\mathrm{Kg} /$ well & 3 & 35 & 4 & 35 & 6 & 35 \\
\hline Total & & & $\begin{array}{|ll|}\text { Relative } & \text { to } \\
\text { Standard(High) } & \\
\end{array}$ & & $\begin{array}{|ll|}\text { Relative } & \text { to } \\
\text { Standard(High) } & \\
\end{array}$ & & Standard(High) \\
\hline $\mathrm{CO}_{2}$ & $\mathrm{t} / \mathrm{well}$ & 48 & 41 & 74 & 63 & 118 & 100 \\
\hline $\mathrm{No}_{\mathrm{x}}$ & $\mathrm{Kg} /$ well & 594 & 41 & 922 & 63 & 1465 & 100 \\
\hline $\mathrm{CO}$ & $\mathrm{Kg} /$ well & 176 & 41 & 266 & 63 & 426 & 100 \\
\hline $\mathrm{PM}$ & $\mathrm{Kg} /$ well & 13 & 41 & 20 & 63 & 32 & 100 \\
\hline $\mathrm{SO}_{2}$ & $\mathrm{Kg} /$ well & 8 & 48 & 10 & 60 & 17 & 100 \\
\hline
\end{tabular}




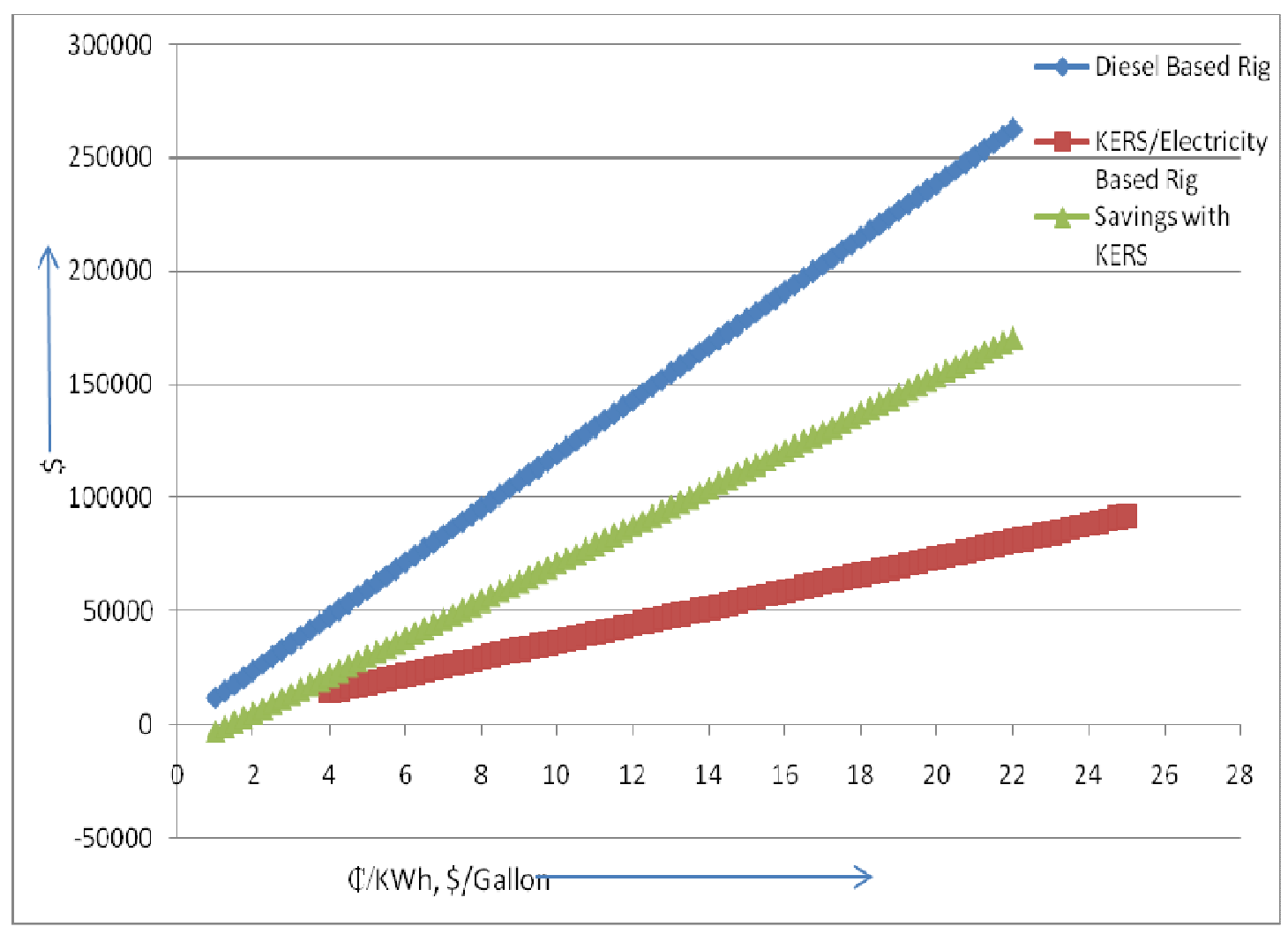

Figure 23 - Cost and savings curve for KERS system with diesel and electricity price variation

The cost benefit analysis in graphical format is shown in Figure 23. It is assumed that the prices of diesel and electricity will increase with time. The rate of increase might be different. The blue line is the trend of total cost per well with increasing diesel prices in $\$ /$ Gallon. The brown trend line is the cost per well when KERS system described in this research is used. The green trend is savings while using KERS system at a particular diesel price per gallon. It is seen that when diesel prices were around a $1 \$$ gallon use of the KERS system was not economic. Slowly increasing the diesel prices increases savings with alternate energy system as shown by the green trend line. Here it is 
assumed that the fuel consumption of a particular rig, LOC-250 in this case, will be more or less the same for an average well with average depth of 8000ft.

\subsection{Inferences}

Hence we come up with following conclusions from this research project:

- The power consumption of casing while drilling rigs, LOC-250 and LOC-400 is much lesser than conventional rigs.

- It is possible to connect these rigs to electrical grid. It is also possible to install a KERS system which can successfully provide peak shaving and reduce the transient power peaks.

- Such an alternate power system can be made mobile with no special freight requirements.

- LOC 400 being an electrically driven system can be easily connected to a power grid within 2 miles of radius.

- It is possible to eliminate all the drilling emissions with this KERS system operating with electrical grid.

- Savings after installing this system increase linearly with increasing cost of diesel.

- The rig with both alternate power system and conventional diesel engines consumes lesser diesel as compared to the same rig with standalone diesel engines. This is true for an average well duration of 20 days and average well depth of $8000 \mathrm{ft}$. 


\subsection{Future Work}

Following investigation can also be conducted in future:

- Analysis of the regenerative power by LOC-400 and losses.

- Detailed design of switchgear and their single line diagrams with rating of fuses and circuit breakers.

- Replacement of flywheel by super capacitor units and redo the peak shaving design once super capacitors are successfully tested.

- Cost quotation and return of investment of switchgear components, flywheel unit, installation and maintenance.

- Design of cooling system for storage winch.

- Study of Environmental regulations in order to lay out high voltage cable on ground.

- Simulation of the circuit design.

- Safety guidelines for operation of KERS based rig power system.

- Interviews with utility companies regarding surcharges and special regulations which vary with state.

- Calculation of power factor of the rig.

- Lab testing of KERS coupled diesel engines to estimate exact fuel savings. 


\section{NOMENCLATURE}

\begin{tabular}{|c|c|}
\hline $\mathrm{AC}$ & Alternating Current \\
\hline Amps & Amperes \\
\hline${ }^{\circ} \mathrm{C}$ & Degree Centigrade \\
\hline $\mathrm{Cm}$ & Centi Meters \\
\hline $\mathrm{CO}_{2}$ & Carbon dioxide \\
\hline $\mathrm{DC}$ & Direct Current \\
\hline $\mathrm{dBA}$ & Decibels \\
\hline $\mathrm{ft}$ & Feet \\
\hline gpm & Gallons Per Minute \\
\hline $\mathrm{Hz}$ & Hertz \\
\hline ISO & International Organization of Standards \\
\hline KERS & Kinetic Energy Recovery and Storage \\
\hline $\mathrm{kG}$ & Kilo Grams \\
\hline $\mathrm{kJ}$ & Kilo Joules \\
\hline kRPM & Kilo Rotations Per Minute \\
\hline $\mathrm{kV}$ & Kilo Volts \\
\hline $\mathrm{kW}$ & Kilo Watts \\
\hline $\mathrm{kWh}$ & Kilo Watt Hour \\
\hline 1 & Litres \\
\hline LOC 250 & Land Offshore Containerized (with hook load of 250 Tonnes) \\
\hline
\end{tabular}




$\begin{array}{ll}\text { MATLAB } & \text { Mathematics Laboratory } \\ \text { MVA } & \text { Milli Meter } \\ \text { NOx } & \text { Fega Electron Volt } \\ \text { SCADA } & \text { Supervisory Control And Data Acquisition System } \\ \text { SF } 6 & \text { Sulphur Hexa Fluoride } \\ \text { SOx } & \text { Family of Sulphur Oxides } \\ \text { V } & \text { Volts } \\ \text { XLPE } & \text { Cross Linked Polyethylene }\end{array}$




\section{REFERENCES}

Brobeck, W.M. and Associates. Conceptual Design of a Flywheel Energy Storage System. Sandia Laboratories, Contract No.DE-AC04-76DP00789, United States Department of Energy, Washington DC (Nov 1979).

Commercial flywheel unit ratings, Chloride Power website. 2008: www.chloridepower.com. (Accessed on Jul 2008).

EG\&G Services, Parsons Inc. Fuel Cell Handbook, Fifth Edition, Science Applications International Corporation, Contract No. DE-AM26-99FT40575, United States Department of Energy, Washington DC. (Oct 2000).

Electrical Transmission and Distribution Reference Book, eighth edition, 1964. East Pittsburg, PA: Central Station Engineers of the Westinghouse Electric Cooperation.

Electricity prices, Electricity Bid website. 2008: www.electricitybid.com. (Accessed on Jan 2008).

Fink D.G., Beaty, H.W. 1987. Standard Handbook for Electrical Engineers, NY: McGraw Hill Book Company Inc.

Flywheel applications, Beacon Power website. 2008: www.beaconpower.com. (Accessed on Aug 2008).

Hendriks, K., Janzic, R. 2005. Environmental impact of standard oil drilling installations versus LOC 250. Ecofys Report for Huisman US, Ref: A04-10050.

Huisman Special Lifting Equipment B.V. 2005. LOC250 Casing Drilling Manual Version 1.0. Schiedam, Netherlands: Huisman.

Huisman Special Lifting Equipment B.V. 2007. Technical Specification LOC400: Husiman Itrec.

Huisman Special Lifting Equipment B.V. 2006 ,User Manual for Containerized Drilling Unit, System Description, Specifications, Operation and Maintenance Volume 1, A04-45000, Schiedam, Netherlands: Huisman.

Kirby, Brendon, PE. 2004. Frequency Regulations Basics and Trends. Power System Research Program Oak Ridge National Laboratory, Oak Ridge, Contract No.DE-AC0500OR22725, US D.O.E, Washington DC. (Jul. 2004).

McAllister, D. 1987. Electrical Cables Handbook. BICC Power Cables Ltd, London, 
UK: Granada Publishing Ltd.

Nichols, D.K, Eckroad, S., 2003. Utility Scale Application of Sodium Sulfur Battery. Battcon, www.battcon.com/PapersFinal2003/NicholsPaperFINAL2003.pdf.

Downloaded January 2009.

Protective Relay Application Guide, third edition, 1995. Stafford UK: Alstom T\&D Protection and Control Ltd.

Rogers, J.D., 2006, Report on Assessment of Technologies for Environmental Friendly Drilling Project: Land Based Operations, draft 3, version 2, Houston Advance Research Center.

Rojas, A. 2004. Flywheel Energy Matrix Systems - Today's Technology, Tomorrow's Energy Storage Solution. Conference Proc., IEEE Power Engineering Society General Meeting, Denver, CO.

Romo, L., Solis,O., Matthews,J., Qin, D. 2007, Fuel Saving Flywheel Technology for Rubber Tired Gantry Cranes in World Ports: Reducing Fuel Consumption through Flywheel Energy Storage System, Final Report, VYOCON ENERGY, CA (2007).

Ruddell, Alan. 2003. Storage Technology Report ST6:

Flywheel.Deliverable_5_030617_CCLRC-RAL, CCLRC-Rutherford Appleton Laboratory, Didcot, UK.

Solar calculator, FindSolar website. 2009: www.findsolar.com. (Accessed on Mar 2009).

Solar cells, US Department of Energy website. 2009: www.eere.energy.gov. (Accessed on Feb 2009).

Tamyurek, B., Nichols, D.K., Demirci, O. 2003. Sodium Sulfur Battery Applications. Conf Proc., IEEE Power Engineering Society General Meeting, Volume 4, OH.

Walsh, B., Wichert, R., 2008. Fuel Cell Technology. www.wbdg.org. (Accessed on May 2008). 
APPENDIX A

VARIABLE DESCRIPTION FOR MATLAB CODE AND SCREENSHOTS 
mp1gpmdata

mppower

mpmv

mpmv2

mpmv3

mpdifference

mpdifference2

mpdifference3

mpenergy1

mpenergy 2

mpenergy3

mpenergy 21

mpenergy 22

mpenergy23

mpenergy31

mpenergy32

mpenergy33

mp2gpmdata

mp2power

$\mathrm{mp} 2 \mathrm{mv}$

mp2mv2

mp2mv3
Flow rate in GPM for mud pump 1

Power for mud pump 1(pump pressure $\mathrm{X}$ flow rate)

Moving average of power for window length $2 \mathrm{Sec}$

Moving average of power for window length $10 \mathrm{Sec}$

Moving average of power for window length $20 \mathrm{Sec}$

Difference between mp1 power and $1^{\text {st }}$ moving avg.

Difference between mp1 power and $2^{\text {nd }}$ moving avg.

Difference between mp1 power and $3^{\text {rd }}$ moving avg.

Energy curve for $1^{\text {st }}$ portion of first difference

Energy curve for $2^{\text {nd }}$ portion of first difference

Energy curve for $3^{\text {rd }}$ portion of first difference

Energy curve for $1^{\text {st }}$ portion of second difference

Energy curve for $2^{\text {nd }}$ portion of second difference

Energy curve for $3^{\text {rd }}$ portion of second difference

Energy curve for $1^{\text {st }}$ portion of third difference

Energy curve for $2^{\text {nd }}$ portion of third difference

Energy curve for $3^{\text {rd }}$ portion of third difference

Flow rate in GPM for mud pump 1

Power for mp1 (pump pressure $\mathrm{X}$ flow rate)

Moving average of mp2 power for window length $2 \mathrm{Sec}$

Moving average of power for window length $10 \mathrm{Sec}$

Moving average of power for window length $20 \mathrm{Sec}$ 
mp2difference

mp2difference2

mp2difference3

mp2energy1

mp2energy2

mp2energy3

mp2energy21

mp2energy22

mp2energy23

mp2energy31

mp2energy32

mp2energy33

Ppdata

rttdata

rtrpmdata

rtpower

tdtdata

tdrpmdata

tdpower

tdmv

tdmv2

tdmv3
Difference between mp2 power and $1^{\text {st }}$ moving avg.

Difference between mp2 power and $2^{\text {nd }}$ moving avg.

Difference between mp2 power and $3^{\text {rd }}$ moving avg.

Energy curve for $1^{\text {st }}$ portion of first difference

Energy curve for $2^{\text {nd }}$ portion of first difference

Energy curve for $3^{\text {rd }}$ portion of first difference

Energy curve for $1^{\text {st }}$ portion of second difference

Energy curve for $2^{\text {nd }}$ portion of second difference

Energy curve for $3^{\text {rd }}$ portion of second difference

Energy curve for $1^{\text {st }}$ portion of third difference

Energy curve for $2^{\text {nd }}$ portion of third difference

Energy curve for $3^{\text {rd }}$ portion of third difference

Pump pressure data

Rotary table torque data

Rotary table RPM data

Rotary table power data

Top drive torque data

Top drive RPM data

Rotary table power data

Moving average of tdpower for Window Length 2 Sec

Moving average of tdpower for Window Length $10 \mathrm{Sec}$

Moving average of tdpower for Window Length 20 Sec 


$\begin{array}{ll}\text { tddifference } & \text { Difference between td power and } 1^{\text {st }} \text { moving avg. } \\ \text { tddifference2 } & \text { Difference between td power and } 2^{\text {nd }} \text { moving avg. } \\ \text { tddifference3 } & \text { Difference between td power and } 3^{\text {rd }} \text { moving avg. } \\ \text { tdenergy1 } & \text { Energy curve for } 1^{\text {st }} \text { portion of first difference } \\ \text { tdenergy2 } & \text { Energy curve for } 2^{\text {nd }} \text { portion of first difference } \\ \text { tdenergy3 } & \text { Energy curve for } 3^{\text {rd }} \text { portion of first difference } \\ \text { tdenergy21 } & \text { Energy curve for } 1^{\text {st }} \text { portion of second difference } \\ \text { tdenergy22 } & \text { Energy curve for } 2^{\text {nd }} \text { portion of second difference } \\ \text { tdenergy23 } & \text { Energy curve for } 3^{\text {rd }} \text { portion of second difference } \\ \text { tdenergy31 } & \text { Energy curve for } 1^{\text {st }} \text { portion of third difference } \\ \text { tdenergy32 } & \text { Energy curve for } 2^{\text {nd }} \text { portion of third difference } \\ \text { tdenergy33 } & \text { Energy curve for } 3^{\text {rd }} \text { portion of third difference } \\ z & \text { a } 1330000 X 1 \text { vector (used for multiple plots) }\end{array}$


4. MATLAB

File Edit View Web Window Help

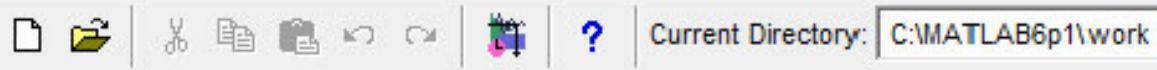

Workspace

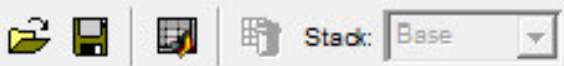

\begin{tabular}{|c|c|c|c|}
\hline Name & Size & Bytes & Class \\
\hline 曲mplgpmdata & $1330216 \mathrm{x} 1$ & 10641728 & double array \\
\hline 曲mp2difference & $1330216 \times 1$ & 10641728 & double array \\
\hline 团mp2difference1 & $1330208 \times 1$ & 10641664 & double array \\
\hline 曲mp2difference2 & $1330198 \times 1$ & 10641584 & double array \\
\hline 曲mp2energy1 & $200001 \times 1$ & 1600008 & double array \\
\hline 曲mp2energy2 & $200001 \times 1$ & 1600008 & double array \\
\hline 曲mp2energy21 & $200001 \times 1$ & 1600008 & double array \\
\hline 曲mp2energy22 & $200001 \times 1$ & 1600008 & double array \\
\hline 曲mp2energy 23 & $200001 \times 1$ & 1600008 & double array \\
\hline 曲mp2energy3 & $200001 \times 1$ & 1600008 & double array \\
\hline 曲mp2energy31 & $200001 \times 1$ & 1600008 & double array \\
\hline 曲mp2energy32 & $200001 \times 1$ & 1600008 & double array \\
\hline 曲mp2energy33 & $200001 \times 1$ & 1600008 & double array \\
\hline 曲mp2gpmdata & $1330217 \times 1$ & 10641736 & double array \\
\hline 曲mp2mv & $1330217 \times 1$ & 10641736 & double array \\
\hline 曲mp2mv1 & $1330217 \times 1$ & 10641736 & double array \\
\hline 曲mp2mv2 & $1330217 \times 1$ & 10641736 & double array \\
\hline 曲mp2power & $1330217 \times 1$ & 10641736 & double array \\
\hline 曲mpdifference & $1329999 \times 1$ & 10639992 & double array \\
\hline 曲mpdifference2 & $1329991 \times 1$ & 10639928 & double array \\
\hline 曲mpdifference3 & $1329981 \times 1$ & 10639848 & double array \\
\hline 曲mpenergy1 & $200001 \times 1$ & 1600008 & double array \\
\hline 曲mpenergy2 & $200001 \times 1$ & 1600008 & double array \\
\hline 曲mpenergy21 & $200001 \times 1$ & 1600008 & double array \\
\hline 曲mpenergy22 & $200001 \times 1$ & 1600008 & double array \\
\hline 曲mpenergy23 & $200001 \times 1$ & 1600008 & double array \\
\hline 曲mpenergy3 & $200001 \times 1$ & 1600008 & double array \\
\hline 团mpenergy31 & $200001 \times 1$ & 1600008 & double array \\
\hline
\end{tabular}




\section{MATLAB}

File Edit View Web Window Help

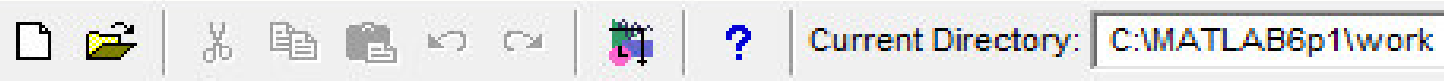

Workspace

\begin{tabular}{|c|c|c|c|}
\hline Name & Size & Bytes & Class \\
\hline 曲 mpenergy32 & $200001 \times 1$ & 1600008 & double array \\
\hline 团 mpenergy33 & $200001 \times 1$ & 1600008 & double array \\
\hline 曲mpmv & $1330000 \times 1$ & 10640000 & double array \\
\hline 曲 mpmv2 & $1330000 \times 1$ & 10640000 & double array \\
\hline 曲mpmv3 & $1330000 \times 1$ & 10640000 & double array \\
\hline 曲mpower & $1330000 \times 1$ & 10640000 & double array \\
\hline 曲ppdata & $1330224 \times 1$ & 10641792 & double array \\
\hline 曲rtpower & $265386 \times 1$ & 2123088 & double array \\
\hline 曲rtrpmdata & $265386 \times 1$ & 2123088 & double array \\
\hline 曲rttdata & $265386 \times 1$ & 2123088 & double array \\
\hline 团tddifference & $1309733 \times 1$ & 10477864 & double array \\
\hline 团 tddifference2 & $1309725 \times 1$ & 10477800 & double array \\
\hline 团 tddifference 3 & $1309715 \times 1$ & 10477720 & double array \\
\hline 曲 tdenergy1 & $200001 \times 1$ & 1600008 & double array \\
\hline 囲 tdenergy2 & $200001 \times 1$ & 1600008 & double array \\
\hline 曲 tdenergy21 & $200001 \times 1$ & 1600008 & double array \\
\hline 曲 tdenergy22 & $200001 \times 1$ & 1600008 & double array \\
\hline 曲 tdenergy23 & $200001 \times 1$ & 1600008 & double array \\
\hline 曲 tdenergy3 & $200001 \times 1$ & 1600008 & double array \\
\hline 曲 tdenergy31 & $200001 \times 1$ & 1600008 & double array \\
\hline 曲 tdenergy32 & $200001 \times 1$ & 1600008 & double array \\
\hline 囲tdenergy33 & $200001 \times 1$ & 1600008 & double array \\
\hline 曲tdmv & $1309734 \times 1$ & 10477872 & double array \\
\hline 团 tdmv2 & $1309734 \times 1$ & 10477872 & double array \\
\hline 曲tdmis & $1309734 \times 1$ & 10477872 & double array \\
\hline
\end{tabular}


APPENDIX B

\section{CONVERSION FACTORS}


Unit conversion so that $\mathrm{Y}$ axis is in terms of power in $\mathrm{kW}$.

For mud pumps:

1 gallon $(\mathrm{US})=.00378 \mathrm{~m}^{3}$

$1 \mathrm{bar}=10^{5} \mathrm{~N} / \mathrm{m}^{2}$

Therefore GPM x Pump Pressure (bar) $=.00378 \mathrm{~m}^{3} / 60 \times 10^{5} \mathrm{~N} / \mathrm{m}^{2}=. \mathbf{0 0 6 3} \mathrm{kW}$ ..............Equation A1

For top drive and rotary table:

Power $=$ Torque $(\mathrm{N}-\mathrm{m}) \times \mathrm{RPM} / 60=2 \times 3.14 / 60=.1046 \mathrm{Watts} / 1000=\mathbf{1 . 0 0 4 6} \times \mathbf{1 0}^{-4} \mathrm{~kW}$ ..Equation A2

An efficiency factor of 0.7 is also multiplied by the amount of maximum power and maximum energy estimated to be supplied from KERS system on the basis of data processing.

Unit Conversion so that $\mathrm{X}$ axis is in terms of time in seconds.

For mud pumps each division on $\mathrm{X}$ axis represents 2 seconds which is the sampling frequency from Table A-3.

For top drive each division on $\mathrm{X}$ axis represents 2 seconds which is the sampling frequency from Table A-3. 
APPENDIX C

RESULTS DATA 


\begin{tabular}{|c|c|c|c|c|}
\hline $\begin{array}{c}\text { Commercial } \\
\text { Electricity } \\
\text { Rates, } \mathbf{C} / \mathrm{KWh} \\
\end{array}$ & $\begin{array}{l}\text { Diesel Rates in } \\
\$ / \text { Gal }\end{array}$ & $\begin{array}{l}\text { Total Diesel cost for a } \\
20 \text { Day well,\$ }\end{array}$ & $\begin{array}{c}\text { Total Electricity } \\
\text { cost for } 20 \text { day } \\
\text { well,\$ }\end{array}$ & Savings/Well,\$ \\
\hline 4 & 1 & 11920 & 14670.76 & -2750.76 \\
\hline 4.25 & 1.25 & 14900 & 15587.6825 & -687.6825 \\
\hline 4.5 & 1.5 & 17880 & 16504.605 & 1375.395 \\
\hline 4.75 & 1.75 & 20860 & 17421.5275 & 3438.4725 \\
\hline 5 & 2 & 23840 & 18338.45 & 5501.55 \\
\hline 5.25 & 2.25 & 26820 & 19255.3725 & 7564.6275 \\
\hline 5.5 & 2.5 & 29800 & 20172.295 & 9627.705 \\
\hline 5.75 & 2.75 & 32780 & 21089.2175 & 11690.7825 \\
\hline 6 & 3 & 35760 & 22006.14 & 13753.86 \\
\hline 6.25 & 3.25 & 38740 & 22923.0625 & 15816.9375 \\
\hline 6.5 & 3.5 & 41720 & 23839.985 & 17880.015 \\
\hline 6.75 & 3.75 & 44700 & 24756.9075 & 19943.0925 \\
\hline 7 & 4 & 47680 & 25673.83 & 22006.17 \\
\hline 7.25 & 4.25 & 50660 & 26590.7525 & 24069.2475 \\
\hline 7.5 & 4.5 & 53640 & 27507.675 & 26132.325 \\
\hline 7.75 & 4.75 & 56620 & 28424.5975 & 28195.4025 \\
\hline 8 & 5 & 59600 & 29341.52 & 30258.48 \\
\hline 8.25 & 5.25 & 62580 & 30258.4425 & 32321.5575 \\
\hline 8.5 & 5.5 & 65560 & 31175.365 & 34384.635 \\
\hline 8.75 & 5.75 & 68540 & 32092.2875 & 36447.7125 \\
\hline 9 & 6 & 71520 & 33009.21 & 38510.79 \\
\hline 9.25 & 6.25 & 74500 & 33926.1325 & 40573.8675 \\
\hline 9.5 & 6.5 & 77480 & 34843.055 & 42636.945 \\
\hline 9.75 & 6.75 & 80460 & 35759.9775 & 44700.0225 \\
\hline 10 & 7 & 83440 & 36676.9 & 46763.1 \\
\hline 10.25 & 7.25 & 86420 & 37593.8225 & 48826.1775 \\
\hline 10.5 & 7.5 & 89400 & 38510.745 & 50889.255 \\
\hline 10.75 & 7.75 & 92380 & 39427.6675 & 52952.3325 \\
\hline 11 & 8 & 95360 & 40344.59 & 55015.41 \\
\hline 11.25 & 8.25 & 98340 & 41261.5125 & 57078.4875 \\
\hline 11.5 & 8.5 & 101320 & 42178.435 & 59141.565 \\
\hline 11.75 & 8.75 & 104300 & 43095.3575 & 61204.6425 \\
\hline 12 & 9 & 107280 & 44012.28 & 63267.72 \\
\hline 12.25 & 9.25 & 110260 & 44929.2025 & 65330.7975 \\
\hline 12.75 & 9.75 & 116220 & 46763.0475 & 69456.9525 \\
\hline 13 & 10 & 119200 & 47679.97 & 71520.03 \\
\hline 13.25 & 10.25 & 122180 & 48596.8925 & 73583.1075 \\
\hline 13.5 & 10.5 & 125160 & 49513.815 & 75646.185 \\
\hline
\end{tabular}




\begin{tabular}{|c|c|c|c|c|}
\hline $\begin{array}{c}\text { Commercial } \\
\text { Electricity } \\
\text { Rates, C/KWh } \\
\end{array}$ & $\begin{array}{c}\text { Diesel Rates in } \\
\text { \$/Gal }\end{array}$ & $\begin{array}{c}\text { Total Diesel cost for a } \\
20 \text { Day well,\$ }\end{array}$ & $\begin{array}{c}\text { Total Electricity } \\
\text { cost for } 20 \text { day } \\
\text { well,\$ }\end{array}$ & Savings/Well,\$ \\
\hline 13.75 & 10.75 & 128140 & 50430.7375 & 77709.2625 \\
\hline 14 & 11 & 131120 & 51347.66 & 79772.34 \\
\hline 14.25 & 11.25 & 134100 & 52264.5825 & 81835.4175 \\
\hline 14.5 & 11.5 & 137080 & 53181.505 & 83898.495 \\
\hline 14.75 & 11.75 & 140060 & 54098.4275 & 85961.5725 \\
\hline 15 & 12 & 143040 & 55015.35 & 88024.65 \\
\hline 15.25 & 12.25 & 146020 & 55932.2725 & 90087.7275 \\
\hline 15.5 & 12.5 & 149000 & 56849.195 & 92150.805 \\
\hline 15.75 & 12.75 & 151980 & 57766.1175 & 94213.8825 \\
\hline 16 & 13 & 154960 & 58683.04 & 96276.96 \\
\hline 16.25 & 13.25 & 157940 & 59599.9625 & 98340.0375 \\
\hline 16.5 & 13.5 & 160920 & 60516.885 & 100403.115 \\
\hline 16.75 & 13.75 & 163900 & 61433.8075 & 102466.1925 \\
\hline 17 & 14 & 166880 & 62350.73 & 104529.27 \\
\hline 17.25 & 14.25 & 169860 & 63267.6525 & 106592.3475 \\
\hline 17.5 & 14.5 & 172840 & 64184.575 & 108655.425 \\
\hline 17.75 & 14.75 & 175820 & 65101.4975 & 110718.5025 \\
\hline 18 & 15 & 178800 & 66018.42 & 112781.58 \\
\hline 18.25 & 15.25 & 181780 & 66935.3425 & 114844.6575 \\
\hline 18.5 & 15.5 & 184760 & 67852.265 & 116907.735 \\
\hline 18.75 & 15.75 & 187740 & 68769.1875 & 118970.8125 \\
\hline 19 & 16 & 190720 & 69686.11 & 121033.89 \\
\hline 19.25 & 16.25 & 193700 & 70603.0325 & 123096.9675 \\
\hline 19.5 & 16.5 & 196680 & 71519.955 & 125160.045 \\
\hline 19.75 & 16.75 & 199660 & 72436.8775 & 127223.1225 \\
\hline 20 & 17 & 202640 & 73353.8 & 129286.2 \\
\hline 20.25 & 17.25 & 205620 & 74270.7225 & 131349.2775 \\
\hline 20.5 & 17.5 & 208600 & 75187.645 & 133412.355 \\
\hline 20.75 & 17.75 & 211580 & 76104.5675 & 135475.4325 \\
\hline 21 & 18 & 214560 & 77021.49 & 137538.51 \\
\hline 21.25 & 18.25 & 217540 & 77938.4125 & 139601.5875 \\
\hline 21.5 & 18.5 & 220520 & 78855.335 & 141664.665 \\
\hline 21.75 & 18.75 & 223500 & 79772.2575 & 143727.7425 \\
\hline 22.25 & 19.25 & 229460 & 81606.1025 & 147853.8975 \\
\hline 22.5 & 19.5 & 232440 & 82523.025 & 149916.975 \\
\hline 22.75 & 19.75 & 235420 & 83439.9475 & 151980.0525 \\
\hline 23 & 20 & 238400 & 84356.87 & 154043.13 \\
\hline 23.25 & 20.25 & 241380 & 85273.7925 & 156106.2075 \\
\hline
\end{tabular}




\begin{tabular}{|c|c|c|c|c|}
\hline $\begin{array}{c}\text { Commercial } \\
\text { Electricity } \\
\text { Rates,C/KWh }\end{array}$ & $\begin{array}{c}\text { Diesel Rates in } \\
\mathbf{\$ / G a l}\end{array}$ & $\begin{array}{c}\text { Total Diesel cost for a } \\
\text { 20 Day well,\$ }\end{array}$ & $\begin{array}{c}\text { Total Electricity } \\
\text { cost for 20 day } \\
\text { well,\$ }\end{array}$ & Savings/Well,\$ \\
\hline 23.5 & 20.5 & 244360 & 86190.715 & 158169.285 \\
\hline 23.75 & 20.75 & 247340 & 87107.6375 & 160232.3625 \\
\hline 24 & 21 & 250320 & 88024.56 & 162295.44 \\
\hline 24.25 & 21.25 & 253300 & 88941.4825 & 164358.5175 \\
\hline 24.5 & 21.5 & 256280 & 89858.405 & 166421.595 \\
\hline 24.75 & 21.75 & 259260 & 90775.3275 & 168484.6725 \\
\hline 25 & 22 & 262240 & 91692.25 & 170547.75 \\
\hline
\end{tabular}




\section{APPENDIX D}

\section{OTHER IMPORTANT MATLAB PLOTS}




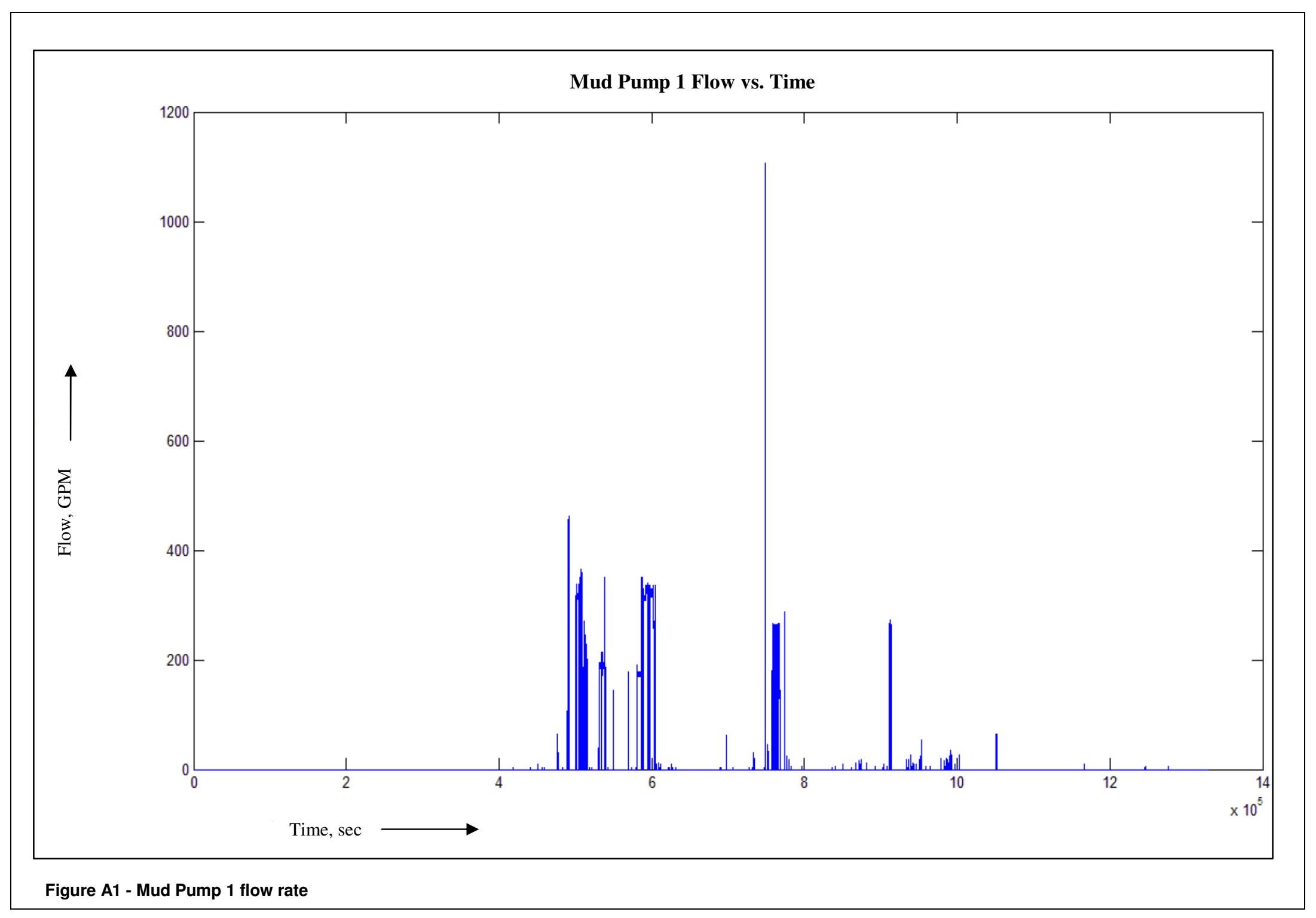




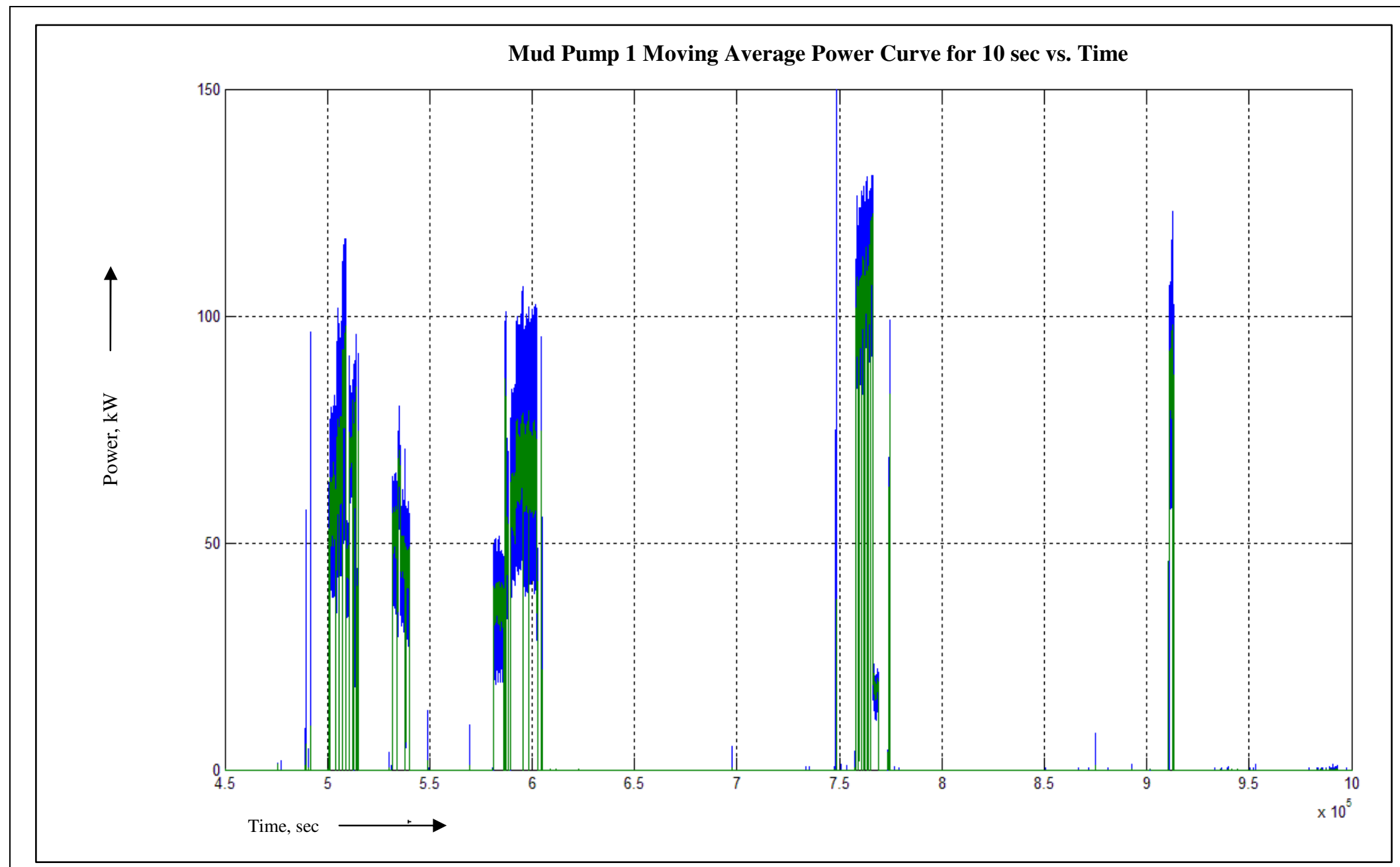

Figure A2 - Mud Pump 1 instantaneous power (blue) and moving average (green) of window length of 10 seconds 


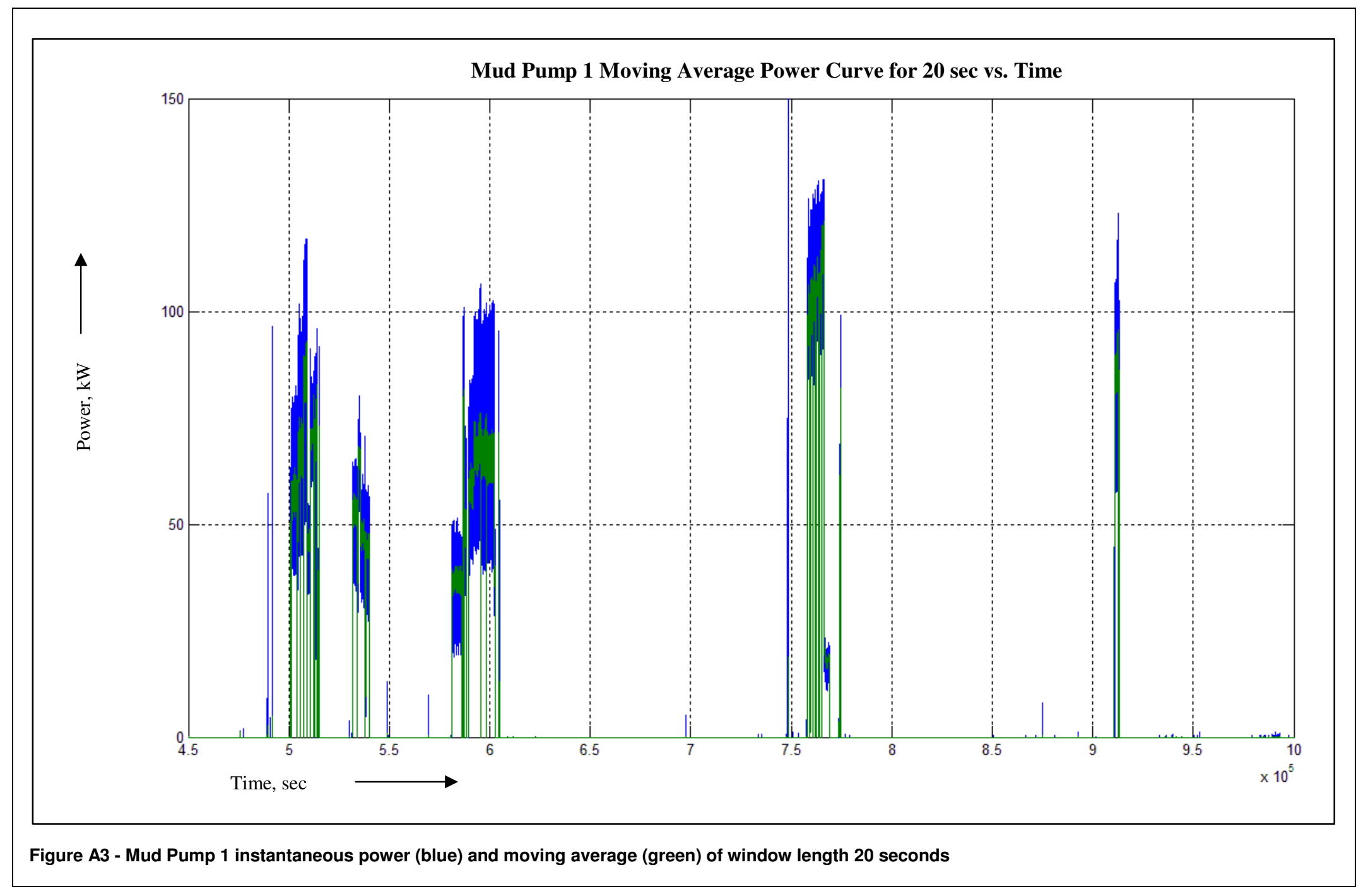

ă 


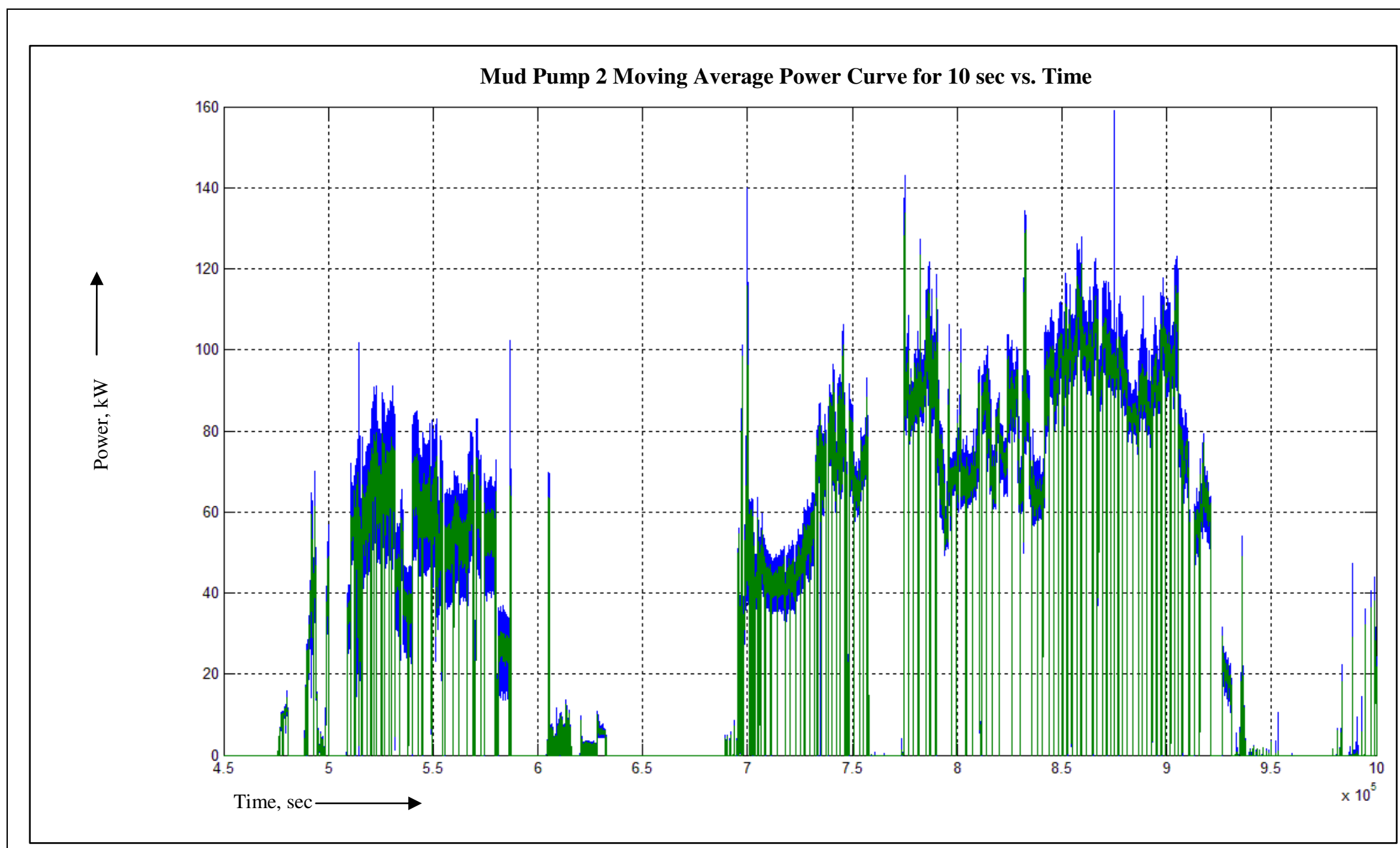

Figure A4 - Mud Pump 2 instantaneous power (blue) and moving average (green) of window length 10 seconds. 


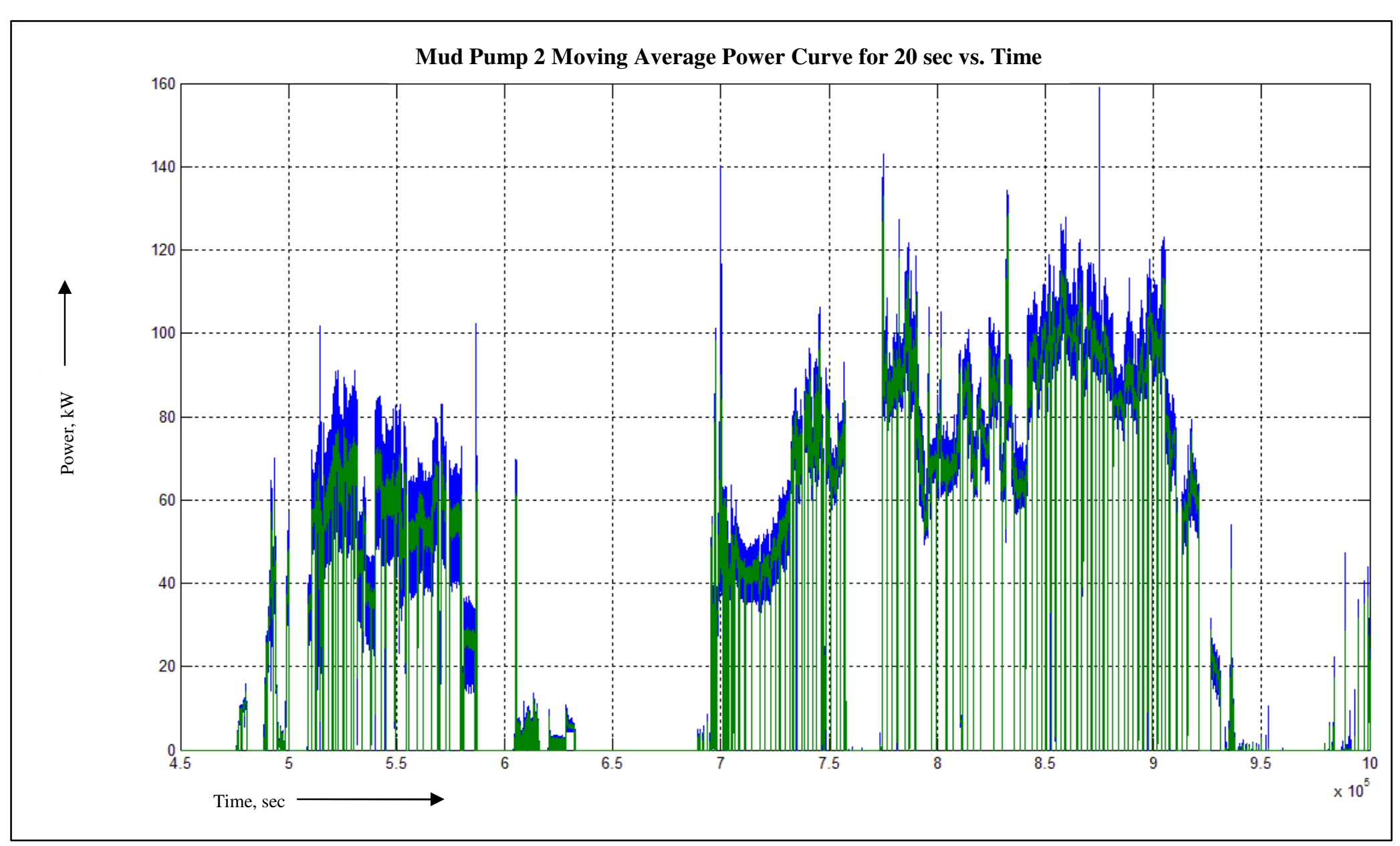

Figure A5 - Mud Pump 2 instantaneous power (blue) and moving average (green) of window length of 20 seconds 


$$
\sqrt{44}
$$




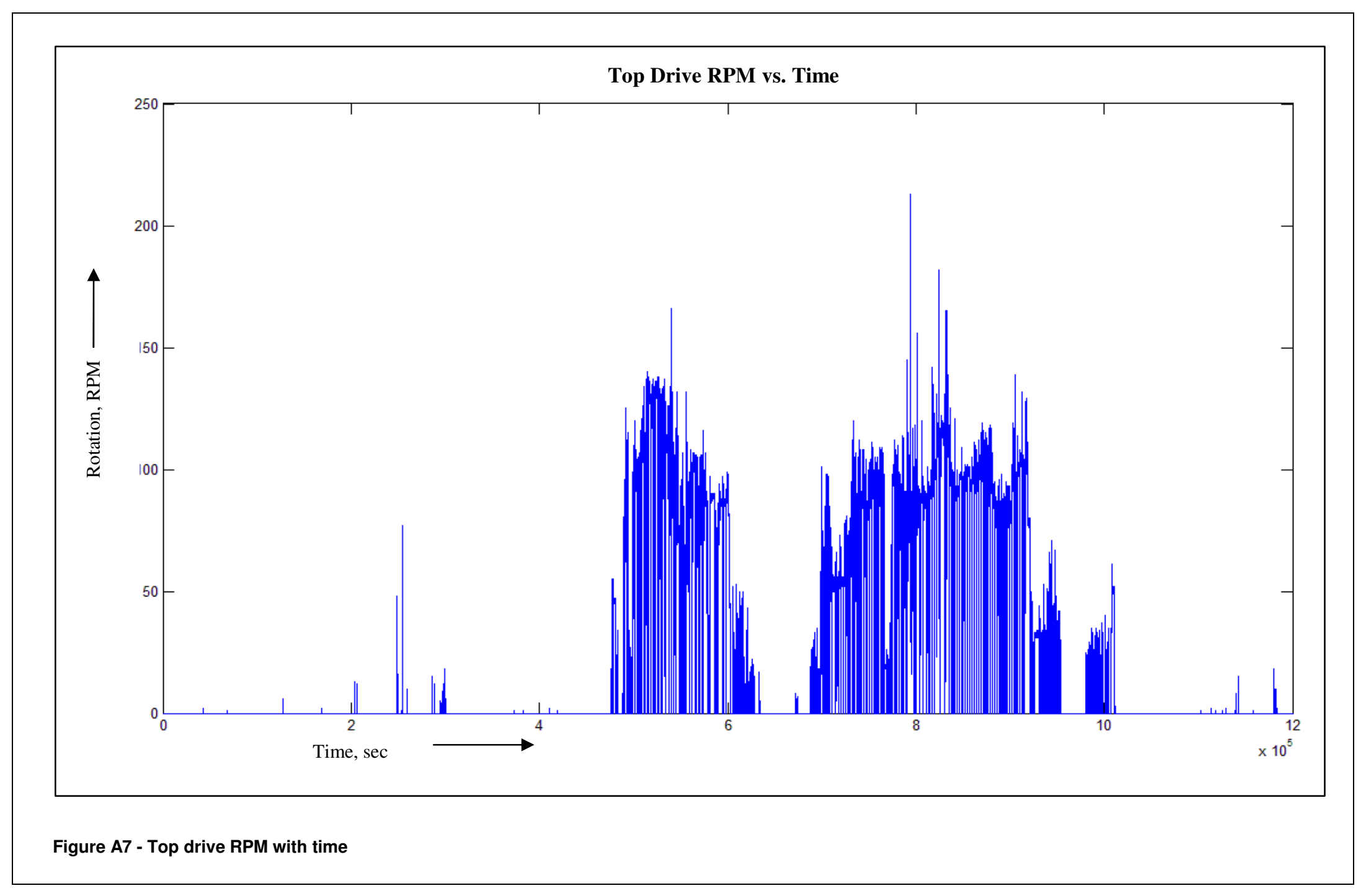




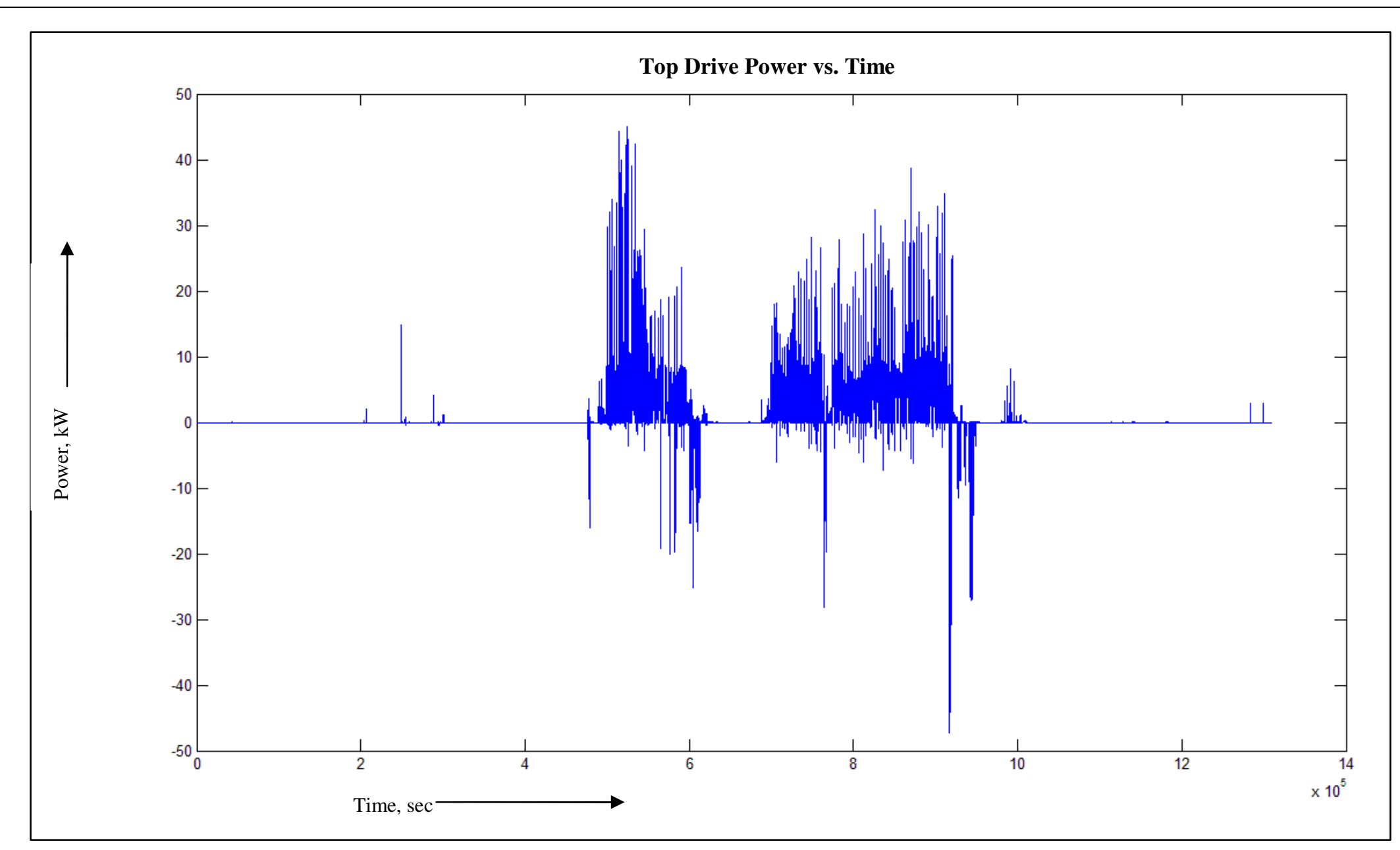

Figure A8 - Top Drive instantaneous power (blue) 


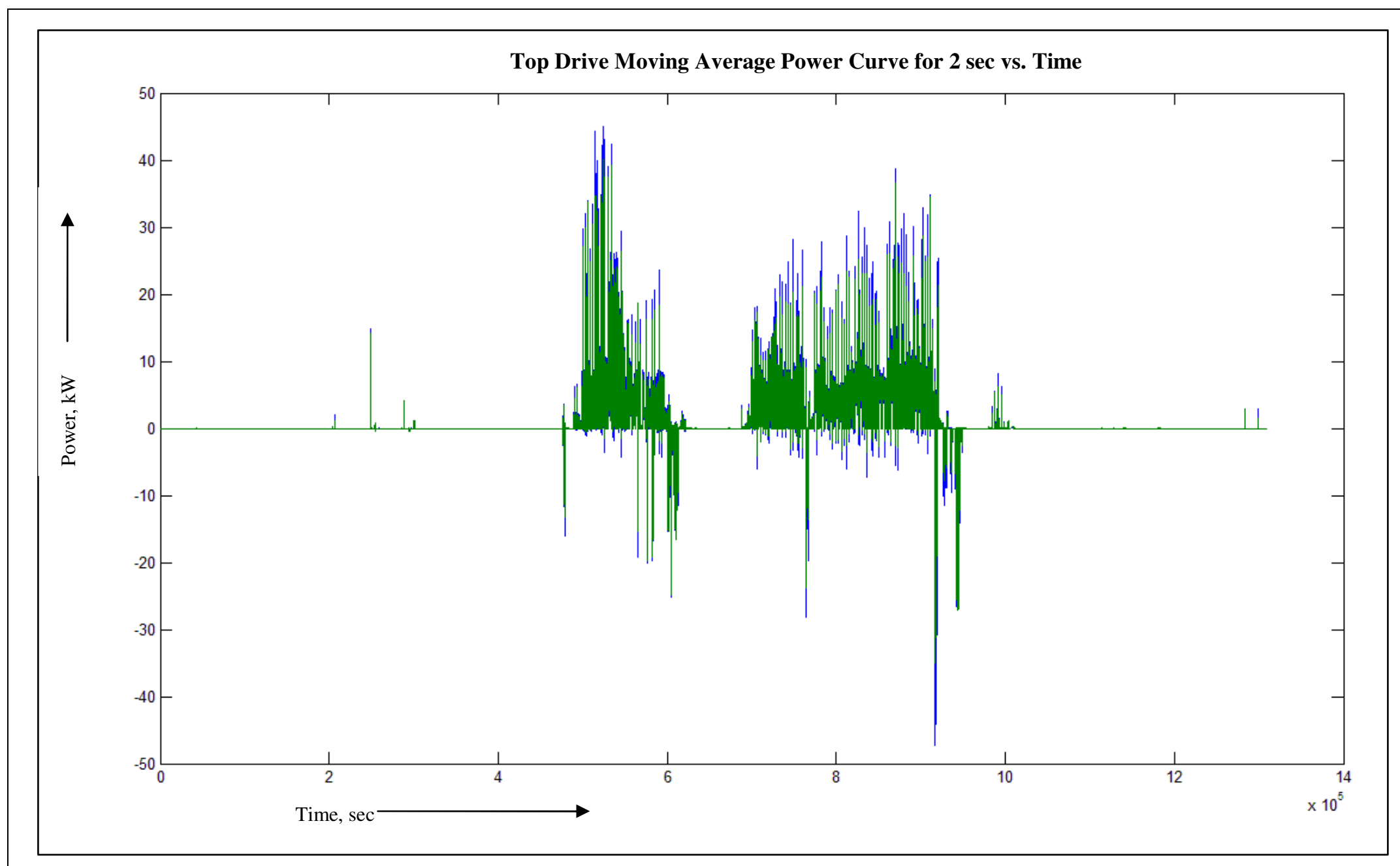

Figure A9 - Top Drive instantaneous power (blue) and moving average (green) of window length 2 seconds 


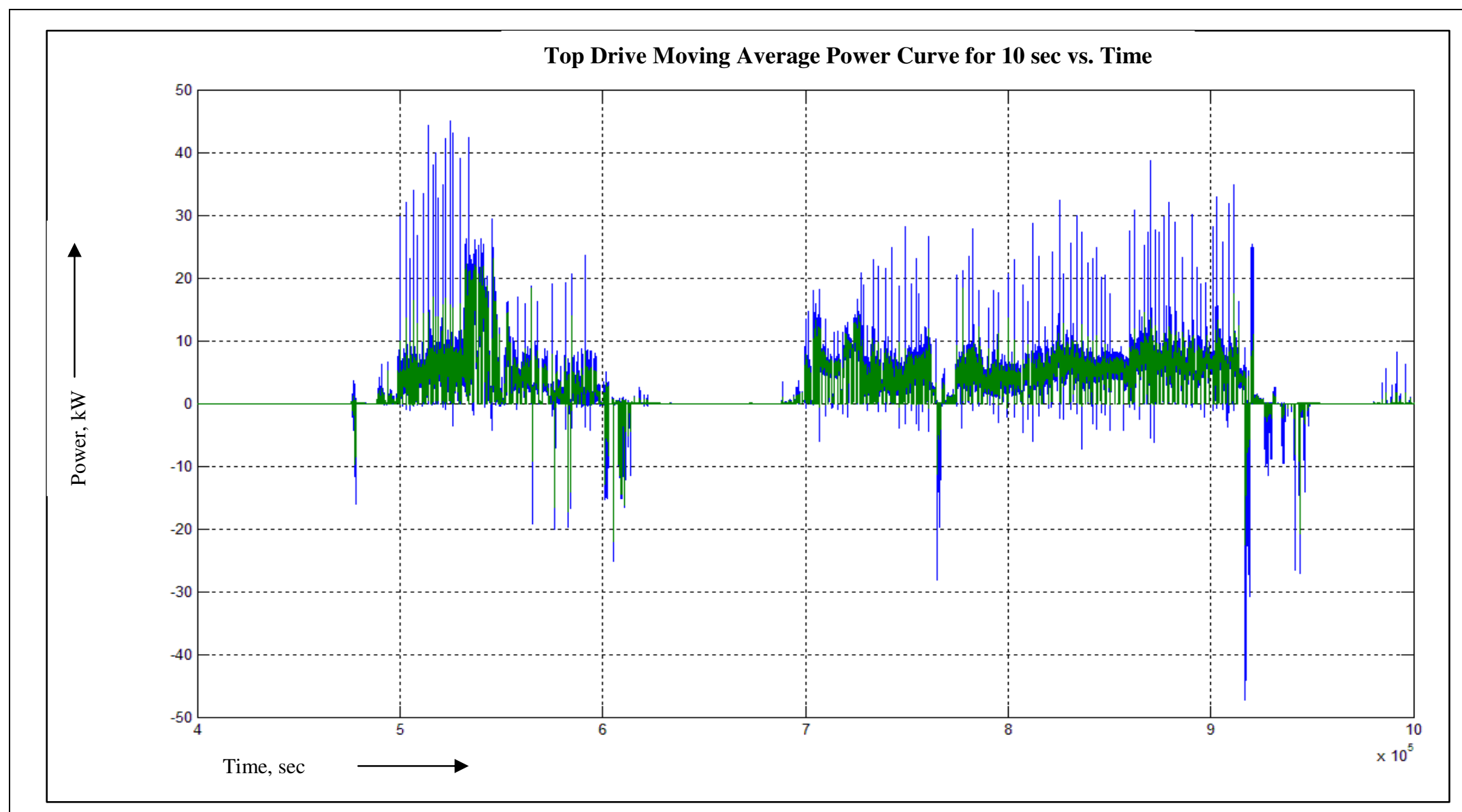

Figure A10 - Top drive instantaneous power (blue) and moving average (green) of window length 10 seconds 


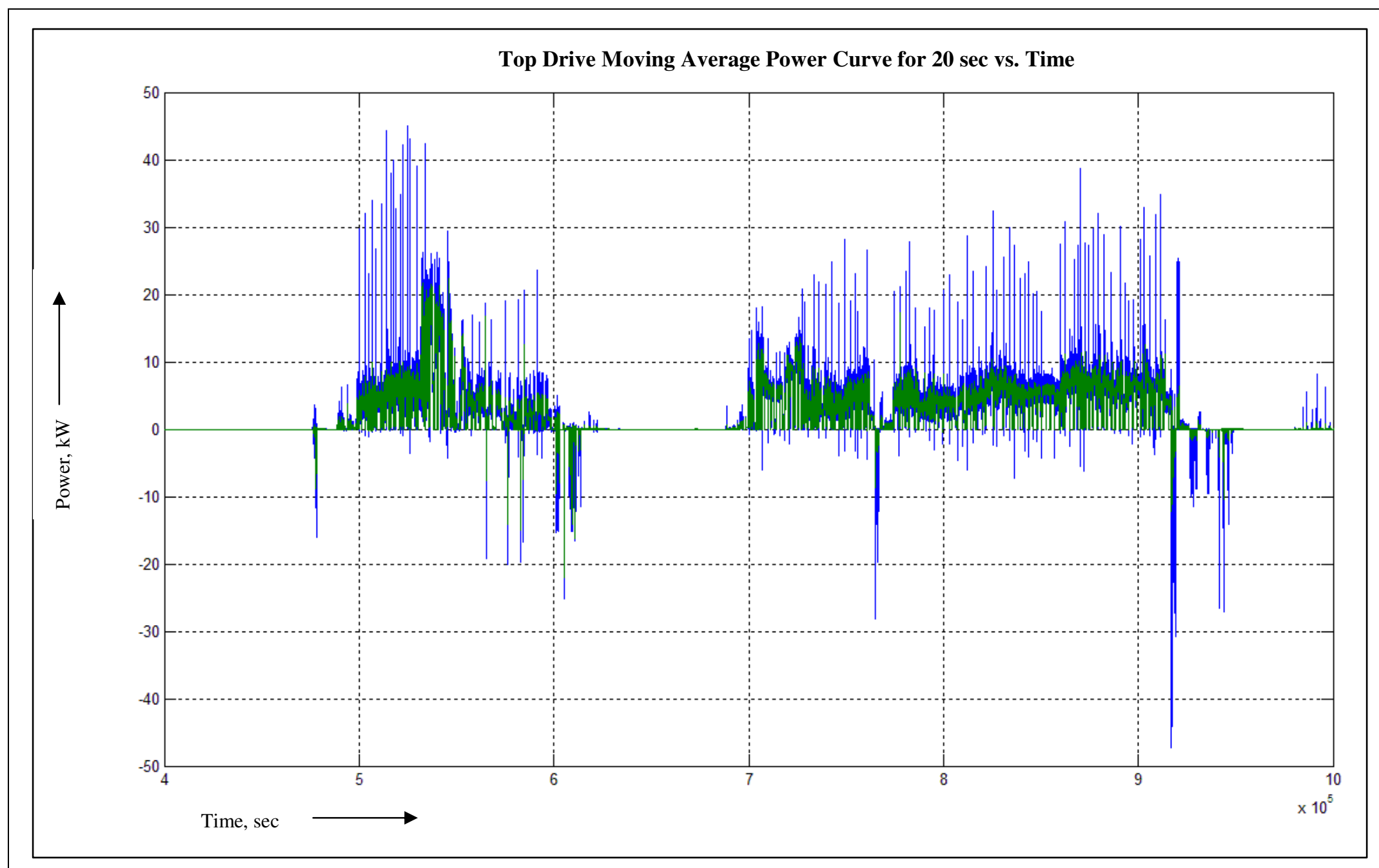

Figure A11 - Top Drive instantaneous power (blue) and moving average (green) of window length 20 seconds 


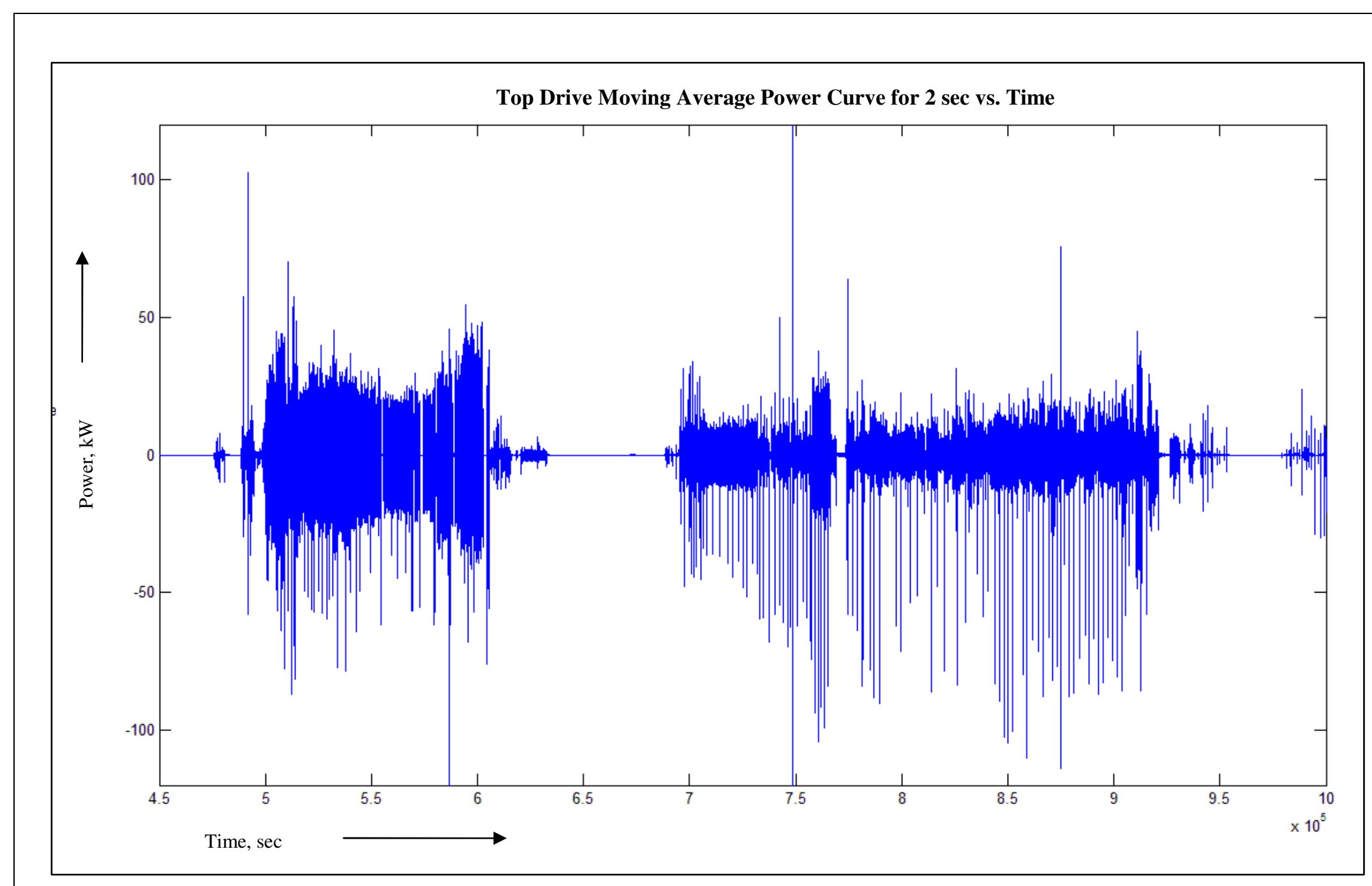

Figure A12 - Difference between instantaneous power and moving average curve for mud pumps and top drive , 2 sec 


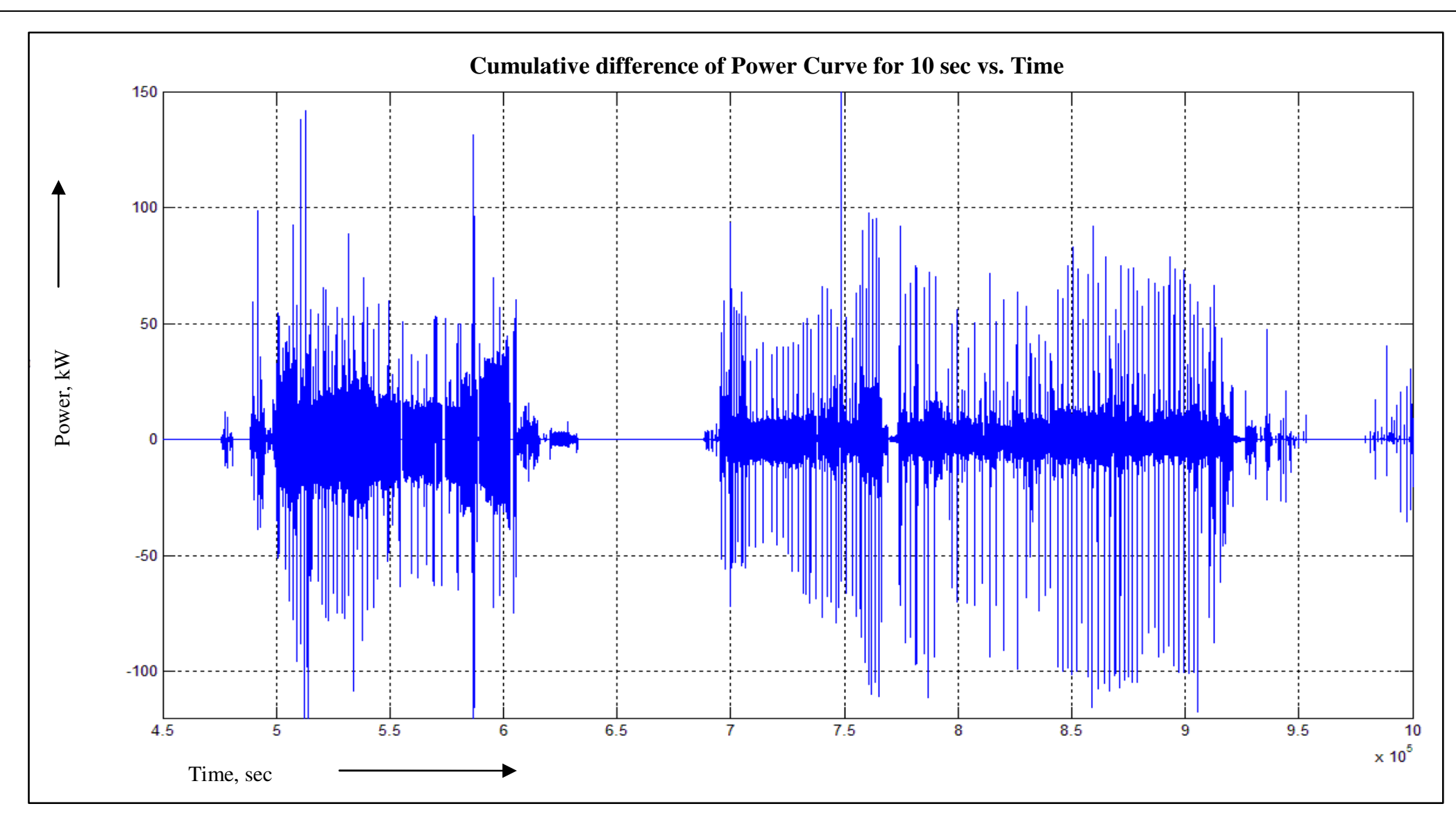

Figure A13 - Difference between instantaneous power and moving average curve for mud pumps and top drive, 10 sec 


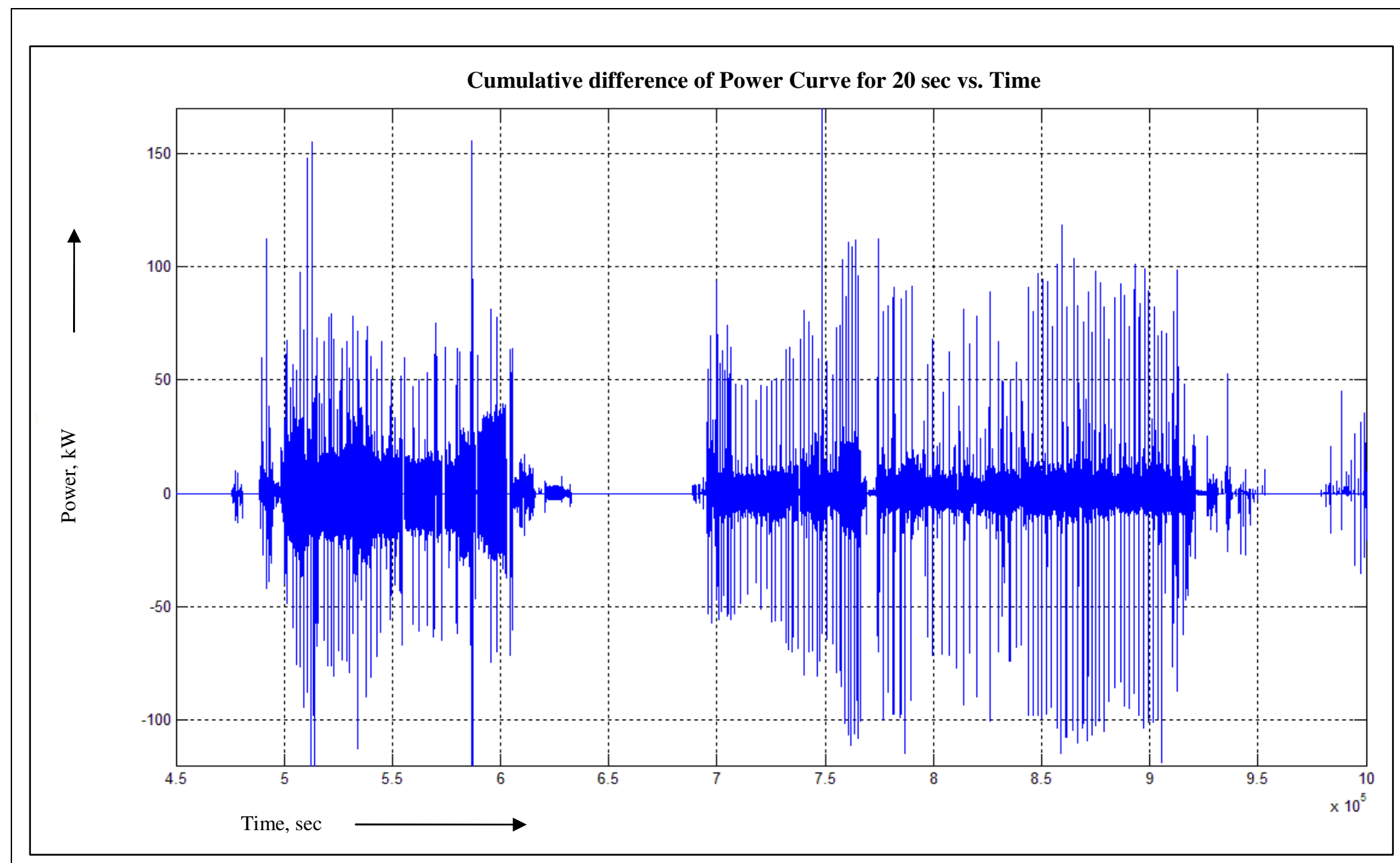

Figure A14 - Difference between instantaneous power and moving average curve for mud pumps and top drive , 20sec 


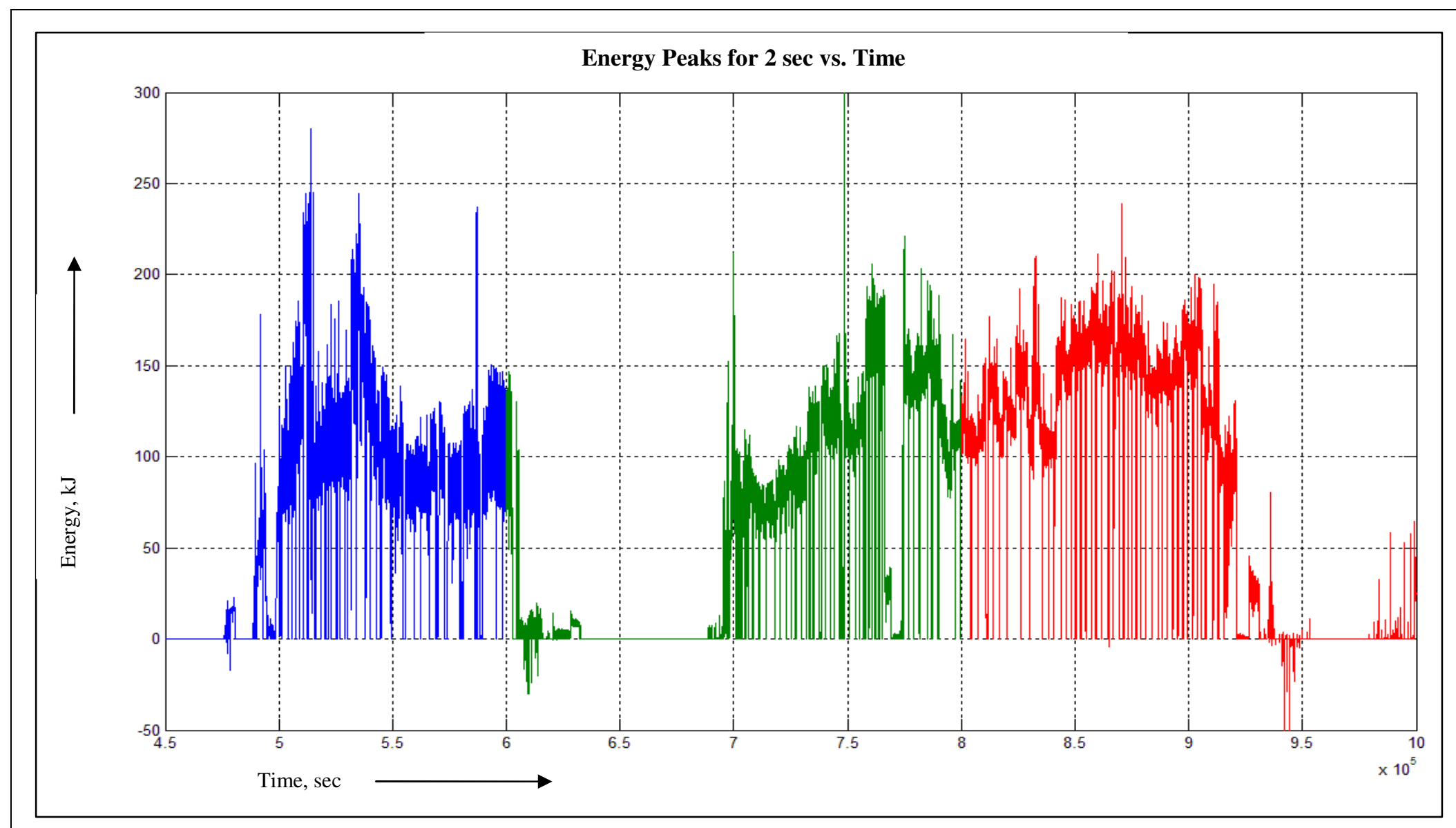

Figure A15 - Overall Energy curve for window length of 2sec (KERS system should be able to provide) 


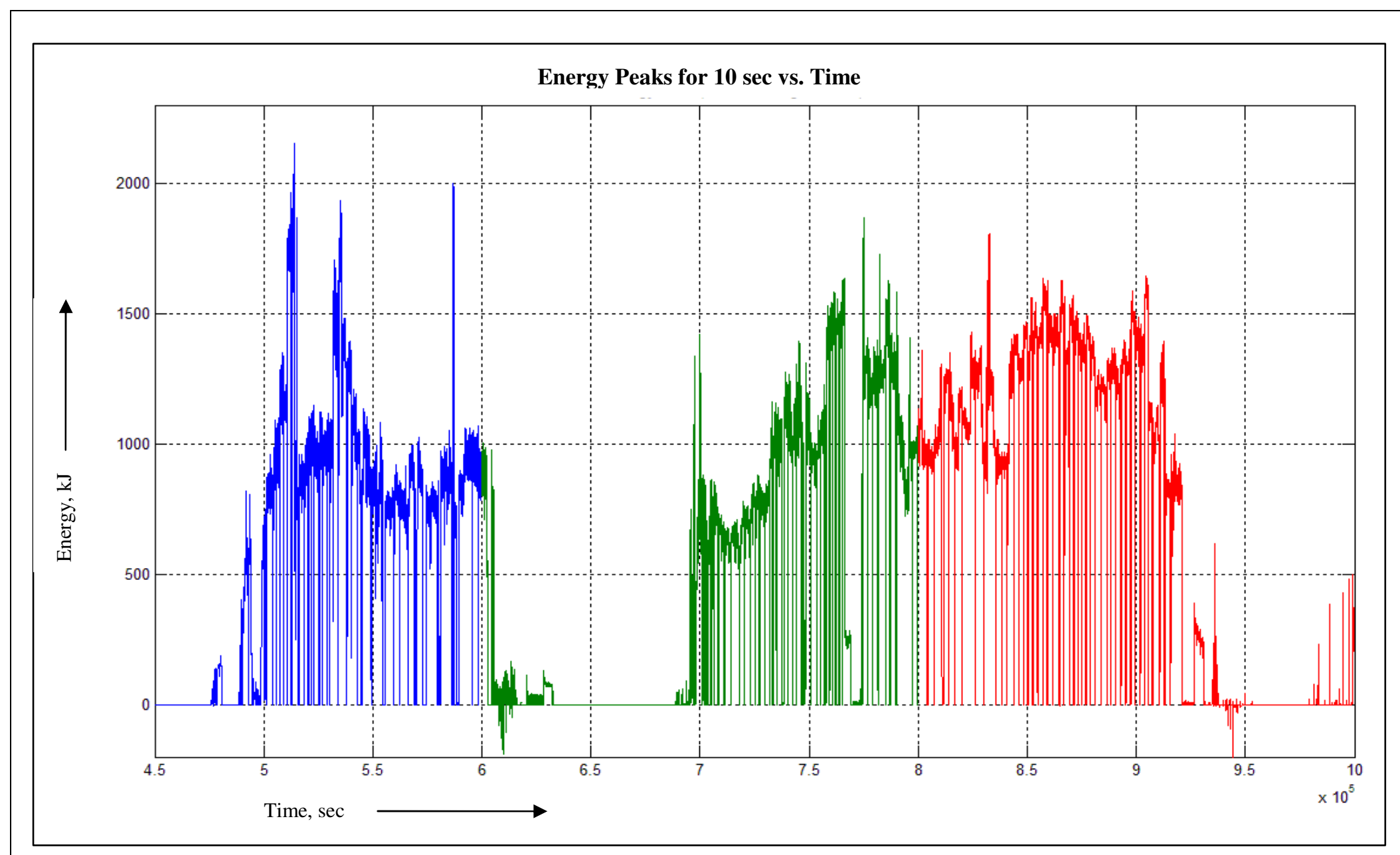

Figure A16 - Overall Energy curve for window length of 10sec (KERS system should be able to provide) 


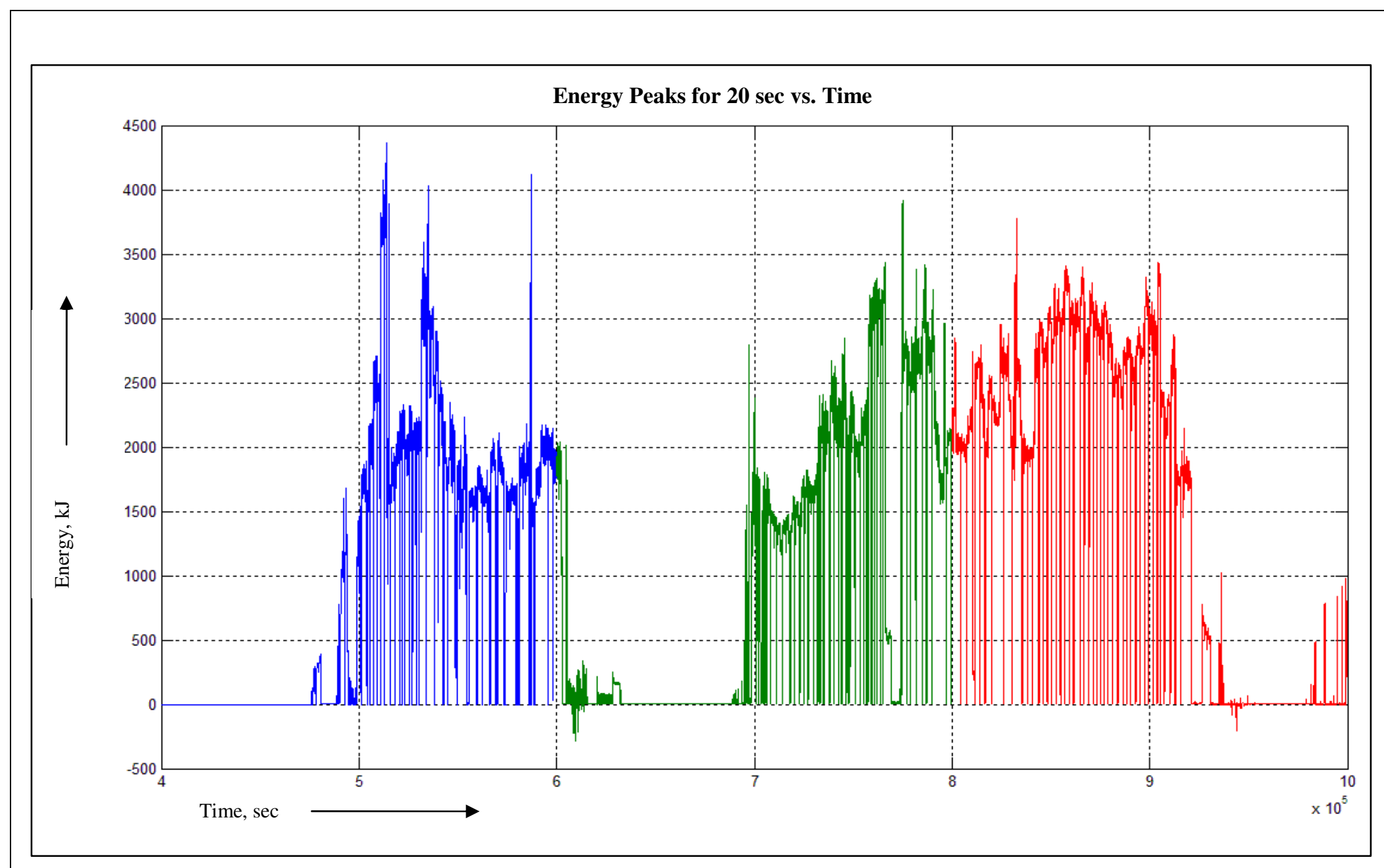

Figure A17 - Overall Energy curve for window length of $20 \mathrm{sec}$ (KERS system should be able to provide) 


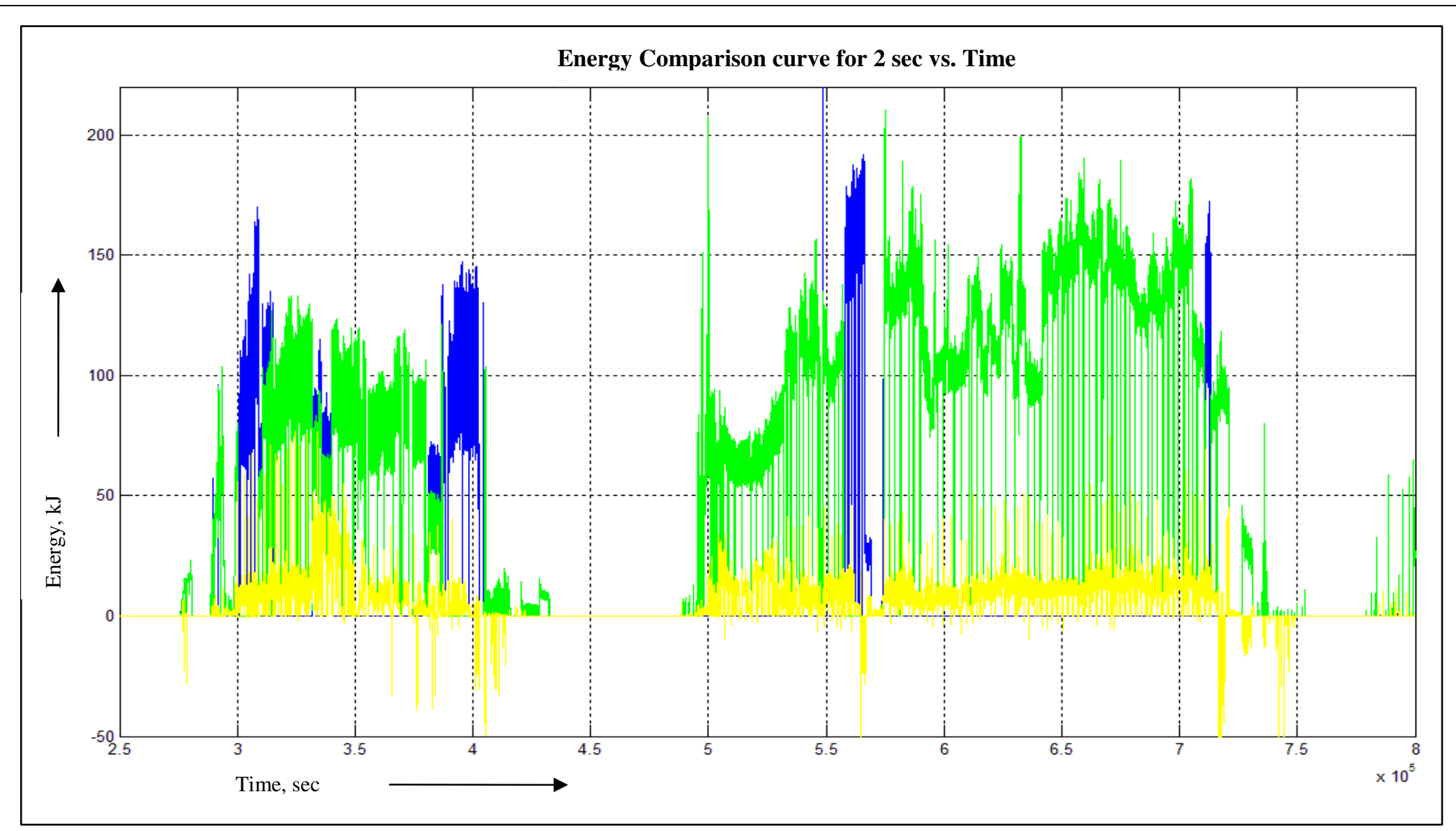

Figure A18 - Energy comparison curve for mud pumps and top drive for a window length of 2 seconds 


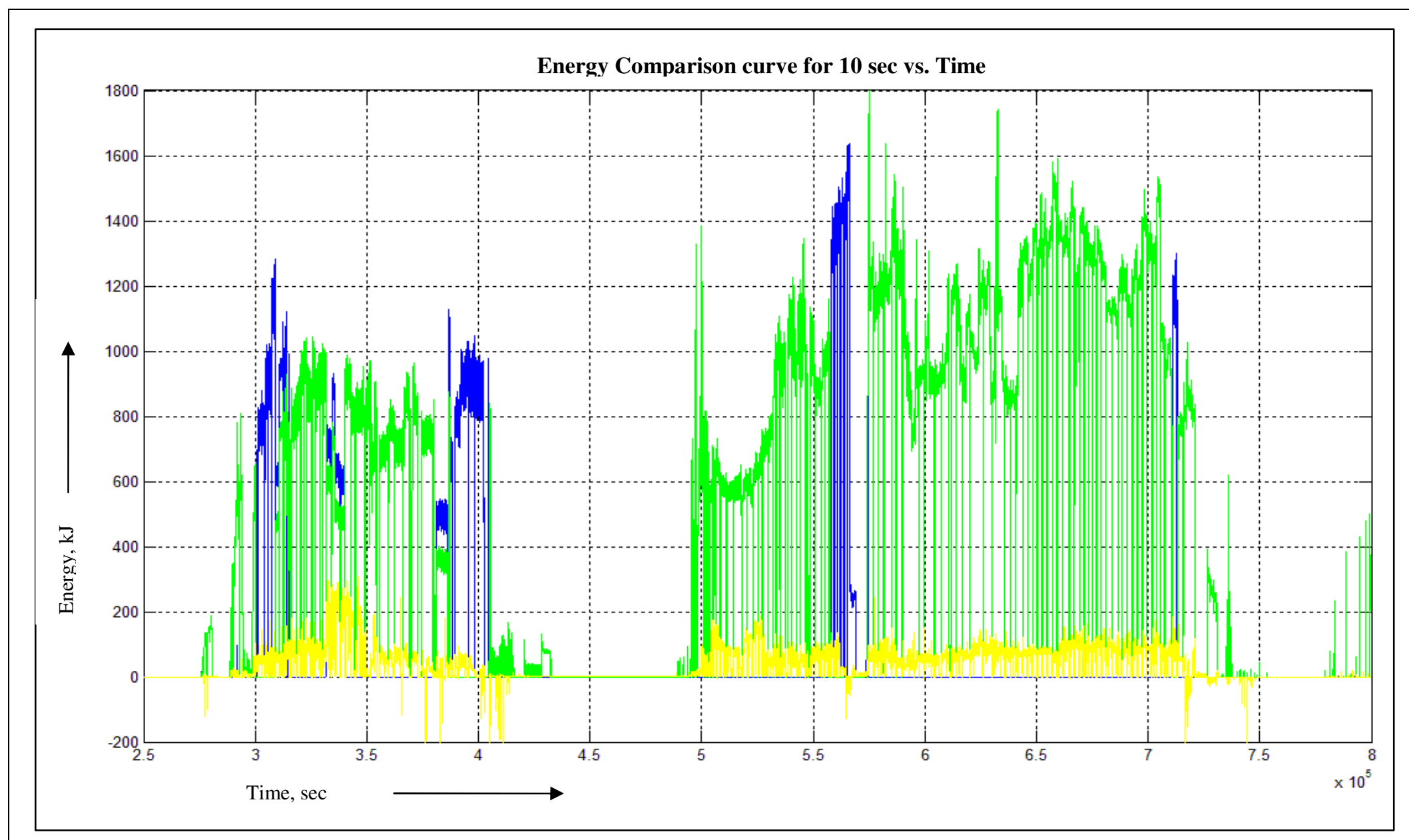

Figure A19 - Energy comparison curve for mud pumps and top drive for a window length of 10 seconds 


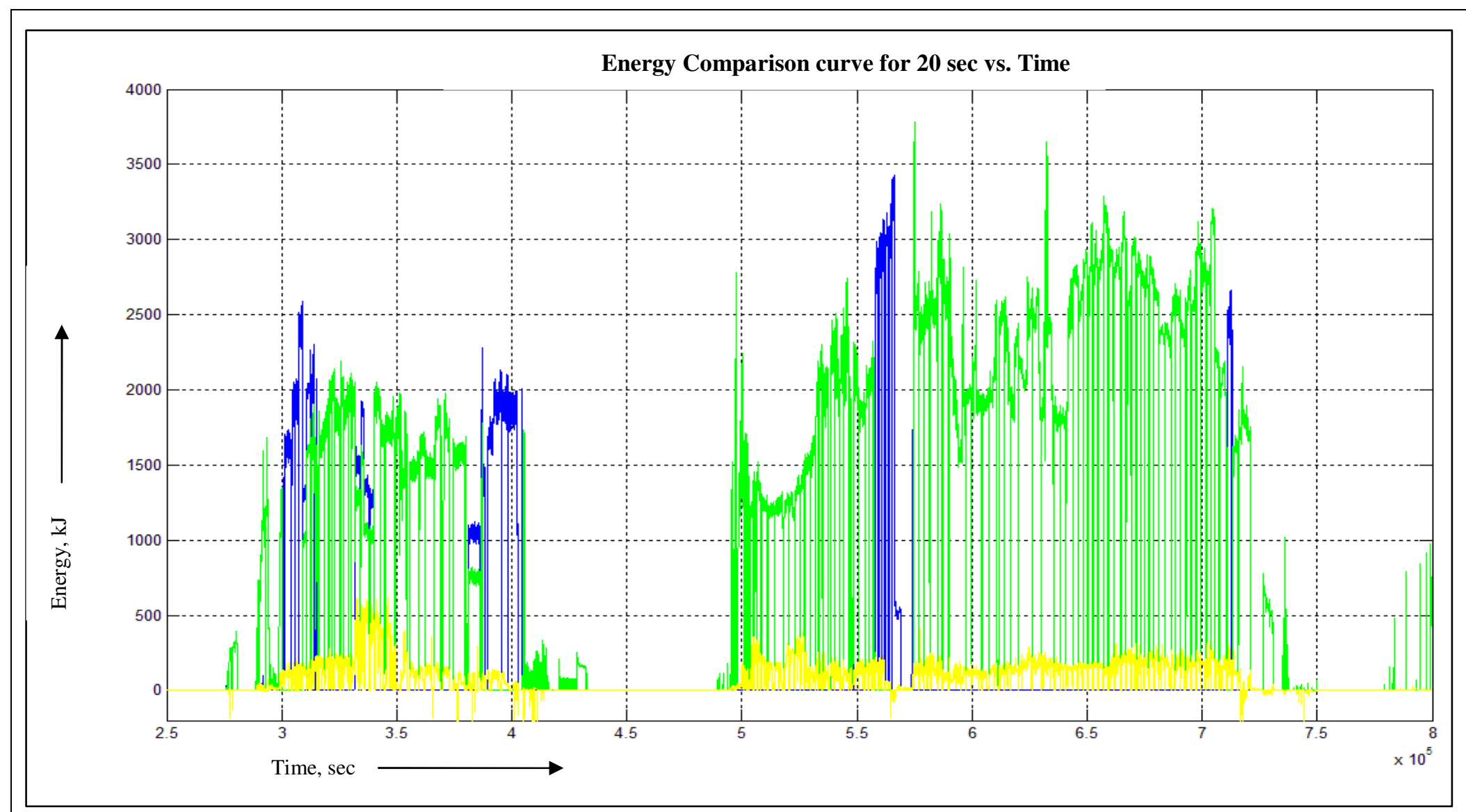

Figure A20 - Energy comparison curve for mud pumps and top drive for a window length of 20 seconds 


\section{VITA}

Name:

Address:

Email Address:

Education:

Member:
Ankit Verma

TAMU mail stop 3116, Room 710A, Department of Petroleum Engineering, Texas A\&M University, College Station, TX 77843

ankitmanit@tamu.edu

B.Tech., Electrical Engineering, National Institute of Technology, Bhopal, India, 2007

M.S., Petroleum Engineering, Texas A\&M University, USA, 2009

Society of Petroleum Engineers 